\title{
TRANSURANIC WASTE CHARACTERIZATION. SAMPLING AND ANALYSIS PLAN
}

Prepared for

\section{LOS ALAMOS NATIONAL LABORATORY Los Alamos, NM 87545}

December 31, 1994

Prepared by

Rogers \& Associates Engineering Corporation P.O. Box 330

Salt Lake City, UT $\mathbf{8 4 1 1 0 - 0 3 3 0}$

with

WASTREN, InG.

12000 N. Pecos, Suite 250

Westminster, CO 80234

DISTAIBUTION OF THIS DOCUMENT IS UNLMMTED 
Transuranic Waste Characterization, Sampling, and Analysis Plan Proparod for Los Alamos National Laboratory by RAE \& WASTREN, Inc.

\section{TABLE OF CONTENTS}

TABLE OF CONTENTS

LIST OF FIGURES

LIST OF TABLES $\ldots \ldots \ldots \ldots \ldots \ldots \ldots \ldots \ldots \ldots \ldots \ldots \ldots \ldots$

PREFACE $\ldots \ldots \ldots \ldots \ldots \ldots \ldots \ldots \ldots \ldots \ldots \ldots \ldots \ldots \ldots \ldots$ vii

EXECUTIVE SUMMARY $\ldots \ldots \ldots \ldots \ldots \ldots \ldots \ldots \ldots \ldots$ ES-1

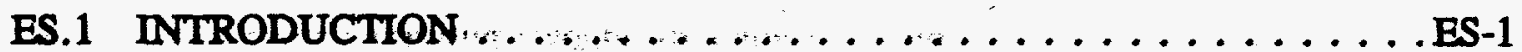

ES.2 WASTE INVENTORY AND APPROACH FOR WASTE STREAM IDENTIFICATION CHARACTERIZATION, AND SAMPLING

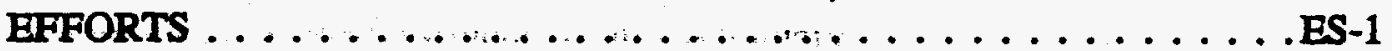

ES.3 PREIIMINARY FIELD STUDY $\ldots \ldots \ldots \ldots \ldots \ldots \ldots \ldots$ ES-2

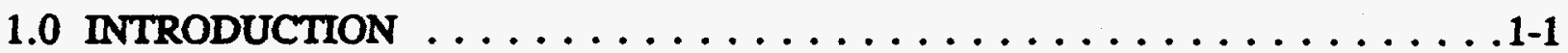

1.1 PURPOSE AND SCOPE $\ldots \ldots \ldots \ldots \ldots \ldots \ldots \ldots \ldots \ldots \ldots \ldots$

1.2 SITE DESCRIPTION $\ldots \ldots \ldots \ldots \ldots \ldots \ldots \ldots \ldots \ldots \ldots \ldots$

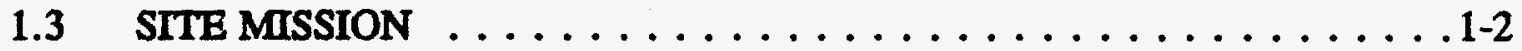

1.4 PROJECT CONVENTIONS AND TERMS $\ldots \ldots \ldots \ldots \ldots \ldots \ldots$

2.0 REGULATORY REQUIREMENTS $\ldots \ldots \ldots \ldots \ldots \ldots \ldots \ldots \ldots$ 2-1

2.1 RESOURCE CONSERVATION AND RECOVERY ACT $\ldots \ldots \ldots \ldots 2-1$

2.2 NEW MEXICO HAZARDOUS WASTE ACT $\ldots \ldots \ldots \ldots \ldots \ldots .2-2$

2.3 FEDERAL FACIIITY COMPLIANCE ACT $\ldots \ldots \ldots \ldots \ldots \ldots 2-2$

2.4 ATOMIC ENERGY ACT $\ldots \ldots \ldots \ldots \ldots \ldots \ldots \ldots \ldots \ldots . \ldots \ldots$

2.5 DOE ORDER 5820.2A, "RADIOACTIVE WASTE MANAGEMENT" . . 2-3

2.6 1993 COMPLIANCE ORDERS NMHWA 93-03 AND 93-04 . . . . . 2-3

2.71993 NOTICB OF DEFICIENCY (NM 0890010515-1) . . . . . . . . 2-4

3.0 WASTE STREAM IDENTIFICATION AND CHARACTERIZATION . . . . . 3-1

3.1 WASTB INFORMATION $\ldots \ldots \ldots \ldots \ldots \ldots \ldots \ldots \ldots . \ldots \ldots$

3.1.1 Types of Information . . . . . . . . . . . . 3-3

3.1 .2 Collection of Information . . . . . . . . . . . . . 3-4

3.2 EVALUATION OF THE QUALITY OF WASTE

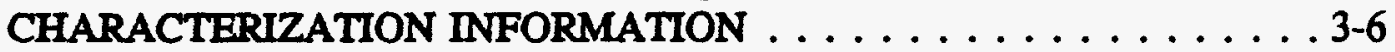

3.2.1 Guidelines for Evaluating the Quality of Information . . . . . 3-6

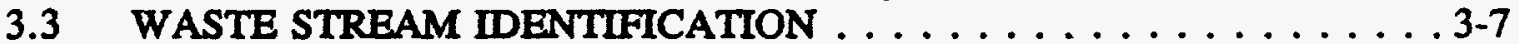

3.3.1 Waste Categories . . . . . . . . . . . . . . 3-7

3.3.2 Identification of Waste Streams . . . . . . . . . . . . . . 3-9

3.4 WASTE STREAM RESOURCE CONSERVATION AND RECOVERY ACT CHARACTERIZATION $\ldots \ldots \ldots \ldots \ldots \ldots \ldots \ldots \ldots$ 3-11 


\section{DISCLAIMER}

Portions of this document may be illegible in electronic image products. Images are produced from the best available original document. 
Transuranic Waste Characterization, Sampling, and Analysis Plan Prepared for Los Alamos National Laboretory by RAE \& WASTREN, inc.

3.4.1 Resource Conservation and Recovery Act Characterization ... . . 3-12

3.4.2 Assignment of Environmental Protection Agency Hazardous Waste Numbers to Waste Streams . . . . . . . . . . . . . . . . . 3-20

3.4.3 Confirmation of Resourco Conservation and Recovery Act Characterization of Homogeneous Waste . . . . . . . . 3-20

3.5 REAL-TIME RADIOGRAPHY AND VISUAL INSPECTION $\ldots \ldots$. . . 3-20

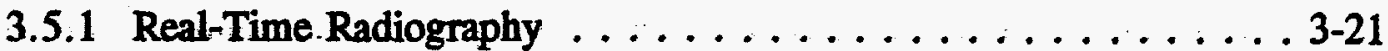

3.5 .2 Visual Inspection . . . . . . . . . . . . . . . . . 3-21

4.0 SAMPLING AND ANALYSIS $\ldots \ldots \ldots \ldots \ldots \ldots \ldots$

4.1 QUALITY ASSURANCE $\ldots \ldots \ldots \ldots \ldots \ldots \ldots \ldots \ldots \ldots$

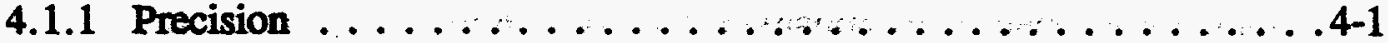

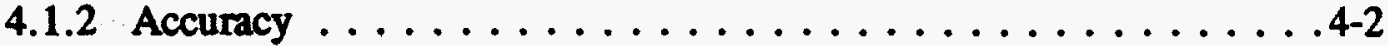

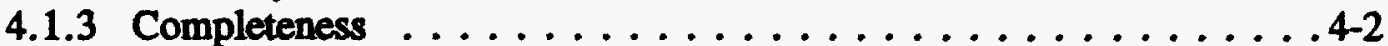

4.1.4 Comparability ........................... 4-3

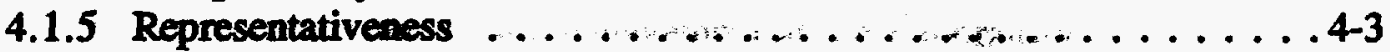

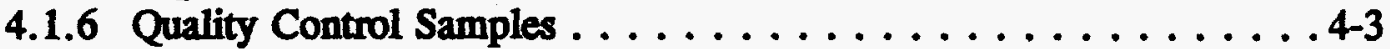

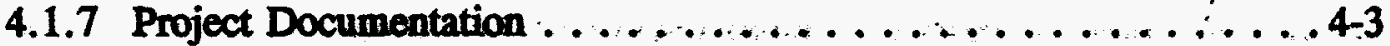

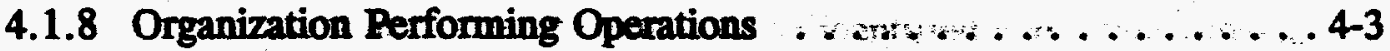

4.2 SAMPLB COLLECTION FOR HOMOGENEOUS WASTB . . . . . . . 4-4

4.2.1 Analytical Parameters ..................... . . . . .

4.2.2 Random Selection of Containers . . . . . . . . . . . . . . 4-9

4.2.3 Number of Containers to be Sampled . . . . . . . . . . . . . 4-9

4.2.4 Sample Methods . . . . . . . . . . . . . . . . . . 4-11

4.2 .5 Analysis Methodology ... . . . . . . . . . . . . . 4-11

4.3 USE OF ANALYTICAL RESULTS . . . . . . . . . . . . . . . 4-12

4.3.1 Number of Additional Samples Necessary for Characterization . . 4-13

4.3.2 Additional Analytical Resulta ................ . . 4-14

4.3.3 Verification of Normal Distribution . . . . . . . . . . . . . . . . .

4.4 FIEID OPERATIONS $\ldots \ldots \ldots \ldots \ldots \ldots \ldots \ldots \ldots \ldots \ldots$

4.4.1 . Field Logistics . . . . . . . . . . . . . . . . . . . . . 4-16

4.4.2 Equipment and Instrumentation ................ 4-16

4.4.3 Operating Procedures .................... . 4-16

4.4.4 Field Quality Assurance and Quality Control Requirements . . . 4-18

4.4.5 Quality Assurance Review . . . . . . . . . . . . . . . . . . 4-19

4.5 LABORATORY OPERATIONS . . . . . . . . . . . . . . . 4-19

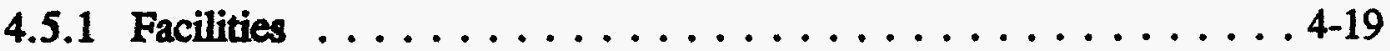

4.5.2 Laboratory Quality Assurance and Quality Control Requirements . 4-20

4.5.3 Laboratory Quality Assurance Review . . . . . . . . . . . . . . 4-22

4.5 .4 Laboratory Records . . . . . . . . . . . . . . . . . . 4-22

5.0 DATA QUALITY OBIECTIVES . . . . . . . . . . . . . . . . . . . . .

5.1 TRANSURANIC WASTE VERIFICATION . . . . . . . . . . . 5-2

5.1 .1 Decision Rule . . . . . . . . . . . . . . . . . . . . . . . . . . .

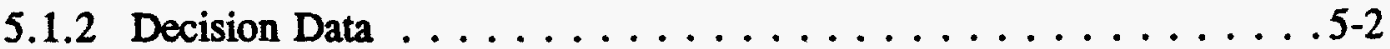


Transuranic Waste Characterization, Sampling, and Analysis Plan Prepared for Los Alamos National Laboratory by RAE \& WASTREN, Inc.

5.1.3 Dethioh Dita Quality Objective . . . . . . . . . . 5-2

5.1.4 Decision Error and Consequences . . . . . . . . . . 5-3

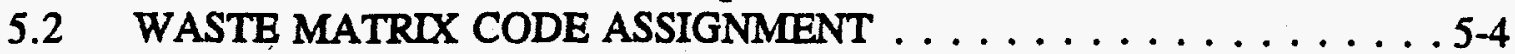

5.2 .1 Decision Rule $\ldots \ldots \ldots \ldots \ldots \ldots \ldots \ldots \ldots$. . . . . . . . .

5.2 .2 Decision Data . . . . . . . . . . . . . . . . .5-4

5.2 .3 Decision Data Quality Objective . . . . . . . . . . . . . . 5-4

5.2.4 Decision Error and Consequences . . . . . . . . . . 5-5

5.3 WASTE STREAM IDENTIFICATION . . . . . . . . . . . 5-5

5.3.1 Decision Rule . . . . . . . . . . . . . . . . 5-5

5.3.2 Decision Data . . . . . . . . . . . . . . . . . . . Junç . . . 5-6

5.3.3 Decision Data Quality Objective . ................ . 5-6

5.3.4 Decision Error and Consequences . . . . . . . . . . . . . . 5-6

5.4 HAZARDOUS WASTE DETERMINATION FOR HOMOGENEOUS

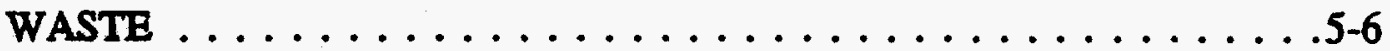

5.4 .1 Decision Rule $\ldots \ldots \ldots \ldots \ldots \ldots \ldots \ldots \ldots \ldots . \ldots \ldots$

5.4 .2 Decision Data . . . . . . . . . . . . . . . . . . . . 5-7

5.4 .3 Decision Data Quality Objective ... . . . . . . . . . . 5-7

5.4.4 Decision Error and Consequences . . . . . . . . . . . . 5-7

5.5 HAZARDOUS WASTB DETERMINATION FOR HETEROGENEOUS

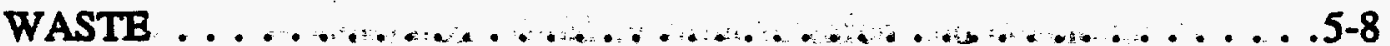

5.5.1 Decision Rule . . . . . . . . . . . . . 5-8

5.5 .2 Decision Data . . . . . . . . . . . . . . . . 5-8

5.5.3 Decision Data Quality Objective . . . . . . . . . . . . . 5-9

5.5.4 Decision Error and Consequences . . . . . . . . . . . 5-9

5.6 CONSTRAINTS $\ldots \ldots \ldots \ldots \ldots \ldots \ldots \ldots \ldots \ldots . \ldots \ldots$

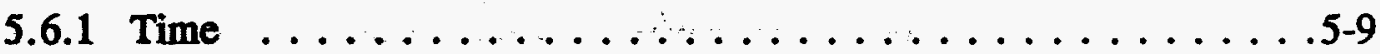

5.6 .2 Budget and Resource . . . . . . . . . . . . . . . 5-9

5.6 .3 Safety . . . . . . . . . . . . . . . . . . . . .5-9

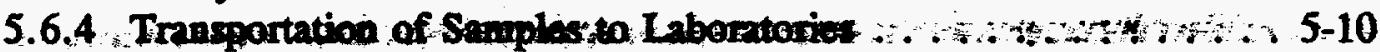

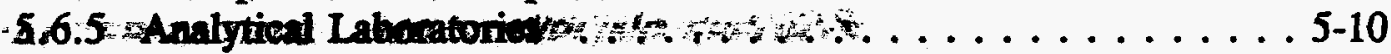

5.6 .6 Analytical Methods . . . . . . . . . . . . . 5-10

5.7 QUANTITATIVE ANALYSIS OF ANALYTICAL DATA . . . . . . 5-10

5.8 DEVIATION FROM DATA QUALITY OBJECTIVES . . . . . . . 5-11

6.0 SCHFDULE . . . . . . . . . . . . . . . . . . . . 6-1

6.1 SCHEDULE DEVELOPMENT . . . . . . . . . . . 6-1

6.2 ESTIMATION OF INDIVIDUAL WASTE STREAMS AND DRUMS TO BE SAMPLED AND DRUMS TO BE VISUALLY INSPECTED . . . . 6-4

6.3 SCHEDULE ANALYSIS $\ldots \ldots \ldots \ldots \ldots \ldots \ldots \ldots \ldots$

APPENDIX A - FIELD STUDY $\ldots \ldots \ldots \ldots \ldots \ldots \ldots \ldots \ldots \ldots$ A-1

A.1 WASTE IDENTIFICATION $\ldots \ldots \ldots \ldots \ldots \ldots \ldots \ldots \ldots$ A-1

A.1.1 Waste Background $\ldots \ldots \ldots \ldots \ldots \ldots \ldots \ldots \ldots$ A-1

A.1.2 Waste Description $\ldots \ldots \ldots \ldots \ldots \ldots \ldots$ A-4 
Transuranic Waste Characterization, Sampling, and Analysis Plan Prepared for Los Alamos National Laboratory by RAE \& WASTREN, Inc.

\section{A.2 IIAZARDOUS WASTE DETERMINATION AND WASTE} CHARACTERIZATION $\ldots \ldots \ldots \ldots \ldots \ldots \ldots \ldots$ A-8

A.2.1 TRUPACT-II Content Code 114A ............. . $\ldots$

A.2.2 Radioactive Solid Waste Disposal Code A18 ..... . . . . . A-9

A.3 REGULATORY DISCUSSION . . . . . . . . . . . . . . . . A-11

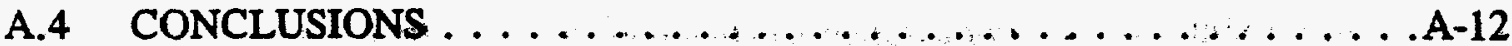

A.5 SUMMARY OF CONTACTS .................A-12

APPENDIX B - APPROACH TO DETERMINING THE NUMBER OF CONTAINERS FOR VISUAL EXAMINATION . . . . . . . . B-1

APPENDIX C - REFERENCES $\ldots \ldots \ldots \ldots \ldots \ldots \ldots \ldots \ldots \ldots$ C-1

APPENDIX D - ACRONYMS $\ldots \ldots \ldots \ldots \ldots \ldots \ldots \ldots \ldots \ldots \ldots \ldots \ldots \ldots \ldots$ 


\section{LST OF FQURES:}

Figure $3.1 \quad$ RCRA Hazardow Waste Characterization $\ldots \ldots \ldots \ldots \ldots \ldots$. . . . . .

Figure 3.2 Process for the Solid Waste Determination . . . . . . . . . . . . 3-13

Figure 3.3 ... Process for RCRA Hazardous Waste Determination

and Assignment of EPA Hazardous Waste Numbers . . . . . . . . 3-15

Figure 4.1 Statistical Approach to Sampling and Analyzing of Waste Stream . . . . 4-10

Figure 6.1 Preliminary Schedule for Characterization of Transuranic Waste . . . . . . 6-2 


\section{UST OF TABLES}

Table 3.1 Number of Waste Containers Requiring Visual Examination . . . . . 3-22

Table 4.1 Toxicity Characteristic Analytes $\ldots \ldots \ldots \ldots \ldots \ldots$

Table 4.2 Additional Required Volatile Organics . . . . . . . . . . . . . . 4-7

Table 4.3 Additional Required SemiVolatile Organics $\ldots \ldots \ldots \ldots \ldots \ldots \ldots$

Table 4.4

Table 5.1

Table 6.1

Table 6.2

Additional Required Metals . . . . . . . . . . . . . . 4-9

Quality Assurance Objectives for Nondestructive Assay . . . . . . . . . 5-3

Number of Waste Streams for Pads 1, 2, and $4 \ldots \ldots \ldots$. . . . . . . .

Table 6.3

Number of Waste Drums Requiring Visual Inspection

for Pads 1, 2, and $4 \ldots \ldots \ldots \ldots \ldots \ldots \ldots \ldots \ldots \ldots$

Table A-1

Table A-2

Number of Sampling Events for Pads 1,2 and 4 .

Selected Waste Containers . . ..................... A-1

Selected Waste Containers ... . . . . . . . . . . . . . . . . . A-4

Table A-4

Characterization Reassessment Results Summary

A-9 
Transuranic Waste Characterization, Sampling, and Analysis Plan Prepared for Los Alamos National Laboratory by RAE \& WASTREN, Inc.

\section{PREFACE}

This Transuranic Waste Characterization, Sampling, and Analysis' Plan (CSAP) was prepared by Rogers \& Associates Engineering Corporation and WASTREN, Inc., for the Los Alamos National Laboratory (the Laboratory). The CSAP will require future updating periodically to incorporate regulatory changes, to ensure consistency with other Laboratory documents, and to incorporate new information as the program develops. The CSAP consists of the document itself and four appendices.

Section 1, Introduction, presents an explanation of the purpose and scope of the CSAP, followed by a brief site description, the site mission, and an explanation of project terminology used throughout the document.

Section 2, Regulatory Requirements, provides a summary of the regulatory requirements and program drivers relevant to transuranic waste management at the Laboratory.

Section 3, Waste Stream Identification and Characterization, describes in detail the process whereby the Laboratory's transuranic waste streams will be identified and characterized, the types and quality of information to be used during the process, and the characterization verification methods to be used.

Section 4, Sampling and Analysis, defines the analytical requirements necessary to generate data that are scientifically valid, legally defensible, and representative of the Laboratory's transuranic waste streams.

Section 5, Data Quality Objectives, describes the data quality objective development process including the need for dynamic data quality objectives over the time frame of the project, and

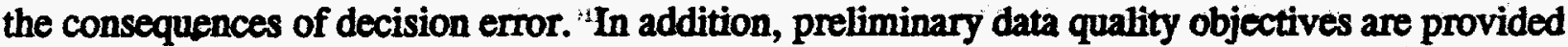
as a starting point.

Section 6, Schedule, develops a preliminary schedule for the characterization of the transuranic waste stored on Pads 1, 2, and 4 in Technical Area 54, Area G.

Section 6 is followed by four appendices that provide information essential to the reader's understanding of the CSAP. Appendix A describes the October 1994 field test of the CSAP methodology. Appendix B explains the statistical approach used to determine the number of containers to be visually inspected. Appendix $C$ includes a list of references, and Appendix D lists the acronyms and abbreviations that are used throughout the CSAP. 
Transuranic Waste Characterization, Sampling, and Analysis Plan

Prepared for Los Alamos National Laboratory by RAE \& WASTREN, Inc.

\section{EXECUTIVE SUMMARY:}

\section{ES. 1 INTRODUCTION}

Los Alamos National Laboratory (the Laboratory) is a facility owned by the U.S. Department of Energy (DOE) and is operated by the University of California. The facility is located approximately 25 miles northwest of Santa Fe, New Mexico, situated on the Pajarito Plateau. Technical Area 54 (TA-54), one of the Laboratory's many technical areas, is a radioactive and hazardous waste management and disposal area located within the Laboratory's boundaries. The Laboratory has been in operation since 1943. Its mission has included nuclear weapons research and development, reducing nuclear danger, and alternative uses of nuclear energy in areas such as space technology, fission reactors, controlled thermonuclear reactions, and medical and biological applications.

The purpose of this Transuranic Waste Characterization, Sampling, and Analysis Plan (CSAP) is to provide a methodology for identifying, charneterizing and sampling approximately 25,000 containers of transuranic waste stored at Pads 1, 2, and 4, Dome 48, and the Fiberglass Reinforced Plywood Box Dome at TA-54, Area G, of the Laboratory. . Transuranic waste currently stored at Area $G$ was generated primarily from research and development activities, processing and recovery operations, and decontamination and decommissioning projects.

This document was created to facilitate compliance with several regulatory requirements and program drivers that are relevant to waste management at the Laboratory, including concerns of the New Mexico Environment Department as outlined in the Notice of Deficiency NM 0890010515-1 and in Compliance Orders NMHWA 93-03 and 93-04.

\section{ES.2 WASTE MVENTORY AND APPROACH FOR WASTE STREAM DDENTIFICATION CHARACTERIZATIOW, AND SAMPLWE EFFORTS}

The CSAP provides a methodology to identify and subdivide transuranic waste into one of three broad waste categories using the DOE's Waste Matrix Parameter System as presented in the DOE Waste Treatability Groups Guidance document (DOE 1993a). Subdivision into waste categories will be based on the bulk physical and chemical form for each waste category. The inventory of waste considered in this effort includes the transuranic waste with Waste Matrix Codes 3000 (solid process residues), 4000 (soils), and 5000 (debris). Each category will be further subdivided into discrete waste streams where each waste stream consists of waste that has uniform chemical and physical properties and that was generated by a single process or activity. The initial Resource Conservation and Recovery Act characterization of each waste stream will be performed using information available about the waste. Waste stream identification, characterization, and sampling efforts will involve compilation and review of existing and new information for both heterogeneous and homogeneous waste; for homogeneous waste, sampling and analysis will provide analytical data which will be reviewed. New waste information will include Real-Time Radiography and visual inspection. 
Transuranic Wasto Characterization, Sampling and Analysis Plan Prepared for Los Alamos National Laboratory by RAE \& WASTREN, Inc.

\section{ES.3 PRELMINARY FIELA STUDY}

A preliminary field study using the methodology defined in this document was conducted in October, 1994. The results demonstrate that ,with adequate information, containers can be grouped together for characterization. However, in some instances, container-by-container evaluations were necessary to arrive at an adequate characterization. Field study results indicate the methodology presented herein ean adequately characterize the Laboratory's transuranic waste and can serve as guidance for future Laboratory waste characterization. 


\subsection{INTRODUCTION}

\subsection{PURPOSE AND SCOPE}

The development of the detailed Transuranic Waste Characterization, Sampling, and Analysis Plan (CSAP) for the Los Alamos National Laboratory (the Laboratory) was undertaken primarily to identify and characterize transuranic waste stored at Pads 1, 2, and 4, Dome 48, and the Fiberglass Reinforced Plywood Box (FRP) Dome in Technical Area 54 (TA-54), Area G. Transuranic waste currently stored at TA-54, Area $G$ was generated primarily from research and development activities, processing and recovery operations, and decontamination and decommissioning projects.

The waste inventory to be assessed by this CSAP includes approximately 25,000 containers of transuranic waste assigned Waste Matrix Codes (WMC) 3000 (solid process residues), 4000 (soils), and 5000 (debris). Containers assigned other Waste Matrix Codes may be present but are out of the scope of this document and will be addressed on a case-by-case basis. The volume of waste assigned other Waste Matrix Codes amounts to less than one percent of the transuranic waste covered by this CSAP. More specifically, the CSAP will:

- Identify the state and federal regulations and agreements that must be addressed by a transuranic waste characterization program

- Address the deficiencies listed in the New Mexico Environment Department's (NMED) Notice of Deficiency (NOD) NM 0890010515-1

- Provide characterization data that is consistent with Waste Isolation Pilot Plant (WIPP) Waste Acceptance Criteria (WAC) (DOE 1990)

The purpose of this plan is to provide a detailed characterization, sampling, and analysis methodology by performing the following activities:

- Identification of the containers to be assessed and categorization of these waste containers by Waste Matrix Codes

- Verification of the assigned Waste Matrix Codes through Real-Time Radiography (RTR) and visual inspection and identification of individual waste streams

- Hazardous waste determinations for individual waste streams according to the applicable regulations

- $\quad$ Application of specific U.S. Environmental Protection Agency (EPA) Hazardous Waste Numbers to individual hazardous waste streams where appropriate 
Transuranic Waste Charactorization, Sampling, and Analysis Plan Prepared for Los Alamos National Laboratory by RAE \& WASTREN, Inc.

- Confirm or refute preliminary characterization of homogeneous waste (WMCs 3000 and 4000) by statistically-based sampling and analysis

- Generation of data that are scientifically valid, legally defensible, and representative of the sulfect wate

- Perform quantitative statistical analysis on analytical data to verify application of EPA Hazardous Waste Numbers

- Development of data quality objectives and assessment of program performance over time

- Preparation of a schedule for characterization, sampling; and analysis events for the transuranic waste stored in drums on Pads 1, 2, and 4

\subsection{SITE DESCRIPTION}

The Laboratory is a facility owned by the DOE and is operated by the University of California. The 43-square-mile, 27,500-acre facility is located in Los Alamos County and is about 25 miles northwest of Santa Fe, New Mexico. TA-54, one of the Laboratory's many technical areas, is a radioactive and hazardous waste management and disposal area within the Laboratory's boundaries. TA-54, Area G, has been in operation since 1957. It serves as the primary waste management area for transuranic waste generated at the Laboratory.

\subsection{SITE MISSION}

The Laboratory has been in use since 1943, when its sole mission was the development of the fission bomb. Since that time, the mission of the Laboratory has continued to be nuclear weapons research and development. More recently, Laboratory efforts have been directed to include reducing nuclear danger, alternate uses of nuclear energy in areas such as space technology, fission reactors, controlled thermonuclear reactions, and medical and biological applications. Increasingly, the Laboratory has expanded into nonnuclear research, primarily geothermal and solar energy sources and use of superconductor technology for energy storage and transmission (DOB 1979). Existing major programs at the Laboratory have included research in nuclear and conventional weapons development, nuclear fission and fusion, nuclear safeguards and security, and waste management (DOE 1993b). 
Transuranic Waste Characterization, Sampling, and Analysis Plan Prepared for Los Alamos National Laboratory by RAE \& WASTREN, Inc.

\subsection{PRONECT CONVENTIONS ANA TERMS}

The term "transuranic waste" is defined by DOE Order 5820.2A as "without regard to source or form, waste that is contaminated with alpha-emitting transuranium radionuclides with halflives greater than 20 years and concentrations greater than $100 \mathrm{nCi} / \mathrm{g}$ at the time of assay" (DOE 1988). For clarification, "transuranic waste" in this document refers to all of the Laboratory's transuranic waste, whether hazardous or nonhazardous.

"Homogeneous" waste as used in this document refers to waste that is physically uniform, whereas, "heterogeneous" waste refers to waste that is not physically uniform.

The use of the term "Waste Matrix Code" in this document refers to the subdivision of transuranic waste into one of three broad waste categories based on the bulk physical and chemical form of the waste. The DOE Waste Treatability Groups Guidance, uses the term "Matrix Parameter Category" while the TRU Waste Characterization Quality Assurance Program Plan uses the term "Waste Matrix Code" (DOE 1993a and 1994b). The definition of these terms is synonymous.

The use of the term "waste stream" in this document refers to the most discrete unit into which a waste can be divided such that the containers in the waste stream are comprised of wastes that have the same physical and chemical properties and the same RCRA characterization. Waste stream is defined more specifically frin Section 3.3.2.

The use of the word "hazardous" in this document means hazardous only in the sense that the waste is subject to the Resource Conservation and Recovery Act (RCRA) hazardous waste regulations. "Nonhazardous," as used in this document, refers to waste not subject to RCRA hazardous waste regulations.

The use of the word "categorization" in this document refers to the assignment of Waste Matrix Codes to the waste. "Identification" refers to identifying waste streams within the Waste Matrix Code categories, and "characterization" refers to the RCRA characterization of the waste streams, which is determining whether the waste stream is hazardous or nonhazardous and assigning EPA Hazardous Waste Numbers where appropriate. 


\subsection{REGULATORY REQUIREMENTS}

There are numerous regulatory requirements and program drivers which are relevant to waste management at the Laboratory. The term "regulatory requirement" refers to federal and state laws and regulations, regulatory agreements, and consent orders that are legally binding (such as RCRA and Compliance Orders NMHWA 93-03 and 93-04). The term "program drivers" refers to requirements that the Laboratory follows in conformance with best management practices (such as DOE Orders).

The CSAP was prepared in accordance with the regulations in effect as of November 1, 1994. In the event that new laws are enacted or new regulations are promulgated, an assessment must be completed to determine the impacts on this document. The major regulatory requirements and program drivers that affect waste management planning at the Laboratory are addressed in the remainder of this section.

\section{RESOURCE CONSERVATION AND RECOVERY ACT}

RCRA was adopted in 1976 as an amendment to the Solid Waste Disposal Act (the Act)(42 USC 6901), which regulates the disposal of solid waste. The Act contains a number of subtitles, the most important of which is Subtitle C, concerning the management of hazardous waste. The Act established a national program to protect human health and the environment from the improper handling of solid waste and to encourage conservation of natural resources. The Act also authorizes the EPA to specify standards for anyone who generates, treats, stores, transports, or disposes of hazardous waste.

Hazardous waste is defined as any solid waste that exhibits hazardous characteristics (such as, ignitability, corrosivity, reactivity, or toxicity), or is named on one of three lists developed by the EPA (that is, wastes from nonspecific sources, wastes from specific sources, and commercial chemical products). This definition includes radioactive wastes containing hazardous constituents (mixed wastes, including low-level mixed waste and transuranic mixed waste). The Laboratory generates and stores both hazardous and mixed waste, all of which are governed by the Laboratory's RCRA Operating Permit (NM 0890010515).

The Hazardous and Solid Waste Amendments (HSWA) of 1984 expanded both the scope and detailed requirements of RCRA. The primary focus of the HSWA was the enactment of the Land Disposal Restrictions (LDR). This program required EPA to evaluate all listed and characteristic RCRA-hazardous wastes to establish the conditions under which land disposal of the waste should be allowed. The LDR program created by the EPA prohibits land disposal of hazardous wastes unless the wastes meet EPA treatment standards prior to land disposal, or if EPA has granted a "no migration" variance. The EPA grants a "no migration" variance based on a demonstration that there will be no migration of hazardous constituents from the unit or injection zone (for underground injection wells) as long as the wastes remain hazardous. 
Transuranic Waste Characterization. Sampling, and Analysis Plan Prepared for Los Alamos Netional Laboretory by RAE \& WASTREN, Inc.

The EPA is the primary regalatery authority for the RCRA program, but has authorized the oversight of the program to the New Mexico Environment Department (NMED). The NMED administers and implements the program in the State of New Mexico through the New Mexico Hazardous Waste Act (HWA) and its implementing regulations:

\section{NEW MEXICO HAZARDOUS WASTE ACT}

The New Mexico HWA is the state's counterpart to RCRA. The State of New Mexico incorporated the RCRA by reference into their hazardous waste management system, with some minor exceptions, thereby ensuring that New Mexico's-hazardous waste regulations are at least as stringent as the federal regulations. The State of New Mexico received final authorization from EPA to administer its base RCRA program on January 25, 1985. The state also applied and received permission for HSWA program authorization on October 7, 1994. The notice appeared in the Federal Register on December 21, 1994. This means that the State of New Mexico will be responsible for the oversight and enforcement of RCRA and HSWA provisions, with the exception of HSWA corrective actions. Until the spring of 1995, therefore, the EPA will enforce HSWA standards for any corrective actions taken in New Mexico.

Historically, the New Mexico HWA has been implemented by the New Mexico Hazardous Waste Management Regulations (HMWR). On September 23, 1994, the New Mexico Environment Improvement Board (EIB) promulgated the 1993 version of the New Mexico Administrative Code, Title 20, Chapter 4, Part 1 (20 NMAC 4.1), which is amendments to the Hazardous Waste Management Regulations, EIB (HWMR-7), filed October 21, 1992, as amended.

In this CSAP, historical issues will be referenced with the regulation in effect at that time; current issues will be referenced by the regulation in effect at the time this document was issued.

\section{FEDERAL FACIUTY COMPUANCE ACT}

The Federal Facility Compliance Act (FFCAct)(42 USC 6961) was enacted in 1992 as an amendment to RCRA to clarify provisions concerning the application of certain requirements and sanctions to federal facilities. The FFCAct waives sovereign immunity for fines and penalties for RCRA violations at federal facilities. However, a provision included in the FFCAct postpones that waiver for mixed wastes that are governed by the RCRA LDR. This provision requires DOE to prepare plans for developing required treatment technologies for mixed wastes. Each plan must be approved by the state or EPA, after consultation with other affected states and consideration of public comment, and an order must be issued by the regulator requiring compliance with the plan. The FFCAct further provides that DOE will not be subject to fines and penalties for LDR storage prohibition violations for mixed waste as long as it is in compliance with an approved plan and order. 


\subsection{ATOMIC ENERGY ACT.}

The Atomic Energy Act as amended (42 USC 2011) authorizes DOE to establish standards for the management of source, special nuclear, or by-product material, and for the protection of the public against radiation from DOE facilities. Requirements are outlined in a series of DOE Orders. These DOE Orders incorporate established national and industrial standards which limit radiation exposures and releases of radioactive materials to the environment to levels that are as low as social, technical, economic, practical, and public policy considerations permit. The Laboratory generates and stores two types of radioactive wastes that are governed by these DOE Orders: transuranic waste and low-level waste.

\section{DOE ORDER 5820.2A, RADIOACTVE WASTE MANAGEMENT"}

DOE Order 5820.2A, revised by the DOE in 1988, establishes policies, guidelines, and minimum requirements by which the DOE manages its radioactive and mixed waste and radioactively contaminated facilities. The primary focus of the Order is to ensure the safe and environmentally responsible management of radioactive and mixed wastes, so that the health and safety of the public, DOE, and contractor employees, and the environment shall be protected. The Order also encourages waste minimization and management in a manner compliant with all applicable federal, state, and local laws.

\section{COMPLANCE ORDERS NMHWA 93-03 AND 93-04}

The 1993 Compliance Orders, issued January 28, 1993, require the University of California to comply with New Mexico Hazardous Waste Management Regulations Revision 6 (HWMR-6). Specifically, the compliance Orders directed the Laboratory to;

- Prepare an NMED-approved plan and schedule for placing the wastes at TA-54, Area G, Pads 1, 2, and 4 into storage that complies with the New Mexico HWA

- Provide documentation that the contents of the containers at TA-54, Area G, Pad 2 have been transferred to containers that are in good condition

- Remove all waste stored at TA-3-40 or provide documentation that the waste stored there is not hazardous

- Submit documentation to NMED that the hazardous waste container at TA-3-40 has been properly labeled

- Submit documentation to NMED that training has been provided to all necessary personnel

- Submit copies of the original manifests for certain hazardous waste shipments 
- Provide documentation to NMED that containers at TA-54, Area L, holding hazardous waste that is prohibited from land disposal have been properly labeled

\subsection{NOTICE OF DEFICIENCY (NM 0890010515-1)}

The NOD, issued December 17, 1993, required the Laboratory to provide the following information so that modification of the Laboratory's RCRA Operating Permit could begin:

- A revised Waste Analysis Plan (WAP) including a detailed chemical and physical analysis of the waste

- A contingency plan, verification of spill decontamination, and verification of closure procedures

- $\quad$ Revision of current waste management practices addressing proper storage of potentially free liquid-containing wastes

The NMED approved the Laboratory's responses to the second and third items listed above on March 15, 1994. However, the Laboratory is required to provide sampling and chemical and physical analysis of the waste under 20 NMAC 4.1. 
Transuranic Wasto Characterization, Sampling, and Analysis Plan

Prepared for Los Alamos National Laboratory by RAE \& WASTREN, Inc.

\subsection{WASTE STREAM IDENTIFICATION AND CHARACTERIZATION}

This section presents the methodology that will be used to identify and characterize the transuranic waste stored at Pads 1,2, and 4, Dome 48, and the FRP Dome at TA-54, Area G of the Laboratory. This methodology for identifying and characterizing wastes can be applied to stored wastes as well as wastes not yet generated.

According to 20 NMAG 4.1 , Subpart III, 262.11 , generators of solid waste, as defined in 20 NMAC 4.1, Subpart II, 261.2, are required to determine if a waste is hazardous as defined in 20 NMAC 4.1, Subpart II, 261.3. Generators of solid waste are allowed under 20 NMAC 4.1, Subpart III, 262.11, to substitute acceptable process information for analytical data when determining if the waste is a hazardous waste. Process information which can be substituted includes the materials used in the process, the nature of the process, and any other available information. However, to substitute process information for analytical data, the generator must document accurately and completely the information used to make the determination.

Transuranic waste is to be identified and subdivided into one of three broad waste categories using DOE's Waste Matrix Parameter System (See Section 1.4). This subdivision is based on the bulk physical and chemical form for each waste category. Each category will be further subdivided into discrete waste streams where each waste stream consists of waste that has uniform chemical and physical properties and that was generated by a single process or activity. The initial RCRA characterization of each waste stream will be performed using information available about the waste.

Section 3.1 describes the types of information to be collected and the sources of this information at the Laboratory. This will involve obtaining information sufficient to define the generation process and determine the generation location and date for each waste stream. Additional supporting information that will aid in defining chemical and physical properties of a waste will also be collected. Section 3.2 describes the method that will be used to evaluate the quality of the waste information. Section 3.3 explains how the wastes will be categorized and subdivided into discrete waste streams. Section 3.4 presents the regulatory. requirements and approach to be used to characterize each waste stream. Section 3.5 describes how RTR evaluation and visual inspection will be used to verify the assignment of Waste Matrix Codes and waste streams.

Figure 3.1 is a flow chart showing the sequence of activities used to identify and to characterize a waste stream and to verify the results. Each block, including the diamonds, represents an activity that must be performed. Diamonds represent decision points and show the action to be taken based on the decision's outcome. The data quality objective decision elements are contained in the bold boxes and are defined in Section 5.0. The blocks are defined in the body of this plan which includes the information needed to identify and characterize the waste, how to evaluate the quality and completeness of the information, the basis for making each decision, the consequences of a wrong decision, and any actions required. 


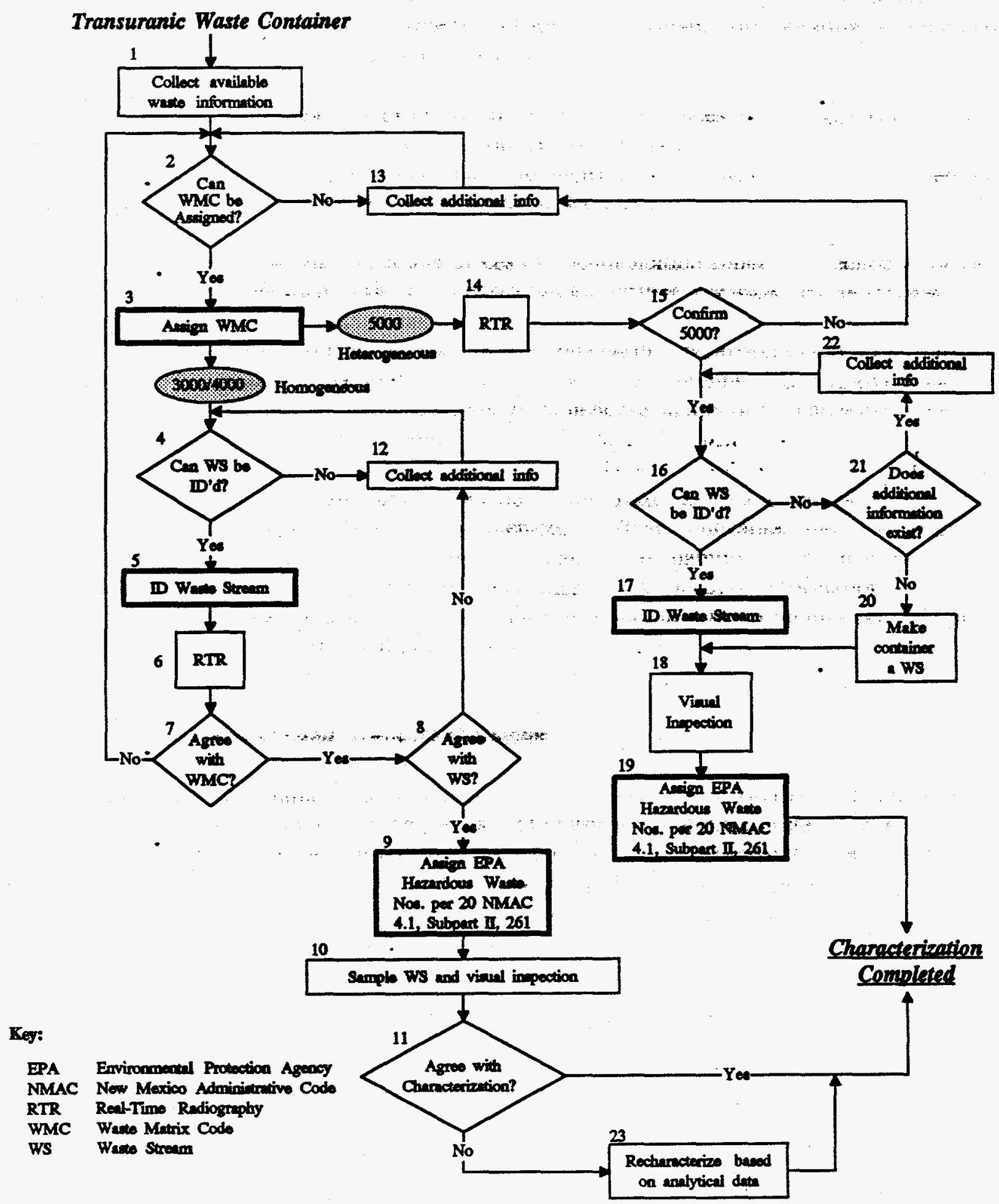

Figure 3.1

RCRA Hazardous Waste Characterization 


\subsection{WASTE INFORMATION}

This section defines the first step (block 1) shown on Figure 3.1, which is information collection. Several types of information should be gathered from a variety of sources for the purpose of waste stream identification and characterization. The types of information that should be collected and typical sources for this information are given below.

\subsubsection{Types of Information}

The following information should be collected and evaluated for accurate identification and characterization of waste streams. All of the information listed may not be available for each waste stream. However, the available information will aid in the identification and characterization process.

- Technical area, building, room, and process glovebox

- Generation date

- Purpose of the process

- Equipment and machinery used in the process

- Source of the primary materials used in the process and their chemical and physical makeup

- Description and diagram of the process and its operations, including operating conditions

- Inputs for each process step and their source and use

- Material-to-material and material-to-equipment contact

- Chemical or physical alteration of inputs

- Outputs for each step and immediate destination

- Waste packaging

- Changes in process operations and date of the changes

- Material Safety Data Sheets (MSDSs), analytical data, laboratory notes, or other supporting documentation 
Transuranic Waste Characterization, Sampling, and Analysis Plan Prepared for Los Alamos National Laboratory by RAE \& WASTREN, Inc.

\subsubsection{Collection of Information}

The information from Section 3.1.1 can be obtained through several sources. The availability of this information from these sources will vary for each waste stream. The accumulation of this information as well as any additional information generated by this methodology will constitute process knowledge. Brief descriptions of those sources are presented below.

\subsubsection{Existing Databases}

The Transuranic Waste Management Database (Los Alamos National Laboratory 1994f) maintained by CST-14, Solid Radioactive Waste Management, was developed for managing the transuranic wastes stored at TA-54, Area G. Some of the listorical container-specific information on file has been transferred into this database.' Quality of the Transuranic Waste Management Database is controlled through the use of a formalized operating procedure, Detailed Operating Procedure TRU Database Validation, CST-7G, Draft 044, Rev. 0, February 11, 1994 (Los Alamos National Laboratory 1994a).

Other databases maintained by specific waste generatiors should also be identified and used. These databases may contain additional information on the generation and chemical constituents of the waste.

\subsection{2:2 Existing Files}

Written documentation on hard copy or microfiche should be available for all containers of transuranic waste on various forms. The forms and types of information presented on them have evolved over several years. Thus, for some containers, detailed information will be available, and for others, only limited information will be available. For example, older forms on microfiche do not show EPA Hazardous Waste Numbers, while some of the newer forms do. As part of the characterization process, review of the documentation should be performed for consistency with the Transuranic Waste Management Database and to obtain any additional information not transferred to the database.

\subsubsection{Interviews with Cognizant Personnel}

Knowledgeable personnel (current and previous Laboratory employees) should be identified and interviewed to obtain detailed process information. A formal interview protocol should be used in the interviews. Also, documentation from previously conducted interviews with waste generators should be evaluated, and follow-up interviews should be conducted as necessary. 


\section{1.2.4 Existing Analytical Data}

Waste stream sampling and analysis data may be available from specific waste generators at the Laboratory. Until recently, data have been limited. However, the recent data can be applied to older waste if the Laboratory can demonstrate that the process that generated a particular waste has not changed since the analysis was performed. In addition, sampling and analysis of process streams may be available which could aid in the identification and characterization of waste streams.

\subsubsection{Real-Time Radiography}

RTR has already been performed on some waste containers and will be performed on all of the transuranic waste containers that are stored at TA-54, Area G. A review of RTR data will provide information on the physical characteristics of the waste.

\subsubsection{Container Labels}

A field investigation should be performed to obtain any information physically attached to containers in storage domes. The containers on Pads 1, 2, and 4 do not have labels. Container labels or markings may provide additional information, such as EPA Hazardous Waste Numbers, relating to the characterization history of the containers.

\subsubsection{Inspection of Process Areas}

Inspection of the process areas that generated the waste, accompanied by Laboratory personnel who are knowledgeable about the process and waste management operations, may provide additional information about the physical and chemical characteristics of the waste.

\subsubsection{Logbooks}

A review of logbooks kept by waste generators should be conducted. These logbooks may discuss various details about the processes that generated the waste and specific information on individual containers.

\subsubsection{Operating Procedures}

Operating procedures provide a detailed explanation of the process, including its purpose, the equipment used, operating conditions, inputs, and general steps of a process. When a process changes, information from operating procedures may be archived. The availability of this information should be determined. 
Transuranic Waste Characterization, Sampling, and Analysis Plan Prepared for Los Alamos Nationd Laboratory by RAE \& WASTREN, Inc.

\subsubsection{Other Information Sources}

Numerous documents prepared by DOE and the Laboratory, including those specific to waste generators, should be identified. These documents will provide more supporting documentation for identifying and characterizing the Laboratory's waste streams.

\subsection{EVALUATION OF THE QUALTY OF WASTE CHARACTERIZATION INFORMATION}

To accomplish the objectives of the CSAP, transuranic waste containers, will bo assigned to appropriate waste streams for characterization. Propec.waste stream assignment requires evaluation of the quality of available waste information and whether the infonmation is sufficient to make the determinations.

The quality of the information is important to two decisions that must be made. The first question is, "Will the available information allow the assignment of specific containers to a Waste Matrix Code and then to a waste stream that is discrete enough to characterize7" (blocks 2,4 , and 16 of Figure 3.1). The second question is, "Does the information allow the waste stream to be characterized?" (blocks 9 and 19 of Figura 3.1). The answers to these questions will be based on available information discussed in Section 3.1.

A programmatic discussion of the quality criteria is presented in this section of the CSAP. These criteria will be applied at each of the decision points shown on Figure 3.1. If a decision cannot be made or a "no" decision is reached, additional information will have to be obtained. If a decision cannot be made or "no" decision is reached after the initial and secondary attempts to obtain information; the container will be assigned to its own waste stream. Information is sufficient if it is adequate to generate a "yes" response at a decision point. Consensus and corroborating documentation are cost-effective means of judging if the information is sufficient.

\subsubsection{Guidelines for Evaluating the Quality of Information}

- Available documentation shall be examined. Relevant information, specific to each container, shall be checked for consistency. After examining existing documentation, a specific decision should be attempted. If necessary, corroborating information should be obtained.

- Assume documented information is correct unless obvious errors have occurred or conflicting information is present. Collect additional information if needed to reach a specific decision. 
Transuranic Waste Characterization, Sampling, and Analysis Plan Prepared for Los Alamos National Leboratory by RAE \& WASTREN, Inc.

- The amount and type of information needed to make a specific decision may vary depending on the waste. A single piece of relevant documentation may or may not be sufficient to make a decision. If possible, corroborating documentation should be collected and evaluated.

- Consideration should be given to the consequenees of an incorrect decision in determining how much additional documentation to pursue, but work should proceed if existing documentation appears to be reliable. The consequences of incorrect decisions are discussed in Section 5.0.

- If multiple but conflicting pieces of documentation apply to a decision; additional documentation must be collected until a definite decision can be reached.

$$
\text { inl: }
$$

- The information collected will be evaluated in comparison to the RTR evaluation, the visual inspections results, and the final sampling and analysis data. This evaluation will demonstrate and document the quality of available information and improve project efficiency.

- Available information should be summarized and resolution of any conflicting information should be documented. When applicable, the justification for selecting information should be stated. Unavailability of information should be noted. It is advisable to include copies of key pieces of information. For quality assurance purposes, the waste generators should sign off on process information, even if the information is limited.

\subsection{WASTE STREAM IDENTIFICATION}

The Laboratory's transuranic waste stored at TA-54, Area G, is classified as either homogeneous (physically uniform) waste or heterogeneous (not physically uniform) waste. These wastes will initially be divided into broad waste categories according to Waste Matrix Codes. Waste Matrix Codes are a DOE coding system that categorizes waste by bulk chemical and physical form (DOE 1993a). This initial categorization is based on the information gathered and evaluated as described in Sections 3.1 and 3.2 of this document. The containers of waste within the same Waste Matrix Codes are subsequently divided into discrete waste streams. The procedure to be used to categorize the waste and identify the waste streams is described below.

\subsubsection{Waste Categories}

Waste Matrix Codes which apply to the Laboratory's homogeneous waste include WMC 3000 , solid process residues and WMC 4000, soils. Applicable Waste Matrix Codes for the Laboratory's heterogeneous waste include WMC 5000, debris. These Waste Matrix Codes are defined as follows: 
Transuranic Waste Characterization, Sampling, and Analysis Plan Propared for Los Alamos National Laboratory by RAE \& WASTREN, Inc.

- WMC 3000, solid process residues, consists of wastes that are solid materials, excluding soil, that do not meet the criteria of debris (as defined below). Examples are sludge- and particulate-type materials that are at least 50 percent by volume solid process residues. The balance of this matrix may be debris or soil.

- WMC 4000 , soils, consists of wastes that are at least 50 percent by volume soil, generated by spill cleanup or from other sources. The balance of the matrix may be debris.

- WMC 5000, debris, consists of wastes that are at least 50 percent by volume materials that meet the regulatory definition of debris (20 NMAC 4.1, Subpart VII, 268.2). This includes any solid material exceeding 60 millimeter (mm) particle size (that is, $60 \mathrm{~mm}$ in any one dimension) that is intended for disposal and that is a manufactured object, plant or animal matter, or natural geologic material.

The wastes are to be divided into Waste Matrix Codes based on the bulk chemical and physical form of the waste (block 2 and 3 of Figure 3.1). This activity will not require the detailed information that will be needed for waste stream identification and characterization. Most of the information defined in Section 3.1 will allow categorization if its quality is acceptable. However, the primary information used for Waste Matrix Code assignment include the generation location, generation process, and generation date. These criteria should be investigated first. These criteria and their application are described in detail in Section 3.3.2. Section 5.2 presents the data quality objectives for this determination.

If the initial effort to assign a Waste Matrix Code (block 2) is not successful, additional information must be collected (block 13), and a second attempt made to assign a Waste Matrix Code. If a Waste Matrix Code cannot be assigned at that point, the waste container or containers are to be segregated until they can be analyzed by RTR as defined below. Following RTR analysis, the information evaluation process will be performed again.

RTR will be performed on all transuranic waste drums (blocks 6 and 14) to verify each container's Waste Matrix Code assignment (blocks 7 or 15). If, upon RTR evaluation, it is suspected that the Waste Matrix Code was incorrectly assigned, or if no further information can be obtained and no categorization can be performed, completion of this activity will be postponed until the drum can be visually inspected, and its contents confirmed (blocks 10 and 18).

A statistically representative number of randomly selected containers (see Section 3.5.2.1) will be visually inspected (blocks 10 and 18) to confirm the quality of RTR evaluations and to further verify the container's contents. All information necessary for completing the categorization must be obtained to ensure the container does not have to be opened twice. If it is found that the RTR data the compiled information collected are erroneous, inconsistencies should be resolved and documented. A detailed explanation of RTR and visual inspection is presented in Section 3.5 . 


\subsubsection{Identification of Waste Streams}

Following categorization of waste into WMCs 3000,4000 , and 5000 , each waste category will then be subdivided into waste streams. A waste stream is the most discrete unit into which a waste can be subdivided. Waste streams are defined as materials that are generated from a single process or activity that have essentially the same physical and chemical properties (DOE 1993a). A single waste stream should be assigned to only one Waste Matrix Code.

Waste stream identification encompasses those activities associated with blocks 4 and 16 of Figure 3.1. The identification procedure involves using the information gathered as described in Section 3.1 of this document. The method provided in Section 3.2 for evaluating the quality of this information is applied throughout the waste stream identification procedure. The major criteria used in waste stream identification, assignment, and verification are presented below.

\subsubsection{Criteria for Waste Stream Identification}

The generation date, generation location, and generation process are the primary criteria required for waste stream identification. These criteria and their application are described in detail below. Alt of this information may not be available for each waste stream; however, as much information as possible should be used to identify a waste stream.

\section{Generation Date}

The time frame in which a waste was generated can influence the physical and chemical characteristics of the waste. For example, changes in the volumes or types of materials used in a production process or in waste packaging could cause the resulting waste to change chemically or physically. Therefore, correlating the waste generation dates with the dates of process or waste packaging changes will aid in waste stream identification. If the dates of generation can only be described in terms of a general range rather than a particular dates, the range should be limited as much as possible to avoid overlap with more than one production process or waste packaging regime. However, it is possible that a general range of time will provide sufficient information to identify a waste stream.

\section{Generation Location}

To identify a waste based on generation location information, its point of generation should be narrowed down as much as possible. This includes the technical area, building, room, and possibly even glovebox where a process was located. Tracing a waste to a container of composited waste might not provide sufficient information for waste stream identification, unless the contributing processes or activities are sufficiently similar. 


\section{Generation Process}

Process information, as described in Section 3.1, is the best source of information for allocating waste containers into waste streams of similar physical and chemical properties. If the generation process can be identified, details on the chemical and physical properties of each process output should be provided:

- Process purpose

- Equipment used

- Material inputs

- Material outputs

- Operating parameters and procedures

- Changes in process operation

- Waste packaging

As noted in Section 3.1, existing databases and files, interviews, process area inspections, and logbooks will be valuable in compiling specific information.

\subsubsection{Assignment of Waste Streams}

The chemical and physical properties of a waste will be determined by evaluating all relevant information. The containers should be grouped by generating process or activity. Then waste containers will be assigned to waste streams which have essentially the same physical and chemical properties (blocks 5 and 17). Section 5.3 presents the data quality objective for these determinations.

If initial efforts to identify waste streams (blocks 4 and 16) are not successful, additional information must be collected if it exists (blocks 12, 21, and 22), and a second attempt made to identify a waste stream. If a homogeneous waste stream cannot be identified at this point, the waste container is to be segregated until it can be analyzed by RTR. Following RTR, the information evaluation process will be performed again (block 4). If a container cannot be assigned to a waste stream at this point, the container will be assigned to its own waste stream. If a heterogeneous waste stream cannot be identified after the initial and secondary attempts, the container will be assigned to its own waste stream (block 20). 
Transuranic Waste Characterization, Sampling, and Analysis Plan Prepared for Los Alamos National Laboratory by RAE \& WASTREN, Inc.

\subsubsection{Verification of Waste Stream Identification}

RTR will be performed on all transuranic waste drums (blocks 6 and 14). Visual inspection will be performed on a statistically representative number of randomly selected containers as outlined in Section 3.5.2.1. These verification techniques provide additional information for waste stream identification and characterization.

For homogeneous wastes, RTR will be performed to verify the waste stream assignment of each container (block 8). If upon RTR evaluation it is suspected that the waste stream to which a container belongs was identified incorrectly, or if no identification can be made and no further information can be obtained, completion of this activity will be postponed until the drum can be visually inspected (block 10), and its waste stream assignment confirmed. When a homogeneous waste container is opened, all information necessary for completing the identification should be obtained to ensure that the container does not have to be opened twice. This includes sample collection if appropriate (block 10) which is discussed in Section 4.2.

For heterogeneous waste, RTR will be performed to verify the Waste Matrix Code assignment and to gather additional information to aid in waste stream identification. Verification of heterogeneous waste stream assignment will be accomplished by visual inspection. Visual inspection will be performed on a statistically representative number of randomily selected waste containers (block 18) to ensure the quality of RTR evaluations and to further verify the waste stream assignment. If it is found that the RTR data or compiled information are erroneous, further investigation should be conducted to resolve inconsistencies.

\subsection{WASTE STREAM RESOURCE CONSERVATION AND RECOVERY ACT CHARACTERIZATION}

The RCRA characterization of waste streams to be performed at the Laboratory is guided by regulations and standards issued by BPA and NMED. The NMAC were drafted to support implementation of the New Mexico HWA and RCRA as discussed in Section 2.2. This document defines RCRA waste characterization requirements for each transuranic waste stream. The specific goals and objectives of RCRA characterization are provided below.

- Determine which transuranic waste streams are hazardous and, therefore, subject to regulations governing their transportation, storage, treatment, and disposal according to 20 NMAC 4.1, Subpart II, 261.

- Assign specific EPA Hazardous Waste Numbers to individual waste streams (blocks 9 and 19).

- Verify characterization of homogeneous waste by sampling and analysis (block 11). 
Transuranic Waste Characterization, Sampling, and Analysis Plan Prepared for Los Alamos National Laboratory by RAE \& WASTREN, Inc.

The approach by which the Laboratory can achieve these goals and objectives is described in the following section. This approach is tailored to the stored transuranic waste at TA-54, Area G. Therefore, regulations, not applicable to the stored transuranic waste are not discussed in the following sections.

\subsubsection{Resource Conservation and Recovery Act Characterization}

Waste generators are required by 20 NMAC 4.1, Subpart III, 262.11, to identify and characterize all waste streams. These characterizations involve determining whether individual waste streams generated at the Laboratory are hazardous or nonhazardous. The RCRA characterizations will be based upon waste stream-specific information collected through methods outlined in Section 3.1.2. Only by reviewing and assessing all information collected can the best determination be made. The requirements and logic for making hazardous, waste determinations and for assigning specific EPA Hazardous Waste Numbers are discussed in the following sections. The data quality objectives for characterization of homogeneous and heterogeneous wastes are presented in Section 5.4 and 5.5, respectively.

The regulations establish the framework for determining whether a solid waste is 2 bazardous waste (20 NMAC 4.1, Subpart II, 261). At the most basic level, a waste will be subject to management as a hazardous waste only if it is a solid waste; does not qualify for an exclusion; and either exhibits one or more of the four hazardous waste characteristics identified in Subpart C of the regulation or is a hazardous waste listed in Subpart D of the regulations. Numerous exclusions and exemptions apply to this simplified explanation for what constitutes a hazardous waste. The exclusions and exemptions that are applicable to the transuranic waste stored at TA-54, Area G are addressed in the following sections that describe the methodology used for solid waste-determinations and subsequent hazardous waste determinations.

\subsubsection{Solid Waste Determination}

A waste must meet the definition of a solid waste before it can be considered a hazandous waste. The term solid waste is specifically defined in 20 NMAC 4.1, Subpart II, 261, and does not refer to the physical state of the waste.

A flow chart of the process used for solid waste determinations is provided in Figure 3.2. Solid waste is defined as any discarded material that is not subject to regulatory exclusion or to a specific variance (20 NMAC 4.1, Subpart II, 261.2(a) through (d)). Discarded materials include those that have been abandoned, recycled, or are considered inherently waste-like. An example of an item which is excluded from the definition of a solid waste and is not regulated by 20 NMAC 4.1 is source, special nuclear, or by-product material as defined by the Atomic Energy Act.

For the purpose of this document, all of the transuranic waste stored at TA-54, Area G is a solid waste. 
Transuranic Waste Characterization, Sampling, and Analysis Plan Propared for Los Alamos National Laboratory by RAE \& WASTREN, Inc.



Figure 3.2

Process for the Solid Waste Determination (20 NMAC 4.1, Subpart II, 261) 
Transuranic Waste Characterization, Sampling, and Analysis Plan Prepared for Los Alamos National Laboratory by RAE \& WASTREN, Inc.

\subsubsection{Hazardous Waste Determination}

Wastes determined to be solid wastes must be further evaluated to determine if they are hazardous wastes as defined by 20 NMAC 4.1 Subpart II, 261. A flow chart of the process used for hazardous waste determination is provided in Figure 3.3. The evaluation of all the information collected on a waste stream is used to make the initial hazardous waste determination.

A solid waste is considered hazardous if it meets any of the criteria specified under the definition of hazardous waste in 20 NMAC 4.1, Subpart II, 261.3. A solid waste which exhibits any characteristic of ignitability, corrosivity, reactivity, or toxicity is a hazardous waste. These wastes are defined as characteristic wastes. Specific wastes, regardless of their characteristics, are also regulated. These wastes are defined as listed hazardous wastes. The chemical and analytical requirements for verifying the hazardous. waste determination are different for listed and characteristic hazardous wastes and are defined below.

\section{A. Listed Hazardous Waste}

By definition, a solid waste that is listed in 20 NMAC 4.1, Subpart II, 261, Subpart $D$, is a listed hazandous waste. A solid waste is also a listed hazardous waste, if it is a solid waste that has been mixed with or derived from a listed hazardous waste. No regulatory limits are specified for listed hazardous wastes, and analytical data cannot be used for making a final determination relative to whether a waste is hazardous because it is a listed hazardous waste or mixed with a listed hazardous waste or derived from a listed hazardous waste. This hazardous determination, as shown on Figure 3.3, can only be made based on information that:

- The solid waste is known to be a listed hazardous waste

- The solid waste is known to have been mixed with a listed hazardous waste

- The solid waste is known to have been derived from the treatment, storage, or disposal of a listed hazardous waste

If no such information exists, the solid waste is not a listed hazardous waste.

The information required to classify a solid waste as a listed hazardous waste primarily consists of the waste's source, its specific use, and its status. The following categories of listed hazardous waste are defined in Subpart D of 20 NMAC 4.1, Pạrt 261:

- 20 NMAC 4.1, Subpart II, 261.31, lists wastes from nonspecific sources or processes and describes the wastes. These wastes carry "F" EPA Hazardous Waste Numbers. 
Transuranic Waste Characterization, Sampling, and Analysis Plan Propared for Los Alamos National Laboratory by RAE \& WASTREN, Inc.

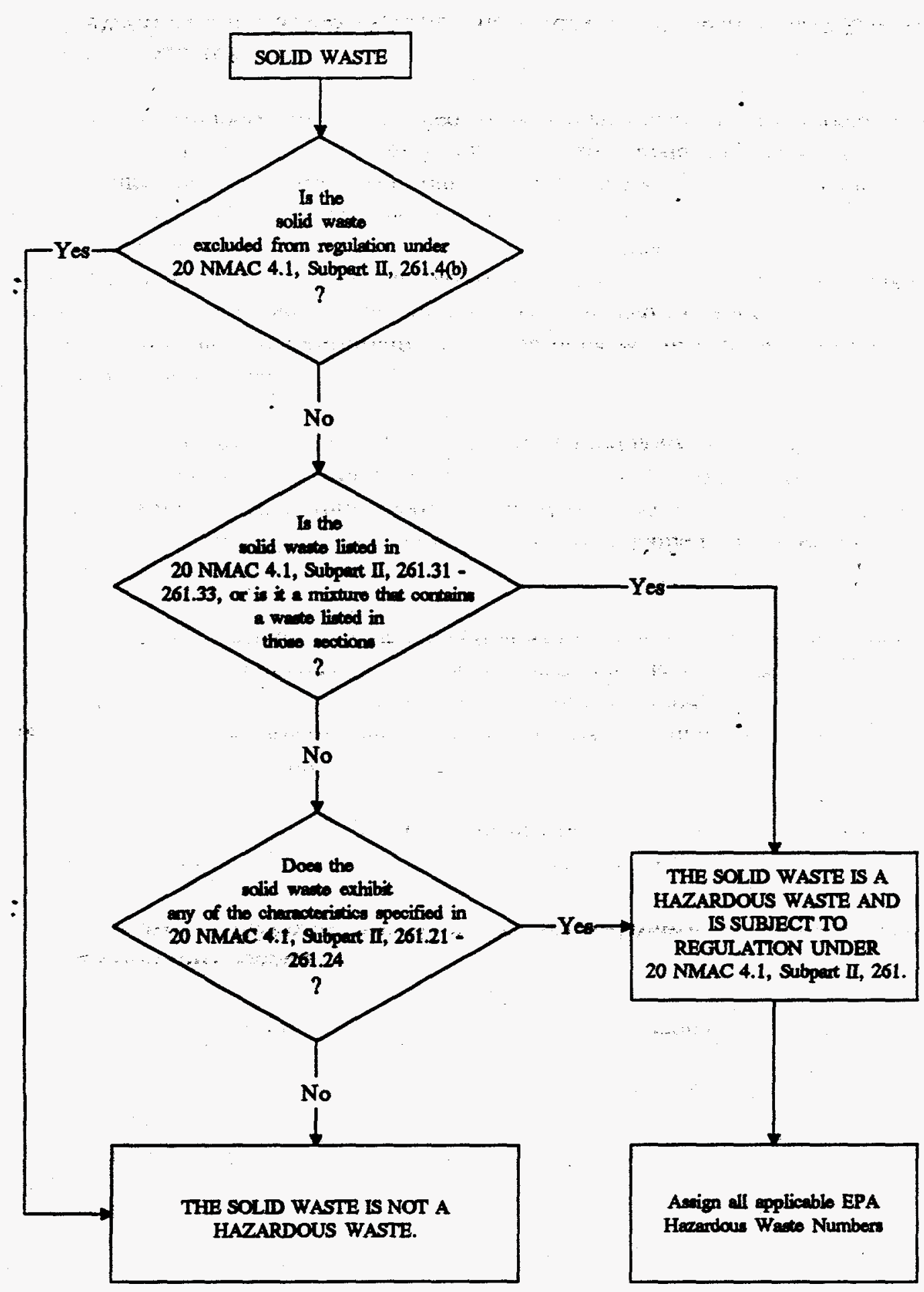

Figure 3.3

Process for RCRA Hazardous Waste Determination and Assignment of EPA Hazardous Waste Numbers

(20 NMAC 4.1, Subpart II, 261) 
Transuranic Waste Characterization, Sampling, and Analysis Plan Prepared for Los Alamos National Laboratory by RAE \& WASTREN, Inc.

- 20 NMAC 4.1, Subpart II, 261.32, lists wastes from specific sources or processes and describes the processes. These wastes carry "K" EPA Hazardous Waste Numbers.

- $\quad 20$ NMAC 4.1, Subpart II, 261.33, lists "sole active ingredients" that are discarded commercial chemical products, off-specification species, container residues, and spill residues thereof." Those that are "acutely hazardous" carry "P" EPA Hazardous Waste Numbers and those that are "toxic and others" carry "U" EPA Hazardous Waste Numbers.

" $K$ " listed hazardous wastes, by their definition, should not be present at TA-54, Area G. Similarly, the "U" and "P" listed hazardous wastes are not expected to be present. The " $F$ " listed hazardous wastes, especially solvents used for cleaning, are expected to be present at the Laboratory.

B. Characteristic Waste

A solid waste is hazardous waste if it exhibits the characteristic of ignitability, corrosivity, reactivity, or toxicity as defined on 20 NMAC 4.1, Subpart II, and as summarized below. If a waste is initially characterized as a hazardous waste because the collected information shows that it may exhibit a characteristic of a hazardous waste, the final determination can be made by testing a representative sample of the waste. Regulatory guidelines are provided in Subpart C of 20 NMAC 4.1 Part 261 for determining whether a solid waste exhibits a characteristic and is therefore a hazardous waste (see Figure 3:2). Consequently, analytical results can be used to verify that the waste exhibits the characteristic(s) identified by the initial characterization. If analysis indicates the solid waste does not exhibit a characteristic, the initial characterization is not supported, and the associated EPA Hazardous Waste Number will not be assigned. If sampling and analysis is not performed on the solid waste, it is assumed that the solid waste exhibits the cliaracteristic; and the appropriate EPA Hazardous Waste Numbers will be assigned. Regulatory guidelines for characteristics of hazardous waste are described below.

\section{Ignitability Characteristic}

The ignitability characteristic identifies solid waste that either present fire hazards under routine storage, disposal, and transportation, or are-capable of severely exacerbating a fire, once started. The characteristic of ignitability is described in 20 NMAC 4.1, Subpart II, 261.21. A waste is considered to exhibit the characteristic of ignitability if:

- It is a liquid, other than an aqueous solution, containing less than 24 percent alcohol by volume and has a flash point less than $60^{\circ} \mathrm{C}\left(140^{\circ} \mathrm{F}\right)$ 
Transuranic Waste Characterization, Sampling, and Analysis Plan Prepared for Los Alamos National Laboratory by RAE \& WASTREN, Inc.

- It is not a liquid and is capable under standard temperature and pressure of causing fire through friction, absorption of moisture, or spontaneous chemical changes and, when ignited, burns so vigorously and persistently that it creates a hazard

- It is an ignitable compressed gas as defined in 49 CFR 173.300

- It is an oxidizer as defined in 49 CFR 173.151

The characteristic of ignitability is determined analytically by measuring the - flashpoint using EPA Test Methods for Evaluating Solid Waste, Physical/Chemical Methods (EPA SW-846) Method 1010 "Pensky-Martens Closeup-Cup Method for Determining Ignitability" or Method 1020A, "Betaflash Closed-Cup Method for Determining Ignitability." Ignitable wastes are assigned the EPA Hazardous Waste Number D001.

Since the transuranic waste stored at TA-54, Area G should not include liquids or compressed gases, they will not exhibit the characteristic of ignitability, with the exception of some nitrate salts which may exhibit the characteristic of ignitability and require assignment of D001.

2. Corrosivity Characteristic

The corrosivity characteristic is defined in 20 NMAC 4.1, Subpart II, 261.22, and applies only to liquids. This characteristic applies to a waste that:

- Is aqueous and has a pH less than or equal to 2 , or greater than or equal to 12.5 , or

- Is a liquid and corrodes steel (SAE 1020) at a rate greater than 6.35 mm $\left(0.250\right.$ inch) per year at a test temperature of $55^{\circ} \mathrm{C}\left(130^{\circ} \mathrm{F}\right)$.

The property used to measure the corrosivity of a liquid is $\mathrm{pH}$. This measurement is performed using EPA SW-846 Method 9041. Corrosive wastes are assigned the EPA Hazardous Waste Number D002.

Since the transuranic waste stored at TA-54, Area G should not include liquids, they should not exhibit the characteristic of corrosivity.

3. Reactivity Characteristic

Reactive waste as defined in 20 NMAC 4.1, Subpart II, 261.23, includes waste that has any of the following properties: 
Transuranic Wasto Characterization, Sampling, and Analysis Plan Prepared for Los Alamos National Laboratory by RAE \& WASTREN, Inc.

- It is normally unstable and readily undergoes violent chemical change

$\therefore$ without detonatifing

- Reacts violently with or forms potentially explosive mixtures with water

- When mixed with water, generates toxic gases, vapors, or fumes in a quantity sufficient to present a danger to human health or the environment

- Is capable of detonation or explodes when subjected to a strong initiating force or if heated under confinement

- Is readily capable of detonation or explosive decomposition at standard temperature and pressure

- It is a forbidden explosive (40 CFR 173.51), a Class A explosive (49 CFR 173.53), or a Class B explosive (40 CFR 173.88). (Please note that HM-181 amendment to 49 CFR changed the U.S. Department of Transportation [DOT] hazard classes. The RCRA regulation has not yet incorporated the HM-181 changes. Therefore, the references in RCRA refer to 199049 CFR.)

- It is a cyanide- or sulfide-bearing waste which, when exposed to $\mathrm{pH}$ conditions between 2 and 12.5 , can generate toxic gases, vapors or fumes in a quantity sufficient to present a danger to human health or the environment.

Currently, the EPA relies on a descriptive definition of reactivity because the available tests for measuring the properties of reactivity suffer from a number of deficiencies. Analytical methods are only employed to evaluate wastes for total reactive cyanide and total reactive sulfide. The action'levels for these parameters are 250 parts per million (ppm) releasable cyanide and $\mathbf{5 0 0} \mathrm{ppm}$ releasable sulfide. Reactive wastes are assigned EPA Hazardous Waste Number D003.

It is possible that some of the transuranic waste stored at TA-54, Area G could be reactive. To exhibit the characteristic of reactivity, the waste would have to include one or more of the reactivity properties defined above or contain the indicated concentration of total reactive cyanide or sulfide.

\section{Toxicity Characteristic}

A solid waste which exhibits the characteristic of toxicity is a hazardous waste. The characteristic of toxicity is measured by analyzing an extract obtained from a representative sample of the waste using the Toxicity Characteristic Leaching Procedure (TCLP). If the waste leaches any of the contaminants listed in Table 1 
Transuranic Waste Characterization, Sampling, and Analysis Plan Prepared for Los Alamos National Laboratory by RAE \& WASTREN, Inc.

of 20 NMAC 4.1, Subpart II, 261.24, in a concentration greater than its respective regulatory level shown as in Table 1 , it is a hazardous waste. These contaminants fall into one of four categories-metals, pesticides, volatile organic compounds, or semivolatile organic compounds. The waste would be assigned a separate EPA Hazardous Waste Number (D004 through D043) for each toxic characteristic the waste exhibits.

The TCLP determines the mobility of a contaminant in the waste. The maximum concentration of a contaminant in a TCLP extract would be reached if the total amount of the contaminant leached out into the extract. Therefore, a totals analysis of the waste can demonstrate than an individual contaminant is not present in the waste or that it is present at such a low concentration that the appropriate regulatory level for TCLP could not possibly be exceeded, and the TCLP need not be run (20 NMAC 4.1, Subpart II, Appendix II). To account for the 20:1 dilution of the TCLP sample in the leaching solution, a multiplier of 0.05 can be applied to the total analyte concentration results to calculate the maximum possible leachate concentration from the TCLP extraction method. This conversion assumes that all of a given analyte would leach.

It is anticipated that for that portion of transuranic waste at TA-54, Area $G$ that uis $i_{3}$ : is hazardous, the most frequent characteristic exhibited will be that of toxicity. tes arTherefore, it will be important to consider contaminants related to toxicity for naxireach waste stream.

- For a particular waste stream, it may not be necessary to test for all of the toxicity contaminants. The information collected on individual waste streams should be used to limit the contaminants analytes. For example, residues from an operating process that did not use pesticides would not need to be tested for pesticides.

\subsubsection{Exclusions}

There are specific materials which meet the definition of a solid waste, but are not a bazardous waste due to the exclusions given in the regulations (20 NMAC 4.1, Subpart II, 261) and as shown on Figure 3.3. The exclusions that should be applicable to the transuranic waste stored at TA-54, Area G are:

- Samples of solid waste collected solely for the purpose of determining their characteristics or composition are excluded from regulation as hazardous waste, assuming they are managed as provided in 20 NMAC 4.1, Subpart II, 261.4(d).

- Residues of hazardous wastes in empty containers are excluded from regulation as a hazardous waste, provided the containers were rendered empty according to regulatory standards (20 NMAC 4.1, Subpart II, 261.7). 
Transuranic Waste Characterization, Sampling, and Analysis Plan

Prepared for Los Alamos National Laboratory by RAE \& WASTREN, Inc.

\subsubsection{Assignment of Environmental Protection Agency Hazardous Waste Numbers to Waste Streams}

EPA Hazardous Waste Numbers will be assigned to individual waste streams (blocks 9 and 19 of Figure 3.1 and on Figure 3.3). By the definition of a waste stream, all containers in a waste stream will be assigned the same EPA Hazardous Waste Numbers. If a waste stream has been determined to be a solid waste, as shown by the logic in Figure 3.2, it must then be evaluated for being a hazardous waste as shown in Figure 3.3. In this process, if the solid waste is not excluded from regulation it will first be evaluated to determine if it is a listed hazardous waste. This evaluation will be made based on the methodology explained in Section 3.4.1.2(A). For each such listed contaminant, the appropriate EPA Hazardous Waste Number will be assigned to the waste stream being evaluated.

The next step is the evaluation of the waste using the methodology of Section 3.4.1.2(B) to determine if it is a characteristic hazardous waste. If the waste is determined to have one or more of the characteristics of ignitability (D001), corrosivity (D002), or reactivity (D003), the EPA Hazardous Waste Number associated with each of the contained characteristics must be assigned to the waste stream.

Finally, the solid waste is evaluated using the methodology of Section 3.4.1.2(B)(4) to determine if it contains any of the contaminants in sufficient concentrations to cause it to exhibit the toxicity characteristic. The EPA Hazardous Waste Numbers (D004-D043) for each of the contaminants found in the waste stream that equals or exceeds its regulatory concentration limit must be assigned to the waste stream.

There is no limitation on the types (listed, characteristic, or both) and number of EPA Hazardous Waste Numbers that may be assigned to a waste stream.

\subsubsection{Confirmation of Resource Conservation and Recovery Act Characterization of Homogeneous Waste}

The initial RCRA characterization of each transuranic homogeneous waste stream will be confirmed using the analytical results from the statistical sampling and analysis of the containers in the waste stream (block 9 of Figure 3.1). If the analytical results of the sampling do not verify the initial RCRA characterization (block 11), the waste stream must be recharacterized based on the analytical results (block 23).

\subsection{REAL-TIME RADIOGRAPHY AND VISUAL INSPECTION}

RTR and visual inspection will be used to verify that gross errors have not occurred in assigning a Waste Matrix Code to individual waste containers and in identifying waste streams. Also, RTR will be able to detect materials which may be unique to a process. If specific outputs are expected to be in a container based on the generation process or waste management process, 
RTR and visual inspection should confirm the presence or absence of the process outputs. For example, if documentation suggests that the drums should contain combustibles, and metal scrap is observed, further investigation will be warranted.

\subsubsection{Real-Time Radiography}

RTR is a nondestructive, qualitative and semiquantitative assay technique that involves X-ray scanning of waste containers to identify and verify waste container contents. The waste categorization or Waste Matrix Code assignment of each transuranic waste container can be verified by RTR (blocks 7 and 15 of Figure 3.1). This technique is also part of confirming that WIPP WAC are met (DOE 1990). Further, RTR can be used to evaluate the quality of information that has been collected on a specific waste.

All transuranic waste containers will undergo analysis by RTR (blocks 6 and 14 of Figure 3.1).

\subsubsection{Visual Inspection}

A statistically significant number of transuranic waste containers will be randomly selected for visual inspection (blocks 10 and 18 on Figure 3.1). The number of containers will be determined using the guidance found in the Waste Isolation Pilot Plant's (WIPP) TRU Waste Characterization Quality Assurance Program Plan (QAPP)(DOE 1994b). This procedure is described in Section 3.5.2.1. The procedure for randomly selecting containers is described in Section 4.2.2. Selected containers will be opened and the contents visually examined to verify:

- The physical characteristics of the waste match the description of the waste in collected information and documentation

- The RTR evaluation of the container

- The accuracy of the Waste Matrix Code assignment

- No gross errors in the identification of waste streams

- Certain WIPP WAC are met such as no free liquids

Visual examination can provide information that will assist in the RCRA characterization of individual waste streams. It can verify the presence of certain hazardous constituents such as lead bricks or lead-lined gloves, but it will be unable to verify the presence of other hazardous constituents such as organic solvents. Although the presence of rags or laboratory wipes can be verified, solvent contamination cannot be verified.

These types of visual confirmations can further verify or refute the overall collection of information used to assign EPA Hazardous Waste Numbers to a waste stream. 
Transuranic Waste Characterization, Sampling, and Analysis Plan Prepared for Los Alamos National Laboratory by RAE \& WASTREN, Inc.

\subsubsection{Selection of Containers for Visual Examination}

The method for determining the number of containers for visual examination is based on a hypergeometric probability distribution quantifying the proportion of waste containers miscertified by the radiography process described in the WIPP QAPP (DOE 1994b). The exact number of containers to be examined in a given year is determined by finding the number of containers in each waste stream that corresponds to an expected miscertification rate. For the first year, the Laboratory will use a miscertification rate of 2 percent, which is based on experience with measuring miscertification at the Idaho National Engineering Laboratory (EG\&G Idaho 1994). In subsequent years, the Laboratory will use the miscertification rate observed at the Laboratory in the previous year to determine the appropriate number of samples.

Table 3.1 provides the number of waste containers that must be visually examined for several miscertification rates and waste container population sizes. Appendix B explains the statistical approach from the WIPP QAPP used to develop Table 3.1. For waste stream where the size is not in the table, the number of containers to be examined is determined by interpolating between the given values. For waste streams less than 22 drums, all drums are to be visually inspected, and for waste streams containing 22 to 50 drums, 22 drums are to be inspected. As stated in the WIPP QAPP, for waste streams of greater than 500 containers, a binomial distribution will be used to determine the number of containers to be visually inspected.

\section{Table 3.1 Number of Waste Containers Requiring Visual Examination}

\begin{tabular}{|c|c|c|c|c|c|c|}
\hline \multirow{3}{*}{ 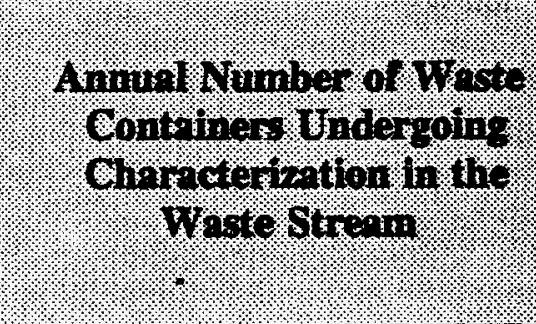 } & \multicolumn{6}{|c|}{ 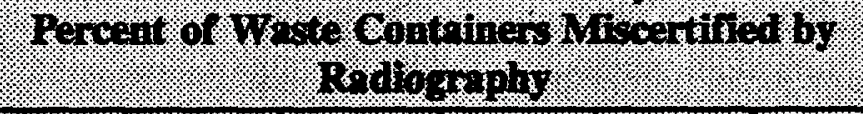 } \\
\hline & $17 \%$ & $28 \%$ & $3 \%$ & 198 & $5 \%$ & $6 \%$ \\
\hline & \multicolumn{6}{|c|}{ 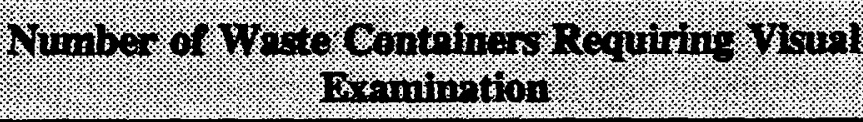 } \\
\hline 50 & $22^{\mathrm{a}}$ & 22 & $22^{\approx}$ & 22 & $29^{2}$ & 29 \\
\hline 100 & 15 & 24 & 24 & 33 & 33 & 41 \\
\hline 200 & 15 & 26 & 26 & 35 & 44 & 52 \\
\hline 300 & 15 & 26 & 26 & 35 & 44 & 53 \\
\hline 400 & 15 & 26 & 26 & 36 & 45 & 62 \\
\hline 500 & 16 & 26 & 26 & 36 & 45 & 63 \\
\hline
\end{tabular}

- Number of containers for the higher even-number percent of miscertified containers is used because an odd percent implies a fraction of a container is miscertified. 
Transuranic Waste Characterization, Sampling, and Analysis Plan Prepared for Los Alamos National Laboratory by RAE \& WASTREN, inc.

\subsection{SAMPLING AND ANALYSIS}

This section defines the regulatory, WIPP, and laboratory analytical requirements necessary to generate data that are scientifically valid, representative, and legally defensible for the transuranic waste stored at Pads 1, 2, and 4, Dome 48, and the FRP Dome at TA-54, Area G.

The primary objective of this section of the document is to direct the Laboratory's transuranic waste characterization activities with regard to RCRA-regulated constituents. In addition, the analytical requirements for WIPP are addressed. Waste streams will be assigned appropriate EPA Hazardous Waste Numbers based on the information collected. Random samples will be collected from homogeneous waste streams to verify initial RCRA characterizations. As much of the required analytical data for WIPP as possible will be collected at the same time, as discussed in Section 4.2.1.2.

Section 4.1 discusses the necessary quality assurance (QA) requirements to ensure that each sample is representative of the population it is being used to characterize. Section 4.2 discusses homogeneous waste sample collection. Section 4.3 outlines the use of the sample results. Section 4.4 describes the requirements for field operations. Section 4.5 defines the laboratory requirements for this plan. Requirements described in these sections will be addressed in either the RCRA Part B Permit Application for TA-54, Area G, Final Draft, WAP, a Quality Assurance Project Plan (QAPjP), or specific operating procedures which will be developed as necessary.

\subsection{QUALTY ASSURANCE}

To ensure that the data generated to characterize transuranic waste are scientifically valid, defensible, and representative of the subject waste, data used in this project must be collected within a quality assurance program documented in a QAPjP. Guidance from EPA SW-846 and the WIPP QAPP should be used to establish the requirements for a QAPjP. These documents were used to define the quality assurance objectives described in this section.

Quality assurance objectives for analytical results must ensure waste stream characterization data are of known and acceptable quality. These objectives are described in terms of precision, accuracy, completeness, comparability, and representativeness. Analytical results will be used to verify the characterization of homogeneous waste.

\subsubsection{Precision}

Precision is the agreement among a set of replicate measurements without assumption of knowledge of a true value. Precision for a set of measurements is estimated by calculating the mean of duplicate analyses. Analytical laboratory precision is measured by analyzing matrix duplicates or duplicate samples. The precision of laboratory duplicates will be assessed by calculating the relative standard deviation $(R S D)$ or the coefficient of variation $(C V)$ where 
Transuranic Waste Characterization, Sampling, and Analysis Plan Prepared for Los Alamos National Laboratory by RAE \& WASTREN, inc.

$$
\begin{aligned}
& \qquad R S D=C V=100\left(\frac{S}{x}\right) \\
& \text { Where, } \quad s=\text { standard deviation } \\
& x=\text { calculated mean of analytical results }
\end{aligned}
$$

or, if only two samples are available, the Relative Percent Difference (RPD) where

$$
R P D=\frac{\left|x_{1}-x_{2}\right|}{\left(x_{1}+x_{2}\right) / 2} \times 00
$$

where,

$$
\begin{aligned}
& x_{1}=\text { First Sample Valive (original) } \\
& x_{2}=\text { Second Sample Value (duplicate) }
\end{aligned}
$$

\subsubsection{Accuracy}

Accuracy is the degree of agreement between an observed sample result and the true valve. Because drums containing homogeneous solid process residues and soils with known quantities of analyte: are not available, sampling accuracy can not be determined (DOE 1994b). Accuracy will be maximized through use of a random sampling strategy such as that described in EPA SW-846 and Section 4.2.2

\subsubsection{Completeness}

Project completeness will be assessed annually by comparing the number of waste streams or number of samples collected to the number of samples determined to be useable by data validation. Factors that contribute to generation of unusable data include, but are not limited to:

- Holding times exceeded

- Matrix interferences that generate unusable results

-. Contaminated field and trip blanks

- Excessive deviation from equipment control criteria (indicating instrument malfunction or the instruments has exceeded calibration tolerances) 
Transuranic Waste Characterization, Sampling, and Analysis Plan Prepared for Los Alamos National Laboratory by RAE \& WASTREN, Inc.

\subsubsection{Comparability}

nats

Data are considered comparable when one set of data can be compared with thother set of data. All data will be reported in units consistent with the conventions used for the given analyte and analytical method employed. Results of analyses are comparable when the following project comparability objectives are met:

- Using standard EPA methodology

- Reporting results from similar matrices in consistent units

- Performing field and laboratory quality assurance procedures in accordance with the QAPjP

\subsubsection{Representativeness}

Representativeness expresses the degree to which sample data accurately and precisely represent characteristics of a population, parameter variations at a sampling location, or an environmental condition. Representativeness is a qualitative parameter and is best satisfied by ensuring that sampling is performed properly and that a sufficient number of samples are collected. Sampling locations and methods will be designed to produce results representative of the sampled waste stream. Requirements for the number of samples that must be collected are discussed in Section 4.2.3.

\subsubsection{Quality Control Samples}

Quality control (QC) samples will be collected and analyzed. These samples provide an internal quality control check and consist of field blanks, trip blanks, equipment blanks, and field duplicates.

\subsubsection{Project Documentation}

Project documentation requirements will be specified in the QAPjP. Project documentation will follow well-defined procedures and meet QAVC requirements necessary to meet the data quality objectives.

\subsubsection{Organization Performing Operations}

Organizations will be identified to perform the various sampling and analysis operations outlined in the program. Organizations will be responsible for specific elements of sampling and analysis associated with their assigned operations. Organizations and their responsibilities will be described in the QAPjP. The following responsibilities will be addressed:

- Performance evaluation 
Transuranic Waste Characterization, Sampling, and Analysis Plan Prepared for Los Alamos National Laboratory by RAE \& WASTREN, Inc.

- Internal assessment by QA function

- Assessment by auditors external to the organization

-. On-site evaluation of actual sampling operations

- QA reports

\subsection{SAMPLE COLLCTON FOR HOMOGENEOUS WASTE}

Solid process residues, (WMC 3000) and soils (WMC 4000) may contain RCRA-regulated metals, volatile organic compounds (VOCs), and semivolatile organic compounds (SVOCs). RCRA-characterization of homogeneous waste will depend on the average, or mean, concentration of each analyte and the associated variance of the concentration. The upper and lower 90-percent confidence limits of the mean concentration will be compared with regulatory threshold limits (RTL) to make characterization determinations. Sampling of WMC 3000 and 4000 wastes will allow the Laboratory to determine which wastes are regulated under RCRA and establish the concentration of the regulated constituents.

This section lists the analytical parameters and the analytical methods used to characterize the waste. Analytical requirements for disposal at WIPP are also included. Many of the requirements were drawn from the WIPP QAA (DOB 1994b). This section then provides an approach to collecting representative samples and statistical interpretation of the results.

\subsubsection{Analytical Paramoters}

Analyses will be performed on homogeneous waste streams to determine if they exhibit the characteristics identified in the initial RCRA characterization and to quantify the chemical concentration for all of the EPA Hazardous Waste Numbers assigned to the waste. In addition, transuranic waste characterization for disposal at WIPP requires an extensive set of analytes. Preliminary planning will include all of the WIPP-specific analytes. The WIPP programmatic requirements will be clarified to determine if an analyte on the WIPP-specific list that has not been identified as a contaminant in a specific waste stream needs to be analyzed for that waste stream.

\subsubsection{Resource Conservation and Recovery Act Analytes}

Table 4.1 is the list of analytes that will be used to determine if a waste.exhibits the toxicity characteristic. The RTL is the concentration at or above which the waste exhibits the toxicity characteristic. The table includes the Method Detection Limit (MDL). The laboratory performing the analysis must be able to detect the analytes at or below the MDL. The listed MDLs are estimates taken from the WIPP QAPP (DOE 1994b). The laboratory selected to perform the analyses may have different MDLs. The MDL will be specified when the analytical method has been tested on transuranic waste; however, it must be at least as low as the RTL unless deviation is preapproved. 
Transuranic Waste Characterization, Sampling, and Analysis Plan Propared for Los Alamos National Laboratory by RAE \& WASTREN, Inc.

\section{Table 4.1 Toxicity Characteristic Analytes}

\begin{tabular}{|c|c|c|c|c|}
\hline GPA Barardoos & Contorimingt & CAS Rumber & $(\mathrm{mTH})$ & 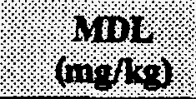 \\
\hline D003 & $\begin{array}{l}\text { Reactivity as releasable cyanides and } \\
\text { sulfides } \\
\text { Cyanides } \\
\text { Sulfides }\end{array}$ & $\begin{array}{l}\text { N/A } \\
\text { N/A }\end{array}$ & $\begin{array}{l}250 \mathrm{mg} / \mathrm{kg} \\
500 \mathrm{mg} / \mathrm{kg}\end{array}$ & $\begin{array}{l}\text { NS } \\
\text { NS }\end{array}$ \\
\hline D004 & Arsenic" & $7440-38-2$ & 5.0 & $0.1 \mathrm{mg} / 1$ \\
\hline D005 & Barium* & $7440-39-3$ & 100.0 & $2 \mathrm{mg} / 1$ \\
\hline D006 & Cadmium ${ }^{*}$ & $7440-43-9$ & 1.0 & $.02 \mathrm{mg} / \mathrm{l}$ \\
\hline D007 & Chromium* & $7440-47-3$ & 5.0 & $0.1 \mathrm{mg} / \mathrm{l}$ \\
\hline D008 & Lead" & $7439-92-1$ & 5.0 & $0.1 \mathrm{mg} / \mathrm{l}$ \\
\hline DOO9 & Mercury" & $7439-97-6$ & 0.2 & $0.0040 \mathrm{mg} / 1$ \\
\hline D010 & Selenium & $7782-49-2$ & 1.0 & $0.02 \mathrm{mg} /$ \\
\hline Do11 & Silver" & $7440-22-4$ & 5.0 & $0.1 \mathrm{mg} / \mathrm{l}$ \\
\hline D012 & Endrin & $72-20-8$ & 0.02 & NS \\
\hline D013 & Lindane & $58-89-9$ & 0.4 & NS \\
\hline D014 & Methoxychlor & $72-43-5$ & 10.0 & NS \\
\hline D015 & Toxaphene & $8001-35-2$ & $0.5^{\circ}$ & NS \\
\hline D016 & 2,4-D & 94-75-7 & 10.0 & NS \\
\hline D017 & 2,4,5-TP (Silvex) & 93-72-1 & 1.0 & Ns \\
\hline D018 & Benzene" & $71-43-2$ & 0.5 & 1 \\
\hline D019 & Carbon Tetrachloride" & $56-23-5$ & 0.5 & 1 \\
\hline D020 & Chlordane & $57-74-9$ & 0.03 & NS \\
\hline $\mathrm{D} 021$ & Chlorobenzene" & $108-90-7$ & 100.0 & 1 \\
\hline D022 & Chloroform" & $67-66-3$ & 6.0 & 1 \\
\hline DO23 & o-Cresol" & $95-48-7$ & 200.0 & 5 \\
\hline D024 & m-Cresol & $108-39-4$ & 200.0 & 5 \\
\hline D025 & p-Cresol" & $106-44-5$ & 200.0 & 5 \\
\hline D026 & Cresol" & N/A & 200.0 & 5 \\
\hline D027 & 1,4-Dichlorobenzene ${ }^{*}$ & $106-46-7$ & 7.5 & 1 \\
\hline D028 & 1,2-Dichloroethane ${ }^{*}$ & $107-06-2$ & $0.5 \cdot$ & 1 \\
\hline
\end{tabular}


Transuranic Wasto Characterization, Sampling, and Analysis Plan Prepared for Los Alamos National Leboratory by RAE \& WASTREN, Ine.

\begin{tabular}{|c|c|c|c|c|}
\hline $\begin{array}{l}\text { EPA Hirnidors } \\
\text { Waste Number. }\end{array}$ & 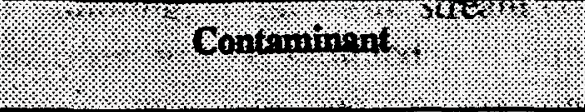 & Costrining & $(\mathrm{ng} / \mathrm{g}$ & $(\lim , 10)$ \\
\hline D029 & 1,1-Dichloroethylene & $75-35-4$ & 0.7 & 1 \\
\hline D030 & 2,4-Dinitrotoluene* & $121-14-2$ & 0.13 & 0.3 \\
\hline D031 & Heptachlor (and its epoxide) & $76-44-8$ & 0.008 & NS \\
\hline D032 & Hexachlorobenzene & $118-74-1$ & 0.13 & NS \\
\hline D033 & Hexachlorobutadiene & $87 \cdot 68-3$ & 0.5 & NS \\
\hline D034 & Hexachloroethane" & $67-72-i^{1}$ & 3.0 & 5 \\
\hline D035 & Methyl ethyl ketone" & $78-93-3 \times$ & 200.0 & 10. \\
\hline D036 & Nitrobenzene" & $98-95-3$ & 2.0 & 5 \\
\hline D037 & Pentachlorophenol & $87-86-5$ & 100.0 & NS \\
\hline D038 & Pyridine* & $110-86-1^{1}$ & 5.0 & $5 \cdots$ \\
\hline D039 & Tetrachloroethylene" & $127-18-4$ & 0.7 & 1 \\
\hline D040 & Trichloroethylene" & $79-01-6$ & 0.5 & 1 \\
\hline D041 & 2,4,5-Trichlorophenol & $95-95-4$ & 400.0 & NS \\
\hline D042 & 2,4,6-Trichlorophenol & $88-06-2$ & 2.0 & NS \\
\hline D043 & Vinyl chloride" & $75-01-4$ & 0.2 & 1 \\
\hline
\end{tabular}

Notes: - - $\quad$ Parameter is a WIPP required analyte.

- Estimnte, to be determined

Acronyms: CAS Chemical Abetract Service

EPA Environmental Protection Agency

MDL method detoction limit

$\mathrm{mg} / \mathrm{kg}$ milligrams per kilogram

mg/1 milligrams per liter

N/A not applicable

NS Not Specified, MDL will be provided with the sampling and analysis plan after the analytical laboratory has been selected.

RTL regulatory threshold limit 
Transuranic Waste Characterization, Sampling, and Analysis Plan Prepared for Los Alamos National Laboratory by RAE \& WASTREN, Inc.

\subsubsection{Waste Isolation Pilot Plan Required Analytes}

The WIPP QAPP (DOE 1994b) provides the analytical parameters which need to be addressed to meet WIPP disposal requirements (DOE 1990). To avoid unnecessary personnel exposure, analyses for these parameters should be performed at the same time as the RCRA characterization analyses. The WIPP QAPP provides separate lists for volatile organics, semivolatile organics, and metals. Tables $4.2,4.3$, and 4.4 below list those WIPP required analytes that are not listed in Table 4.1 as RCRA required analytes. It is expected that WIPP will require analysis for only those analytes that are suspected to be present in the waste stream.

\section{Table 4.2 Additional WIPP QAPP Required Volatile Organics}

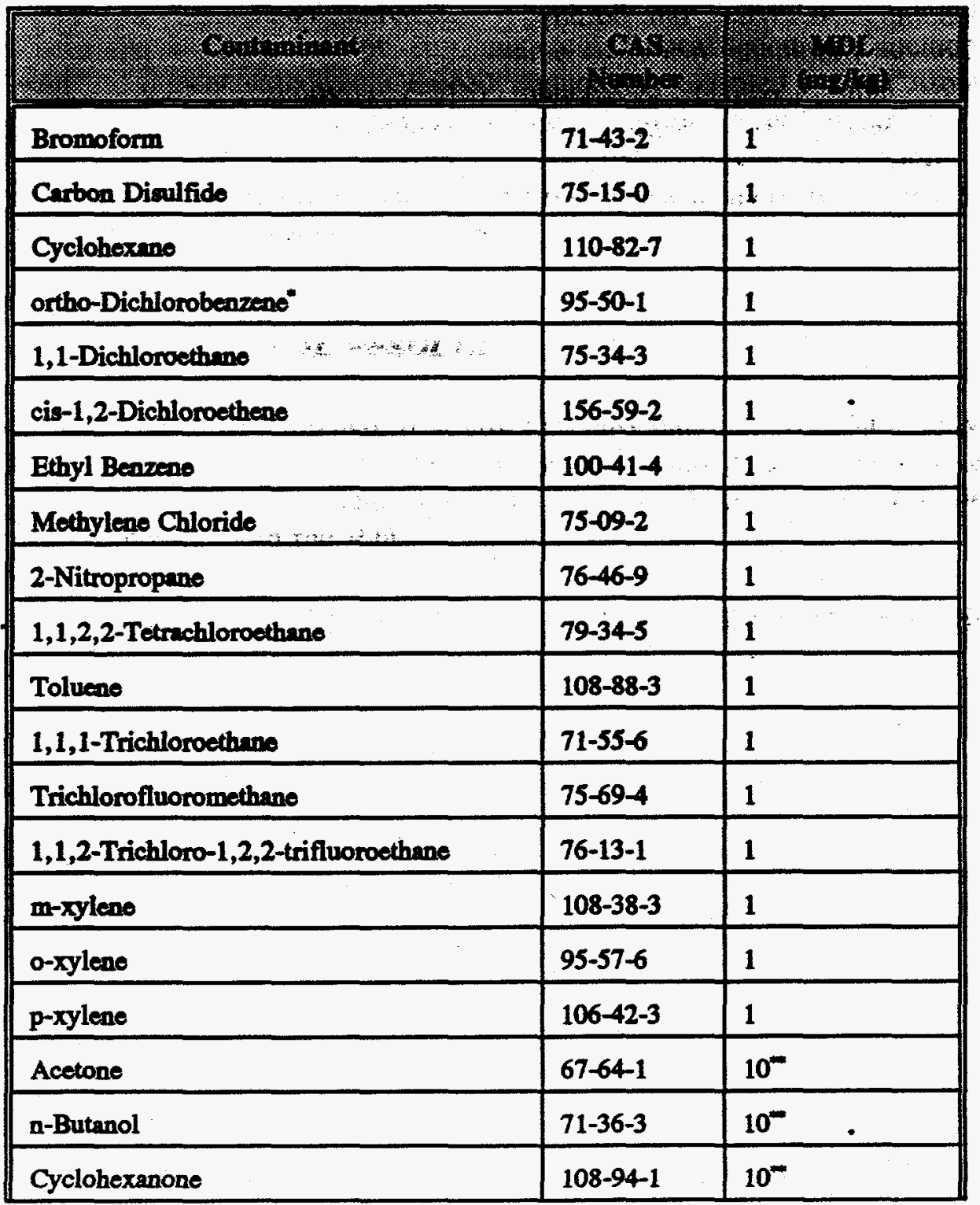


Transuranic Waste Characterization. Sampling, and Analysis Plan Propared for Los Alamos National Laboratory by RAE \& WASTREN, Inc.

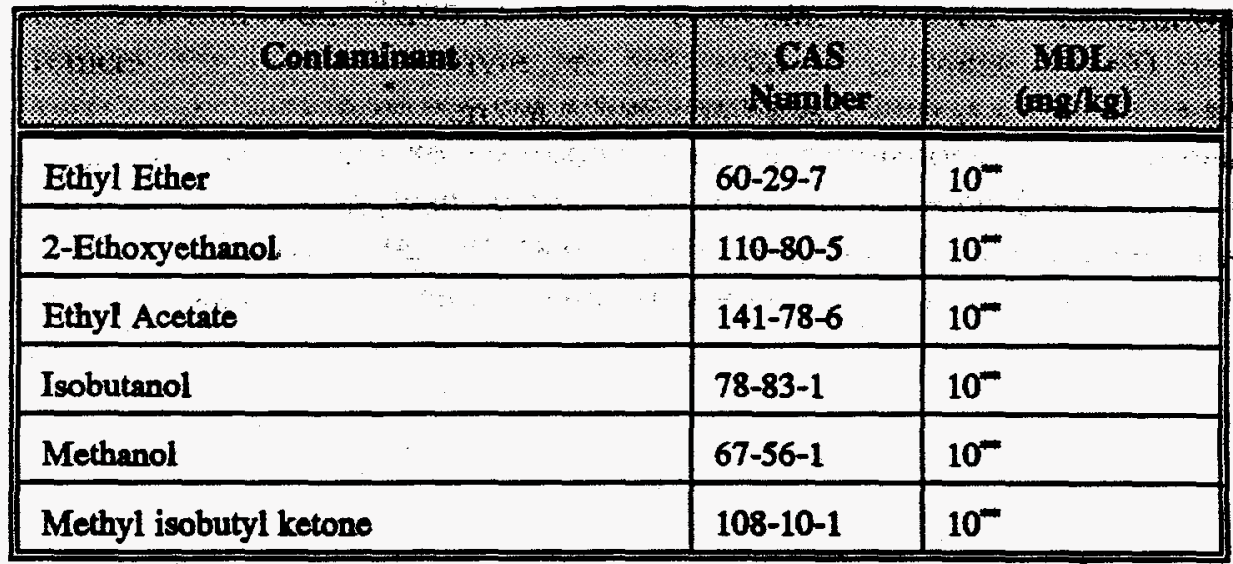

Notes: - Can also be analyzed as a semi-volatile organic compound Estimate, to be determined

Acronyms: CAS Chemical Abstract Service MDL method detection limit $\mathrm{mg} / \mathrm{kg}$ milligrams per kilogram

\section{Table 4.3 Additional WIPP OAPP Required SemiVolatilo Organics}

\begin{tabular}{|l|l|l|}
\hline \multicolumn{1}{|c|}{} & \multicolumn{1}{|c|}{} \\
\hline ortho-Dichlorobenzene" & $95-50-1$ & 5 \\
\hline Aroclor $1016^{-}$ & $12674-11-2$ & 5 \\
\hline Aroclor $1221^{-}$ & $11104-28-2$ & 5 \\
\hline Aroclor $1232^{-}$ & $11141-16-5$ & 5 \\
\hline Aroclor $1242^{-}$ & $53469-21-9$ & 5 \\
\hline Aroclor $1248^{-}$ & $12672-29-6$ & 5 \\
\hline Aroclor $1254^{-\infty}$ & $11097-69-1$ & 5 \\
\hline Aroclor $1260^{-}$ & $11096-82-5$ & 5 \\
\hline
\end{tabular}

Notes: - Can also be analyzed as a volatile organic compound

- PCBs; only required for Waste Matrix Code 3220 (organic sludges)

Acronyms: CAS Chemical Abstract Service

MDL methöd detection limit

$\mathrm{mg} / \mathrm{kg}$ milligrams per kilogram 
Transuranic Wasto Characterization, Sampling, and Analysis Plan Proparod for Los Alamos National Laboratory by RAE \& WASTREN, InC.

Table 4.4 Additional WIPP QAPP Required Motals

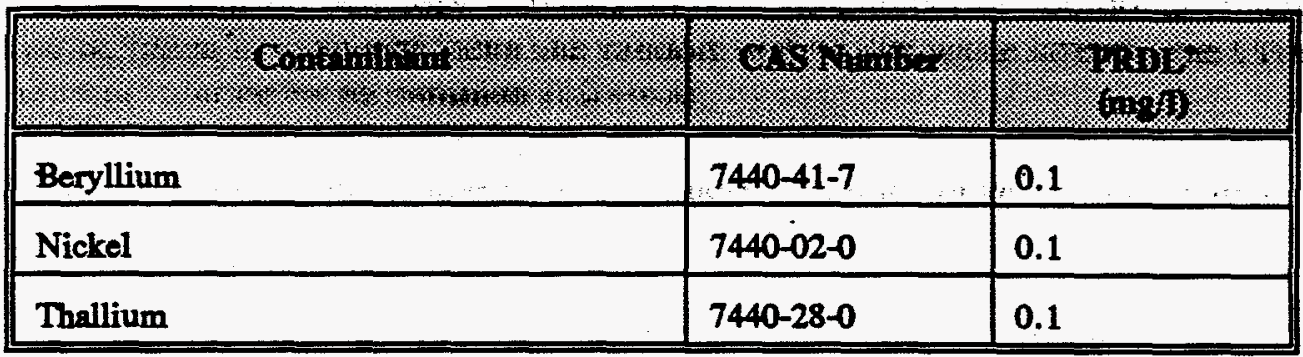

Notes: - Instrument detection limits must be less than or equal to the PRDL for the method used to quantitate a specific analyte.

Acronyms: CAS Chemical Abstract Service

mg/1 milligrams per liter:

PRDL Program Required Detection Limit

\subsubsection{Random Selection of Containers}

Random sampling will be performed to ensure that the results are representative of the waste stream whenever feasible. The identification numbers for all of the containers in a waste stream will be input into a commercially available random sort program. A random sort will then be used to sequentially select drums for sample collection and visual examination. Random sampling will provide an equal probability that each container in the waste stream could be selected for sampling. Samples will be collected from the individual drums using techniques such as collecting a core from the top to the bottom of the drum to provide representative samples within the drum. Experience shows that simple random selection of containers and random coring are not always feasible. Any deviation must be documented and the reason defined.

Sampling and visual examination will be coordinated to minimize radiation exposure to personnel. The visual examination will be performed during sampling operations until the necessary number of containers have been sampled. If additional containers must be visually examined, they will be selected in the order provided by the random sort.

\subsubsection{Number of Containers to be Sampled}

Sampling and analysis will be conducted in two phases as shown in Figure 4.1. The first round of sampling will provide initial analytical results used to determine the need for second round sampling. For the first round of sampling, the first 10 drums selected by the random sort will be sampled to provide initial analytical data for statistical interpretation. Additional samples will be taken if the analytical results do not provide mean constituent concentrations with sufficient confidence to make a hazardous waste determination. Section 4.3 .1 defines the number of additional samples necessary to make regulatory determinations. 
Transuranic Waste Characterization. Sampling, and Analysis Plan Prepared for Los Alamos National Laboratory by RAE \& WASTREN, InC.

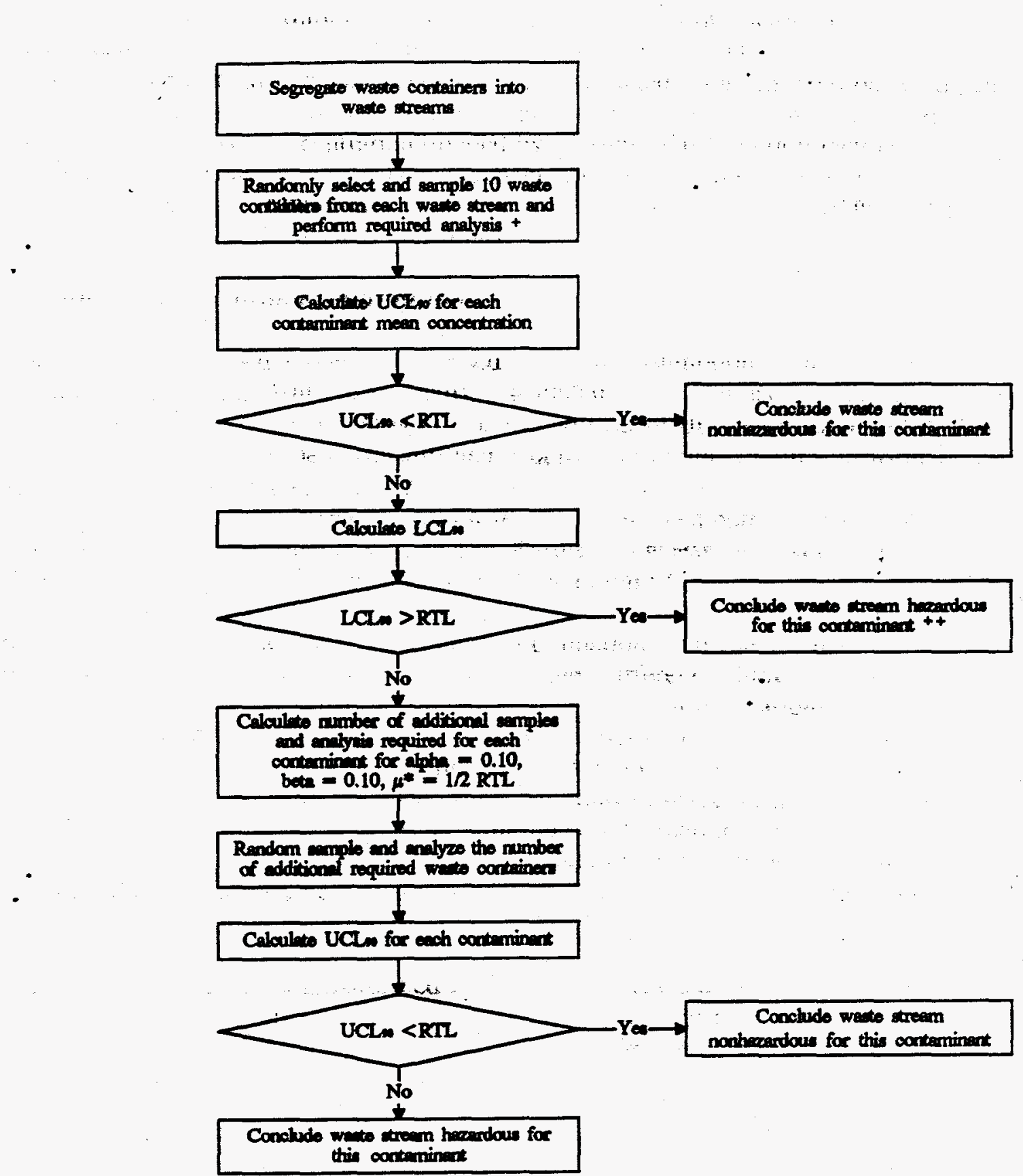

RTL = Regalvary Theobold Limit

UCLo = Upper 90-percert confidence limi: (ono-sided)

$L_{C L}=$ Lower 90 -percent confidence limit (ono-sided)

+ See text for number of semples to colloct for wate streame with fewer then 10 containers.

${ }^{++}$Confidence statement invalid if semplea total concentretion divided by a dihtion factor of 20 usd for comperison to RTL. Reanalyzo amples using the TCLP and repeet calculations.

Figure 4.1

Statistical Approach to Sampling and Analyzing of Waste Streams 
Transuranic Waste Characterization, Sampling, and Analysis Plan Prepared for Los Alamos National Laboratory by RAE \& WASTREN, Inc.

In the first round of sampling, if the waste stream consists of fewer than 10 and more than two containers, each container will be sampled. A minimum of three samples will be randomly collected from waste streams with one or two containers. Three samples is the minimum necessary to demonstrate with 90 percent confidence that a constituent is less than the RTL if all three of the results are below the detection limit. If the number of containers is less than 10 , a second round of sampling witt not be required.

\subsubsection{Sample Methods}

Sampling methods for WMC 3000 and 4000 wastes will be selected to ensure that all of the waste in a container has an equal probability of being collected in a sample. In a drum, this is achieved by obtaining a core which runs from the top to the bottom of the drum. The location of the core on the surface of the waste must be randomly identified by using a procedure which allows an equal probability that the core bit can be located anywhere in a concentric ring on the top of the container (using a pie grid and a randomly selected cell on the grid). Once a core is obtained, one or more randomly selected sections along the length of the core will be cut to collect the sample. The size of these sections are determined by the amount of material required for the various analyses by the laboratory. DOE 1s developing sampling methods for this type of waste (DOE 1994a). These methods will be used to collect representative samples from Laboratory waste.

If a container is not a solid monolith of material, such as a drum with several smaller containers inside, coring of the entire drum may not be possible. If the individual containers are not cemented in place, they will be numbered. A random selection will choose one of these individual containers for coring. This container will be cored similar to the full length core of a drum. If the single small container does not provide sufficient material for the sample, other containers will be selected in the order provided by the random sort to collect additional material from the drum.

\subsubsection{Analysis Methodology}

The hazardous constituents listed in 20 NMAC 4.1, Subpart II, 261.24, will be analyzed for total concentrations. Totals analysis can be used to determine if the analytes are present in hazardous concentrations. The totals digestion will liberate all of the hazardous constituents in a sample. Therefore, totals concentrations will be divided by the dilution factor of 20 to make the totals results comparable to regulated standards which are based on TCLP results. Totals analysis is also necessary for the transuranic waste characterization used in the WIPP performance assessment.

Preparation methods such as those found in EPA SW-846, TRU Waste Characterization Program Sampling And Analysis Method Manual (DOE 1994a), or other nationally recognized standard methods (such as ASTM) are acceptable (EPA SW-846). Reduction in sample aliquot size and final volume from those suggested in the published methods is allowable, provided the data quality objectives and the WIPP QAPP Quality Assurance Objectives can be met (DOE 1994b). 
Transuranic Waste Characterization, Sampling, and Analysis Plan Preparod for Los Alamos National Laboratory by RAE \& WASTREN, Inc.

At this time, the WIPP QAPP requires laboratories to use Gas Chromatography/Mass Spectrometry (GC/MS) for the analysis of volatile organic analytes; Gas Chromatography/Flame Ionization Detector (GC/FID) must be used for the determination of nonhalogenated voCs that perform poorly by purge and trap methods. Two GC/MS methods, EPA SW-846 Methods $8240 \mathrm{~A}$ and 8260 , meet program requirements. One GC/FW method which meets the requirements of the WIPP QAPP is provided in the TRU Waste Characterization Program Sampling and Analysis Method Manual (DOE 1994a). Semivolatile analytes will also be measured using GC/MS. EPA SW-846 Methods 8250 and 8270A will meet the requirements of this program. Gas Chromatography/Electron Capture Detection (GC/ECD) is available for the analysis of polychlorinated biphenyls (PCBs). Alternative methods will require approval of NMED or EPA, and DOE/CAO.

Total metals analysis may require multiple preparation methods and analytical techniques to complete the analysis of all metal analytes. Preparation and analytical techniques for metals analysis can be found in EPA SW-846. Acceptable analytical techniques include Inductively Coupled Plasma Mass Spectroscopy (ICP-MS), Inductively Coupled Plasma Atomic Emission Spectroscopy (ICP-AES), Graphite Furnace Atomic Absorption Spectroscopy (GFAA), Flame Atomic Absorption Spectroscopy (FLAA), Cold Vapor Atomic Absorption Spectroscopy (CVAA), and Hydride Generation Atomic Absorption Spectroscopy (HAA). FLAA should only be used as a backup to ICP-AES (DOE 1994b).

\subsection{USE OF ANALYTICAL RESULTS}

The analytical results will be validated to ensure that only data of sufficient quality are used to make regulatory decisions. Statistical interpretation of validated data will consist of calculation of the mean, the variance, the confidence intervals, and correction for dilution so the confidence intervals can be compared with the RTL.

The mean and the variance for the concentration of each contaminant are calculated as follows:

$$
\begin{gathered}
\bar{x}=\frac{1}{n} \sum_{i=1}^{n} x_{i} \\
s^{2}=\frac{1}{n-1} \sum_{i=1}^{n}\left(x_{i}-\bar{x}\right)^{2}
\end{gathered}
$$

$s^{2}=$ calculated variance

$x_{i}=$ analytical result for sample $i$

$\bar{x}=$ calculated mean of analytical results

$i=$ index from 1 to $n$

$n=$ number of samples 
Transuranic Waste Characterization, Sampling, and Analysis Plan Prepared for Los Alamos National Laboratory by RAE \& WASTREN, Inc.

For each waste stream and each analyte in that waste stream, estimated concentration means and associated variances for a given analyte are measured to calculate the 90 percent upper confidence limit ( $\left.\mathrm{UCL}_{90}\right)$ and the 90 percent lower confidence limit $\left(\mathrm{LCL}_{90}\right)$. The EPA uses an 80-percent confidence interval to make hazardous waste determinations. The confidence interval is described within which the true mean occurs if the sample is representative, which is expected of about 80 out of 100 samples (EPA SW-846). Therefore, there is a 10 percent chance that the mean may be either greater or less than the interval (the $\mathrm{UCL}_{90}$ and the $\mathrm{LCL}_{90}$ ). These limits are calculated using

$$
\begin{aligned}
& U C L_{90}=\bar{x}+\frac{t_{\alpha, n-1} s}{\sqrt{n}} \\
& L C L_{90}=\bar{x}-\frac{t_{\alpha, n-1} s}{\sqrt{n}}
\end{aligned}
$$

$$
t_{\alpha, n-1}=t \text {-distribution for } \alpha \text {-level significance and } n-1 \text { degrees of freedom. }
$$

The confidence limits calculated from the totals analysis results must be divided by the TCLP dilution factor of $\mathbf{2 0}$ so they are comparable with the RTL. If the UCL $\mathrm{US}_{30}$ for a constituent is less than the RTL, then the waste stream will be determined nonhazardous for that constituent. If the LCL $_{90}$ is greater than the RTL, the waste stream may be declared hazardous for that constituent. Because totals analysis results in an equal to or higher concentration than TCLP results, totals analysis may provide concentrations that demonstrate a waste is nonhazardous. If it appears that based on the totals analysis results, the TCLP would result in a hazardous determination, or if the Laboratory decides it is cost effective, the Laboratory may declare a particular waste hazardous and not perform the TCLP.

\subsubsection{Number of Additional Samples Necessary for Characterization}

If the number of containers is 10 or more and the RTL lies between the UCLL and the LCL, the number of additional samples, $n_{2}$, necessary to make an accurate characterization will be calculated by

$$
n_{2}=\frac{\left(Z_{1-\alpha}+Z_{1-\beta}\right)^{2} s^{2}}{\left(\mu^{*}-R T L\right)^{2}}
$$

$$
\begin{aligned}
& \mu^{*}=1 / 2 R T L \\
& \mathrm{Z}_{\mathrm{i}}=\text { standard normal distribution value for } i \text {-level significance } \\
& \alpha=\text { Type I error rate (determine the waste to be nonhazardous when it is }
\end{aligned}
$$


The specified value for $\mu^{*}$ helps ensure that the sample statistics used in the determination exhibit tolerance levels appropriate for controlling the Type II error rate in an accoptable manner. The value for $\mathrm{Z}_{\mathrm{i}}$ is found in introductory statistics texts. The number of additional containers to be sampled will be taken in sequence from the random sort of the waste stream (the 11th container through the total number to be sampled $\left.\left[10+n_{2}\right]\right)$.

For waste streams with small numbers of containers, an adjustment to the number of samples may be necessary. If the inequality

$$
\begin{gathered}
\qquad n_{2}\left(1+\frac{2}{n_{1}}\right)<n_{2}+n_{1} \\
n_{1}=\text { initial number of containers sampled, } 10, \\
n_{2}=\text { number of additional containers to be sampled }
\end{gathered}
$$

is satisfied, then the number of additional containers to be sampled, $n_{2}$, must be adjusted. The adjusted additional number of containers to be sampled, $m_{2 a}$, is determined by

$$
n_{2 \text { adf }}=n_{2}\left(1+\frac{2}{n_{1}}\right)-n_{1}
$$

If the total number of containers to be sampled $\left(n_{1}+n_{2}\right.$ or $n_{1}+n_{2 a d}$, as appropriate) exceeds the number of containers in the waste stream, the number of containers sampled equals the number of containers. At this point, the additional samples must be obtained and analysis must be performed.

\subsubsection{Additional Analytical Reisults}

If a second round of sampling and analysis is performed, the final mean and UCL concentrations must be determined using all available analytical data. These results will be used to perform a statistical test with 90-percent confidence for whether a sampling population contains contaminants at concentrations less than their respective RTL. The null hypothesis for the statistical test for each contaminant is that the mean contaminant concentration in the sampling population is equal to (or greater than) the RTL. The alternative hypothesis is that the mean concentration is less than the RTL. The hypothesis test will be performed with a nominal Type I error rate (commonly called a false positive) of 10 percent. This means that the contaminant will be considered present at hazardous levels unless it can be shown with 90 percent confidence that the mean is less than the RTL. The nominal Type II error rate (commonly called a false negative) will be set at 10 percent for the case in which the true mean value is one-half the RTL limit for the additional sample size calculation. Thus, the probability of falsely concluding the contaminant is present at hazardous levels, when in fact the mean concentration is one-half the RTL, will be 10 percent. 
Transuranic Wasto Characterization, Sampling, and Analysis Plan Prepared for Los Alamos National Laboratory by RAE \& WASTREN, Inc.

For cases in which total concentration divided by the TCLP dilution factor of 20 is used to determine the mean and the UCL $\mathrm{UC}_{90}$, and the UCL $\mathrm{U}_{90}$ is less than the RTL (that is, the waste is determined to be nonhazardous), the confidence level for associated decisions exceeds 90 percent because TCLP results can be expected to be equal to or lower than the corrected total concentration. If total analyte concentration divided by 20 (the TCLP dilution factor) indicates the waste stream is hazardous, a confidence statement for the decision is invalid. In such a situation, samples may be reanalyzed using the TCLP and the calculations repeated. Alternatively, the waste may be declared hazardous.

\subsubsection{Verification of Normal Distribution}

The statistical tests described above are based on the assumption that the measured concentrations of each contaminant are normally distributed. The validity of this assumption must be verified. Since the number samples available will be small, verification will best be achieved by comparing the fit of the untransformed data to the fit after certain transformations. Appropriate transformation families are $\ln (x+c)$, and $-\exp (-a x)$, where $x$ is the raw data and $c$ and $a$ are positive constants chosen to maximize fit among members of the same family (DOE 1994b). These transformations reduce negative skewness in data and, because environmental data are commonly skewed, will be applied here.

The Shapiro-Wilk test statistic or a suitable approximation will be used to assess fit (Madansky 1988). For the family $\ln (x+c)$, for example, different values of $c$ will be tried, calculating the Shapiro-Wilk test statistic for the data after each transformation. (Note, values of $c$ must be large enough to ensure that $x+c$ is always greater than zero.) The final value for $c, c_{m}$, that has the largest Shapiro-Wilk statistic will be chosen. Similarly, the value $a_{m}$ that maximizes the Shapiro-Wilk statistic calculated for the untransformed data will be compared to that for $\ln \left(x+c_{m}\right)$ and $-\exp \left(-a_{m} x\right)$. The data set with the largest Shapiro-Wilk test statistic will be used for the comparison to the RTL. Compare the Shapiro-Wilk statistic calculated for the untransformed data to that for $\ln \left(x+c_{m}\right)$ and $-\exp (-a, x)$. If the value for the untransformed data is the largest, no transformation is required.

If a transformation is required, the transformed RTL will be calculated so that the statistical test is performed using mathematically comparable values. The transformed RTL will be calculated by either $\ln \left(R T L+c_{m}\right)$ or $-\exp \left(-a_{m} R T L\right)$. The tests will be performed the same as before using the equation for the UCL ${ }_{90}$ and $\mathrm{LCL}_{90}$, substituting the transformed data and the RTL in the equations. .

If possible, actual numeric values for each measurement, whether they are below the detection limit, will be obtained. These values will allow calculation of unbiased values of mean concentrations and associated variances, to be used in the above equations. If chemical concentrations are reported as simply less than detectable (LTD), suitable substitutions should be made for the data and calculations altered appropriately. The simplest suitable method would be to substitute one-half the method detection limit for the measurement and then carry out the remaining calculations as indicated, except use $t_{\alpha, n=1}$, where $n^{*}$ is the number of non-LTD measurements in the data set. More precise (but more difficult to calculate) results may be obtained using the methods described by Gilliom and Helsel (Gilliom and Helsel 1986) and Atwood and others (Atwood, Blackwood, Harris, and Loehr 1991). 
All error levels and confidence levels given by these methods will be nominal values; actual values will be somewhat different because of the effects of the two-phase testing procedures and the methods used for dealing with transformations and LTDs.

\subsection{FIELD OPERATHONS}

This section describes field operations associated with sampling and analysis. Field operations will follow specified procedures and all activities will be documented to ensure that wastes are accurately characterized as defined in the QAPjP. The following sections briefly describe the material that will be covered in the QAPJP.

\subsubsection{Field Logistics}

Guidance to the sampling team will be provided by Sampling and Analysis Plans (SAPs) written according to guidelines set forth in the QAPjP. Sampling requirements assoclated with specific waste streams will be included in the SAPs. Requirements include the number of samples, containers selected for sampling, sampling location, and sampling procedures applioable to the waste.

\subsubsection{Equipment and Instrumentation}

Solid process residues (WMC 3000) and soils (WMC 4000) will be core sampled. Equipment requirements depend on the type of matrix being sampled. A rotational cutting tool will be used for sampling hard materials. Relatively soft materials will be sampled using a nonrotational coring tool such as a thin-walled sampler. Coring tools and other sampling equipment, instrumentation, and supplies will be described in more detail in the QAPJP.

\subsubsection{Operating Procedures}

The QAPjP will include various operating procedures that will be followed for transuranic waste sampling, such as:

\section{Sample Management}

- Sample management procedures outline numbering systems used for labels and tags, sample container types, chain-of-custody, holding times, sample volumes, and sample preservation. Samples will be tracked from collection to receipt by the analytical laboratory. 
Reagent and Standard Preparation

- Reagent and standard preparation procedures describe the preparation, use, labeling and recordkeeping of reagents and standards. The procedures specify the types of reagents and standards used in the field. Requirements for reagent purity and standard values are also provided.

Decontamination of Sampling Equipment

- Decontamination procedures specify requirements for cleaning the coring tools and other equipment before and during the sample collection process. Disposable sampling equipment may be used.

\section{Sample Collection}

- Sampling collection procedures will be based on methods provided by SW-846 (EPA SW-846), the IRU Waste Characterization Program Sampling and Analysis Methods Manual (DOE 1994a), Standard Practice for Thin-Walled Tube Sampling of Soils (ASTM 1983), and Standard Practice for Sampling Waste and Soils for Volatile Organic Compounds (ASTM 1991). Sample collection procedures will also address safety issues.

Field Measurements

- Field measurement procedures will specify the types of measurements that will be made in the field. The procedures will describe methods used in the field to determine a chemical or physical parameter.

Field Equipment Calibration and Maintenance

- Equipment calibration and maintenance procedures will describe the daily activities that will be performed to ensure the proper operation of sampling equipment and instrumentation. Maintenance logbooks and other documentation

- will also be described.

\section{Corrective Action}

- Corrective action procedures will specify the activities that will be performed to identify any errors, defects, failures, or deviations from specified requirements during sampling operations. These deficiencies will be reported, documented, and corrected. 
Transuranic Waste Characterization, Sampling, and Analysis Plan Prepared for Los Alamos National Laboratory by RAE \& WASTREN, Inc.

Data Reduction and Validation of Field Measurements

- Data reduction and validation procedures will explain computation of results from field measurements. Data review and validation will also be described.

Reporting Field Measurements

- Reporting procedures outline the documentation of field sampling activities. Requirements will be specified for the content and use of field worksheets, field logbooks, and maintenance logbooks.

Records Management

- Records management procedures describe the maintenance of field sampling records generated by sampling personnel. The procedures will address generating, controlling, and archiving of project-specific records and field operations records.

\section{Waste Disposal}

- Waste disposal procedures control the disposal of waste samples and other waste - materials resulting from field operations. Samples will be discarded after the individual analysis is complete and results are approved by a specified chemist. The sample will be retumed to the container of origin or discarded as laboratory waste.

\subsubsection{Field Quality Assurance and Quality Control Requirements}

QA/QC will be maintained for field sampling activities, including establishing control samples, defining acceptance criteria, handling data, and providing methods for dealing with deviations and corrective actions. QA provisions include daily calibration of field instruments, routine maintenance of equipment, QC samples, chain-of-custody, and logbook notes.

\section{Control Samples}

- Control samples ensure the quality of field samples. Control samples include field blanks, trip blanks, equipment blanks, field duplicates, and characterization verification samples.

Acceptance Criteria

- Acceptance criteria for sampling activities will be established by qualified data validation personnel in an independent organization. Validation criteria will assess field events and data to assure they meet the requirements and specifications of this program. Acceptance criteria will be established for sampling parameters such as sample size, preservation, container type, and sample extraction methodology for each matrix and analysis. 
Deviations

- Any deviations from sampling procedures will be documented by sampling personnel. Significant deviations from sampling protocol must be approved. Minor deviations from routine sampling protocols may not require approval prior to sampling. Documentation will describe the reason for and extent of the deviation. Deviations will be reviewed during data validation.

Corrective Actions

- Errors, deficiencies, deviations, field events, or data that fall outside established acceptance criteria require reporting and resolution.

Data Handling

- Field sample data are handled by the sampling personnel and the laboratory receiving the sample. Field data are controlled through the document control system described in Section 4.4.3. Field measurement data should be reduced according to procedures referenced in the QAPjP.

\subsubsection{Quality Assurance Reviow}

Assessment of sampling operations will consist of internal self-appraisals, in addition to formal audits. Appraisal and audit findings will be documented and distributed for review and corrective action, if necessary. Assessments should ensure that the QA and QC procedures are in use and that field staff conform to these procedures. Assessments will be described in the QAPjP.

\subsection{LABORATORY OPERATIONS}

Laboratory operations for this program may be performed by a number of facilities, including laboratories that are outside the direct control of the Transuranic Characterization Program. All laboratories should conduct their operations in such a way as to provide reliable information. Accordingly, this section defines the minimum facility requirements for laboratories selected to participate in this sampling and analysis effort. The requirements are drawn from EPA SW-846, Chapter 1 (EPA SW-846), and from the WIPP QAPP (DOB 1994b).

\subsubsection{Facilities}

This section addresses facility-related issues that may impact project data quality. Each laboratory should be of suitable size and construction to facilitate the proper conduct of the analyses. Radioactivity limits and resulting design requirements, if any, together with resulting sample capacity limitations should be specified. Other issues to be considered include: 
- Laboratories should be designed so that there is adequate separation of functions to ensure that no laboratory activity has an adverse affect on the analyses.

- There should be adequate facilities for receipt and storage of samples.

- Storage areas for reagents, solvents, standards, and reférence materials should be adequate to preserve their identity, concentration, purity, and stability.

- Adequate facilities should be provided for the collection and storage of all wastes.

- Equipment and instrumentation should meet the requirements and specifications of specific test methods and other procedures. The laboratory should maintain an equipment and instrument description list that includes the manufacturer, model number, year of purchase, accessories, and any modifications, updates, or upgrades that have been made.

- Standard Operating Procedures (SOPs) should be written for routinely performed activities such as sample management, reagent and standard preparation, general laboratory techniques, test methods, equipment calibration and maintenance, quality control requirements, corrective actions, data reduction, reporting, and laboratory records management.

- Waste disposal procedures.

\subsubsection{Laboratory Quality Assurance and Quality Conitrol Requirements}

The following required elements of the laboratory QC program are to be implemented.

\section{Method Proficiency}

- Procedures should be in place for demonstrating proficiency with each analytical method routinely used in the laboratory. These should include procedures for demonstrating the precision and bias of the method as performed by the laboratory and procedures for determining the method detection limit (MDL).

Control Limits

- Procedures should be in place for establishing and updating control limits for analysis. Control limits should be established to evaluate laboratory precision and bias based on the analysis of control samples. 
Laboratory Control Procedures

- Procedures should be in place for demonstrating that the laboratory is in control during each data collection activity. Analytical data generated with laboratory control samples that fall within prescribed contral limits are judged to be generated while the laboratory was in control Laboratory control procedures will address

- Laboratory Control Samples

- Method blank

- $\quad$ Matrix spikes

- $\quad$ Matrix-specific bias

- Matrix-specific precision

- Matrix-specific detection limit

Deviations

- Any activity not performed in accordance with laboratory procedures or project plans is considered a deviation. All deviations from plan or reference methods should be documented as to the extent of, and reasonfor, the deviation.

\section{Corrective Action}

- Errors, deficiencies, deviations, or laboratory events or data that fall outside established acceptance criteria should be investigated. The investigation of the problem and any subsequent corrective action taken should be documented.

Data Handling

- Data resulting from the analyses of samples should be reduced according to protocols described in the laboratory procedures. All data should be reviewed by a second analyst or supervisor according to laboratory procedures to ensure that calculations are correct and to detect transcription errors. Spot checks should be performed on computer calculations to confirm program validity. It is recommended that the supporting documentation include at the minimum:

- Laboratory name and address 
- Sample information including unique sample identification, sample collection date and time, date of sample receipt, and dates of sample preparation and analysis

- Analytical results reported with an appropriate number of significant figures

- Detection limits that reflect dilutions, interferences, or correction for equivalent dry weight

- Method reference

- Appropriate QC results with documented traceability to the sample batch

- Data qualifiers with appropriate references and narrative on the quality of the results

\subsubsection{Laboratory Quality Assurance Reviow}

The QA review consists of internal and external assessments to ensure that QAVC procedures are in use and to ensure that laboratory staff conform to these procedures. QA review should be conducted as deemed appropriate and necessary.

\subsubsection{Laboratory Records}

Records provide the direct evidence and support for the necessary technical interpretations, judgements, and discussions concerning project activities. These records, particularly those that are anticipated to be used as evidentiary data, should directly support technical studies and activities, and provide the historical evidence needed for later reviews and analyses. The discussion in this section outlines recommended procedures for recordkeeping.

Laboratory records generally consist of bound notebooks with prenumbered pages, personnel qualification and training forms, equipment and maintenance and calibration forms, chain-ofcustody forms, sample analysis request forms, and analytical change request forms. Records of sample management should be available to permit the re-creation of an analytical event for review in the case of an audit or investigation of a dubious result. Laboratory records should include at least the following:

- Operating Procedures

- QA Plans

- Equipment Maintenance Documentation

- Personnel Qualification and Training Records 
- Proficiency

- Calibration Records and Traceability of Standards and Reagents

- Sample Management

- Original and QC Data

- Correspondence

- Deviations

- Final Report

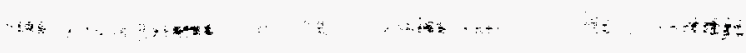




\subsection{DATA QUALTY OBJECTIVES}

The primary objective of this document is to provide a methodology for characterizing the transuranic waste stored at Pads 1, 2, and 4, Dome 48, and the FRP Dome at TA-54. This will entail the identification and characterization of the discrete waste streams to ensure appropriate waste management and future disposal. To achieve this goal the following questions must be answered for each container:

- Is the waste in this container transuranic?

- What Waste Matrix Code should be assigned to this container?

- Which containers are physically and chemically similar and can be grouped together as a waste stream?

- Does the waste meet the definition of a hazardouis waste as defined by 20 NMAC 4.1, Subpart II, 261. If so, what EPA Hazardous Waste Numbers apply?

These questions represent the primary decision elements for this program and will be answered using existing historical documentation, information gained from interviews, RTR review, visual inspection, and analytical data.

Data quality can only be measured as a function of the frequency that the correct determination is made for a given decision element. Higher quality decision data will decrease the frequency of incorrect determinations. The cost of increasing data quality should be weighed against the consequences of incorrect decisions. For example, if the consequence of error is minimal and the cost of obtaining additional data is high, it may be justifiable to accept the consequences of a higher agreed-to level of error.

The acceptable level of error must be estimated, approved where appropriate by the regulatory decision makers, monitored periodically, and adjusted as appropriate. Preliminary data quality objectives (DQOs) are usually estimates based on reasonable goals that meet the expectations of the decision makers. Review and approval of the objectives should weigh the consequences of error against the cost of data quality. It is crucial at this point for the appropriate decision makers to consider:

- The decision to be made

- The data required to support the decision

- Consequences of incorrect determinations

- Cost of additional data collection 
- Unnecessary radiation exposure

- Method proposed to monitor program performance

The DQOs must be reviewed periodically and compared to actual program performance. It may be necessary to adjust the objectives over the course of the program. Any adjustments should be evaluated and approved in the same manner as the original objectives. The DQOs presented in this section are preliminary recommendations to be used as a starting point for the objective development and approval process. The objectives to be assessed by agreement with subsequent investigations (see Sections 5.2.3, 5.3.3, and 5.5.3) should be reviewed and adjusted based on industry precedence with input from the regulatory decision makers.

\subsection{TRANSURANIC WASTE VERIFICATION}

This decision element is applied to verify that the containers of waste meet the DOE definition of transuranic waste. This decision element is not part of this plan and this question will be answered'under a different program. However, for completeness, this DQO is included herein.

\subsubsection{Decision Rule}

DOE Order 5820.2A outlines the management requirements for transuranic waste (DOE 1988). The Order defines transuranic waste as "Without regard to source or form, waste that is contaminated with alpha-emitting transuranium radionuclides with half-lives greater than 20 years and concentrations greater than $100 \mathrm{nCi} / \mathrm{g}$ at the time of assay."

Waste with transuranic nuclide concentrations less than 100 nanocuries per $\mathrm{gram}(\mathrm{nCi} / \mathrm{g})$ are considered low-level and are outside of the scope of this plan.

\subsubsection{Decision Data}

Currently, the transuranic containers stored at Pads 1, 2, and 4, Dome 48; and the FRP Dome at TA-54 Area G have been classified by radioassay, radiochemistry, and mass balance to determine container gram content of transuranic radionuclides. Existing assay data are documented on a variety of forms and stored in the Transuranic Waste Management Database. The containers will be reassayed to augment and verify existing assay results.

\subsubsection{Decision Data Quality Objective}

The Quality Assurance Objectives for nondestructive assay defined in the WIPP QAPP must be met for this decision element. The WIPP QAPP summarizes DQOs for nondestructive assay determinations of transuranic containers (DOE 1994b). Table 5.1 outlines these requirements. 
Transuranic Waste Charactorization, Sampling, and Analysis Plan Preparod for Los Alamos National Laboratory by RAE \& WASTREN, Inc.

\section{Table 5.1 Quality Assurance Objectives for Nondestructive Assay}

\begin{tabular}{|c|c|c|c|c|c|}
\hline \multirow{2}{*}{ 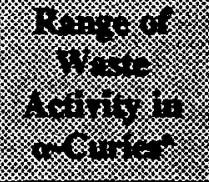 } & \multirow{2}{*}{$\frac{1}{4(2)}$} & \multicolumn{3}{|c|}{ ? } & \multirow{2}{*}{ 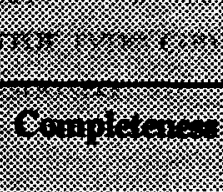 } \\
\hline & & 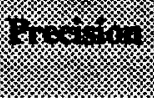 & 3. & $\frac{1}{3} x^{2}$ & \\
\hline 0 & 0 & 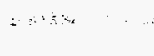 & $\cdots$ & & 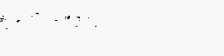 \\
\hline$>0$ to 0.04 & $\begin{array}{l}0.008 \\
(0.1)\end{array}$ & $\pm 40 \%$ & $\begin{array}{l}\geq 75 \% \text { and } \\
\leq 125 \%\end{array}$ & $\pm 100 \%$ & $100 \%$ \\
\hline$>0.04$ to 0.4 & $\begin{array}{l}0.08 \\
(1.0)\end{array}$ & $\pm 20 \%$ & $\begin{array}{c}250 \% \text { and } \\
\leq 150 \%\end{array}$ & $\pm 200 \%$ & $100 \%$ \\
\hline$>0.4$ to 4.0 & $\begin{array}{l}0.8 \\
(10)\end{array}$ & $\pm 10 \%$ & $\begin{array}{l}\geq 50 \% \text { and } \\
\leq 150 \%\end{array}$ & $\pm 200 \%$ & $100 \%$ \\
\hline$>4.0$ & $\begin{array}{r}12.8 \\
(160)\end{array}$ & $\pm 5 \%$ & $\begin{array}{c}275 \% \text { and } \\
\leq 125 \%\end{array}$ & $\pm 50 \%$ & $100 \%$ \\
\hline
\end{tabular}

Notes: - Applicable range of transurnnic activity in a 208-lifer (55-gallon) drum to which the Quality Assurance Objectives spply, unite are Curies of alpha-emitting transuranic isotopes with half-lives greater itien 20 years.

- The nominal activity (or weight of $\mathrm{Pu}$ ) in the 208-liter (55-gallon) drum used to demonstrate that Quality Assurance Objectives can be achieved for the corresponding range in column 1, values in parentheses are the approximate equivalent weights of weapons-grade plutonium (WG Pu), 15 years after purification; for purposes of demonstrating Quality Assurance Objectives, "nominal" means within $\pm 10 \%$

$\begin{array}{lll}\text { Acronyma: } & \text { g } & \text { grams } \\ \text { WG } & \text { Weapons grade } \\ & \text { Pu } & \text { Plutonium }\end{array}$

\subsubsection{Decision Error and Consequences}

Error for this decision could result from statistical counting errors, analytical interferences, and methodology and instrumentation limitations. These errors could result in the following:

- Low-level Waste Identified as Transuranic Waste: Additional costs may be incurred for waste management and disposal. Improper utilization of disposal capacity may result.

- Transuranic Waste Identified as Low-level Waste: Potential for elevated exposure to waste management personnel. The possibility exists that transportation, packaging, and disposal site WAC may be violated. This error could result in exposure to workers, the environment, and the public, in addition to being a performance assessment issue. 


\subsection{WASTE MATRX CODE ASSIGNMENT}

Assignment of Waste Matrix Codes is required by DOE in an effort to consistently categorize wastes generated at all DOE sites. The wastes addressed by this plan will be assigned the following Waste Matrix Codes:

- WMC 3000 - Solid Process Residues

- WMC 4000 - Soils

- WMC 5000 - Debris Waste

For the purposes of this document, WMCs 3000 and 4000 wastes are defined as homogeneous wastes and WMC 5000 wastes are defined as heterogeneous wastes. Homogeneous waste characterization will ultimately be verified by sampling and analysis activities. Heterogeneous waste will be characterized based on existing information, $R T R$, and visual inspection of a subset of containers. Containers of wastes other than WMCs 3000, 4000, and 5000 may be present but will be addressed on a case-by-case basisis. Section 3.3 outlines the approach to be used to assign Waste Matrix Codes.

\subsubsection{Decision Rule}

The requirements for assignment of Waste Matrix Codes are defined in the DOE Waste Treatability Groups Guidance (DOB 1993a).

\subsubsection{Decision Data}

This decision will be based on the information described in Section 3.1, including, but not limited to, documented process information, personnel interviews, existing databases, existing analytical data, and operating procedures. In addition, RTR will be performed on each container and visual inspection will be performed on a subset of containers to support existing information for Waste Matrix Code assignment activities.

\subsubsection{Decision Data Quality Objective}

Sampling and analysis will be performed for the homogeneous waste (WMCs 3000 and 4000). Visual inspection of the waste during sampling operations will be used to verify Waste Matrix Code assignment. Less than 10 percent disagreement between the initial assignment and subsequent verification should be observed.

Visual inspection will be conducted for a subset of heterogeneous waste containers (WMC 5000). Visual inspection of the waste should verify less than 10 percent disagreement with the initial Waste Matrix Code assignment. 
Transuranic Waste Characterization. Sampling, and Analysis Plan Prepered for Los Alamos National Laboratory by RAE \& WASTREN, InC.

\subsubsection{Decision Error and Consequences}

Error for this decision could result from limited or inconsistent waste information and RTR methodology limitations for some waste matrices. These errors could result in the following:

- WMC 3000 assigned WMC 4000 or WMC 4000 assigned WMC 3000: The consequence of this misassignment is minimal, because both of these Waste Matrix Codes will be sampled during characterization activities resulting in correct Waste Matrix Code reassignment. This misassignment error may result in an increase in the number sampling iterations dute to containers being removed or added to the waste streams, resulting in higher sampling and analysis costs and personnel exposure.

- WMC 5000 assigned WMC 3000 or WMC 4000: The consequence of this misassignment is minimal, because WMCs 3000 and 4000 will be sampled during characterization activities that would likely result in the correct Waste Matrix Code reassignment. This misassignment error may result in an increase in the number sampling iterations due to containers being removed or added to the waste streams, resulting in higher sampling and analysis costs and personnel exposure. However, because the containers contents will be assessed by RTR, this misassignment will be unlikely.

- WMC 3000 or WMC 4000 assigned WMC 5000: The consequence of this

- misassignment is that a container of waste assigned WMC 3000 or 4000 would not be subject to sampling and analysis. However, because the containers contents will be assessed by RTR, this misassignment will be unlikely.

If Waste Matrix Code assignment "errors are not identified, containers could eventually be shipped in the wrong category, thereby violating the WIPP QAPP requirements.

\subsection{WASTE STREAM IDENTIFICATION}

DOE requires categorization of waste into discrete waste streams originating from a single process or activity with essentially the same physical and chemical properties.

\subsubsection{Decision Rule}

The requirements for assignment of waste streams is defined in the DOE Waste Treatability Groups Guidance (DOE 1993a). 
Transuranic Waste Characterization, Sampling, and Analysis Plan Prepared for Los Alamos National Laboratory by RAE \& WASTREN, Inc.

\subsubsection{Decision Data}

This decision will be based on the information described in Section 3.1, including, but not limited to, documented process information, personnel interviews, existing databases, existing analytical data, and operating procedures. In addition, RTR will be performed on each container to support existing information for waste stream identification activities.

\subsubsection{Decision Data Quality Objective}

Sampling and analysis will be performed for the homogeneous waste (WMCs 3000 and 4000). Visual inspection of the waste during sampling operations and analytical results will be used to verify waste stream assignment. Less than 10 percent disagreement between the initial assignment and subsequent verification should be observed.

Visual inspection will be conducted on a subset of heterogeneous waste containers (WMC 5000). Visual inspection of the waste should verify less than 10 percent disagreement with the waste stream assignment based on the physical makeup only.

\subsubsection{Decision Error and Consequences}

Error for this decision could result from limited or inconsistent waste information and RTR methodology limitations for some waste matrices. These errors could result in the improper definition of waste streams or containers assigned to the wrong waste stream. For the homogeneous waste, the consequence of this error is minimal because the waste will be sampled and errors in waste stream assignment will be identified. This error will result in an increase in the number sampling iterations due to containers being removed or addect to the waste streams resulting in higher sampling and analysis costs and personnel exposure. For heterogenous waste, this error may not be identified as often as for the homogeneous waste, because the heterogeneous waste will not be sampled.

The net result of improper waste stream assignment would be containers with incorrect RCRA characterization. The consequence of this error is described in Section 5.4.4.

\subsection{HAZARDOUS WASTE DETERMINATION FOR HOMOGENEOUS WASTE}

This decision element pertains to whether a waste stream identified by the decision element in Section 5.3 meets the definition of a hazardous waste, and if so, what BPA Hazardous Waste Numbers apply. This section applies to the characterization of the homogenous waste streams (WMCs 3000 and 4000) made using process information verified by analytical data. 
Transuranic Waste Characterization, Sampling, and Analysis Plan Prepared for Los Alamos National Laboratory by RAE \& WASTREN, Inc.

\subsubsection{Decision Rule}

Waste generators are required by the 20 NMAC 4.1, Subpart III, 262.11, to identify and characterize all waste streams. Waste generators are required first to determine if a waste stream meets the definition of a solid waste per 20 NMAC 4.1, Subpart II, 261.2. If the waste is determined to be a solid waste, a hazardous waste determination must be made and EPA Hazardous Waste Numbers assigned. It has been assumed that the containers to be assessed by this document meet the definition of solid waste. Any containers that can be excluded or are exempt from this definition will be addressed on a case-by-case basis. Section 3.4.1 describes the RCRA characterization process.

\subsubsection{Decision Data}

The hazardous waste decision for homogenous waste streams will be based on waste information and verified by analytical data. The initial hazardous waste determination will be based solely on the information described in Section 3.1, including, but not limited to, documented process information, personnel interviews, existing databases, existing analytical data, and operating procedures.

Analysis will verify or refute characteristic waste determinations, which include ignitability, corrosivity, reactivity, and toxicity. Listed hazardous waste determinations are not based on RTLs. These determinations are based on whether the waste was generated from a specified source, a nonspecific source, or is an acute or toxic compound. Analysis alone cannot be used to refute listed hazardous waste characterization. However, analytical data may be used as an indicator of when review of existing information should be performed for possible container reassignment or recharacterization when suspected compounds are not detected or unsuspected compounds are detected.

\subsubsection{Decision Data Quality Objoctive}

A statistical assessment of analytical data will be performed for each waste stream. A confidence interval test will be used to evaluate whether hazardous constituents exceed RTLs (for characteristic waste parameters only). For each chemical constituent of concern, the 90 percent upper confidence level must be less than the regulatory threshold limit.

Section 4.0 describes the sampling and laboratory requirements that must be achieved to ensure analytical data used for waste stream characterization are of acceptable quality.

\subsubsection{Decision Error and Consequences}

Characterization errors can be a result of insufficient or conflicting information, nonrepresentative sampling, analytical error, and other sampling and analysis methodology limitations. These errors could result in the following: 
Transuranic Waste Characterization, Sampling, and Analysis Plan Prepared for Los Alamos National Leboratory by RAE \& WASTREN, Inc.

- Failure to assign EPA Hazardous Waste Numbers to hazardous waste: This error could result in unanticipated exposure to workers, the environment, and the public. In addition, incompatible wastes could be stored improperly. This error could result in deficient waste management. For example, this error type could result in hazardous waste being managed, shipped, and disposed of as nonhazardous.

- Assignment of EPA Hazardous Waste Numbers to nonhazardous waste: Hazardous waste storage capacity would be improperly utilized.

- Failure to assign an EPA Hazardous Waste Number to hazardous wastes assigned multiple EPA Hazardous Waste Numbers: This error and the following error will be the most commonly made, as waste streams can be - assigned several EPA Hazardous Waste Numbers. This error would not affect the general hazardous waste management of the waste streams. However, this error could result in the improper storage of incompatible wastes.

- Assignment of extraneous EPA Hraxardous Waste Numbers to hazardous waste: This error involves conservative characterization by applying EPA Hazardous Waste Numbers which are not required. The risks of this error are minimal, because the hazardous waste would be managed conservatively. However, this characterization approach may limit treatment options or result in expensive, unnecessary treatment should treatment be required in the future.

\subsection{HAZARDOUS WASTE DETERMINATION FOR HETEROGENEOUS WASTE}

This decision element pertains to whether a waste stream identified by the decision element in Section 5.3 meets the definition of a hazardous waste, and if so, what EPA Hazardous Waste Numbers apply. This section applies to the characterization of the heterogeneous waste streams (WMC 5000) made using waste information.

\subsubsection{Decision Rule}

The decision rule for this determination is the same as the homogeneous waste described in Section 5.4.1.

\subsubsection{Decision Data}

The hazardous waste decision for heterogeneous waste streams will be based solely on the information described in Section 3.1, including, but not limited to, documented process information, personnel interviews, existing databases, existing analytical data, and operating procedures. RTR and visual inspection will also be used to assess physical makeup of the waste streams. 


\subsubsection{Decision Data Quality Objective}

Because the visual inspection of heterogeneous wastes will be performed after characterization activities, it is critical to coordinate this effort to assess the waste stream physical properties and to verify the container contents. The contents of the container must be consistent with the waste stream determination information. For example, if the observed waste consists of plastics covered with oil, and the waste stream originated from an area where oil was not used, further investigation and recharacterization may be required. Visual inspection of the waste should verify less than 10 percent disagreement with the waste stream assignment based on the physical makeup only.

\subsubsection{Decision Error and Consequences}

The decision error and consequences would be the same as those described in section 5.4.4 except for the increase in sample personnel exposure. However, additional visual inspections may be required, resulting in an increase in exposure to those individuals. Because sampling and analysis will not be used to verify the assignment of EPA Hazardous Waste Numbers, heterogeneous waste will be managed conservatively. Containers will be managed as hazardous waste whenever there is reason to believe that they contain hazardous constituents, even if this methodology determines that they are not hazardous wastes.

\subsection{CONSTRANTS}

This section discusses the constraints on the project where the DQOs must be applied.

\subsubsection{Time}

Work needs to be performed as quickly as possible to ensure regulatory compliance and to meet the deadlines of the regulatory drivers.

\subsubsection{Budget and Resource}

Budget constraints are a major consideration for a program requiring the assessment of thousands of containers. Primary concerns are limits of on-site sampling capacity and analytical constraints due to limited laboratory space, instrumentation, and personnel. In addition, the cost of investigations and data management must be considered.

\subsubsection{Safety}

The safety of the personnel supporting the program must be considered. Exposure to radioactive and hazardous compounds is a primary concern and the following must be considered:

- As-Low-As Reasonably Achievable (ALARA) Program 
Transuranic Wasto Charactorization, Sampling, and Analysis Plan Prepared for Los Alamos National Laborotory by RAE \& WASTREN, Inc.

- Occupational Safety and Health Administration (OSHA) regulations

- DOE Order 5480.11 "Radiation Protection for Occupational.Works" and the Los Alamos National Laboratory Radiological Controls Manual.

- DOE Orders

\subsubsection{Transportation of Samples to Laboratories}

Both the DOT and DOE regulations present constraints. Additionally, state and local regulations may present constraints that must be investigated prior to selection of off-site laboratories, if necessary.

\subsubsection{Analytical Laboratories}

The following specific issues act as constraints on laboratories:

- Availability of laboratories

- Sample capacity of laboratories

- Radioactivity and radiation limits of laboratories

- Disposal of waste samples and contact wastes

\subsubsection{Analytical Methods}

Due to the.diversity and complexity of waste matrices, technology may not be available for analysis of all the waste streams. Also, technology for sampling and analyzing radioactive samples is limited at present. These constraints may restrict the number of samples that can be collected and analyzed.

\subsection{QUANTITATIVE ANALYSIS OF ANALYTICAL DATA}

Quantitative statistical analysis of analytical data will be used to verify characteristic EPA Hazardous Waste Number assignments. Initially, these EPA Hazardous Waste Numbers are based on process knowledge. Analytical data will be used to support and verify process knowledge decisions.

It is important to understand that this methodology will apply to a majority of the waste streams; however, it is anticipated that anomalies will be encountered. Anomalies include complex matrix interference, actinide interference, detection of unexpected constituents, abnormal analysis disagreement, and detection and quantitation limits exceeding regulatory limits. Anomalous data will be reviewed and their use documented. 
Once sufficient analytical information is generated, waste streams can be classified as hazardous or nonhazardous as described in Section 3.4. Chapter 9 of EPA SW-846, presents EPA guidelines and statistical classification methodology that can be used to determine the hazardous status of a waste streai (EPA SW-846), A confidenee interval approech is recommended to determine if hazardous constituents exceed regulatory limits. The methodalogy_consists of computing an 80-percent, two-tailed confidence interval for the mean of each constituent of concern (equivalent to 90 percent upper confidence level). If the upper limit of this confidence interval is less than the associated regulatory limit, the constituent is considered as not exhibiting these characteristics. If this condition is not met for any of the waste stream constituents, the waste steam is considered hazardous. Statistical interpretation of analytical data is discussed in Chapter 4.

\subsection{DEVLTION FROM DATA QUAUTY ORJECTIES}

Evaluation of compliance with the DQOs will be monitored throughout the duration of the program. Deviations or trends suggesting possible deviations from the established DQOs must be identified. As information is collected, the DQOs will be assessed to determine if the goals are realistic.

Corrective Action Reports or Deficiency Reports will be submitted for review when the DQOs have not been achieved. The report will be reviewed by the responsible Laboratory personnel to determine appropriate corrective action measures. This may involve assessment of affected portions of the program for deficiency resolution or may involve the adjustment of DQOs if they are determined to be either too stringent or too lenient. All corrective actions affecting the DQOs must be evaluated and approved in the same manner as the original objectives. 


\subsection{SCHEDULE}

In NMEDs, March 15, 1994, correspondence to DOE/LAAO regarding NOD NM 0890010515-1 (New Mexico Environment Department 1993), the Laboratory was required to develop and submit a schedule for the characterization of the transuranic waste stored on Pads 1, 2, and 4 in TA-54, Area G. Only a preliminary schedule can be developed until individual waste streams are identified, sampled, and analyzed as explained in Sections 3.3.2, 4.2.3, and 4.3.1. A preliminary schedule has been developed and is represented by Figure 6.1.

Various activities are requited before each contitiner can be characterized. The major activities considered and included in the preliminary schedule are:

- Drum retrieval

- RTR of each drum -

A.

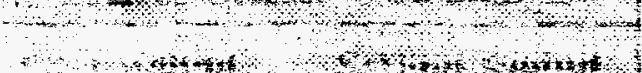

- Visual inspection of statistically selected drums from cach waste stream

- Sampling and analysis of statistically selected drums from each homogeneous waste stream.

\subsection{SCHEDULE DEVELOPMENT}

The basis for this schedule is:

- The activities discussed in Section 6.3 are not included for the reasons specified.

- The number of drums, start dates, rates, and other data used are as provided in interviews with appropriate Laboratory personnel and in various Laboratory documents.

- Only 55-gallon drums are to be included in this evaluation and the number of drums is:

- $\quad$ Pad $1-4,776$ drums

- $\quad$ Pad 2 - 7,293 drums

- $\quad$ Pad 4-4,554 drums 


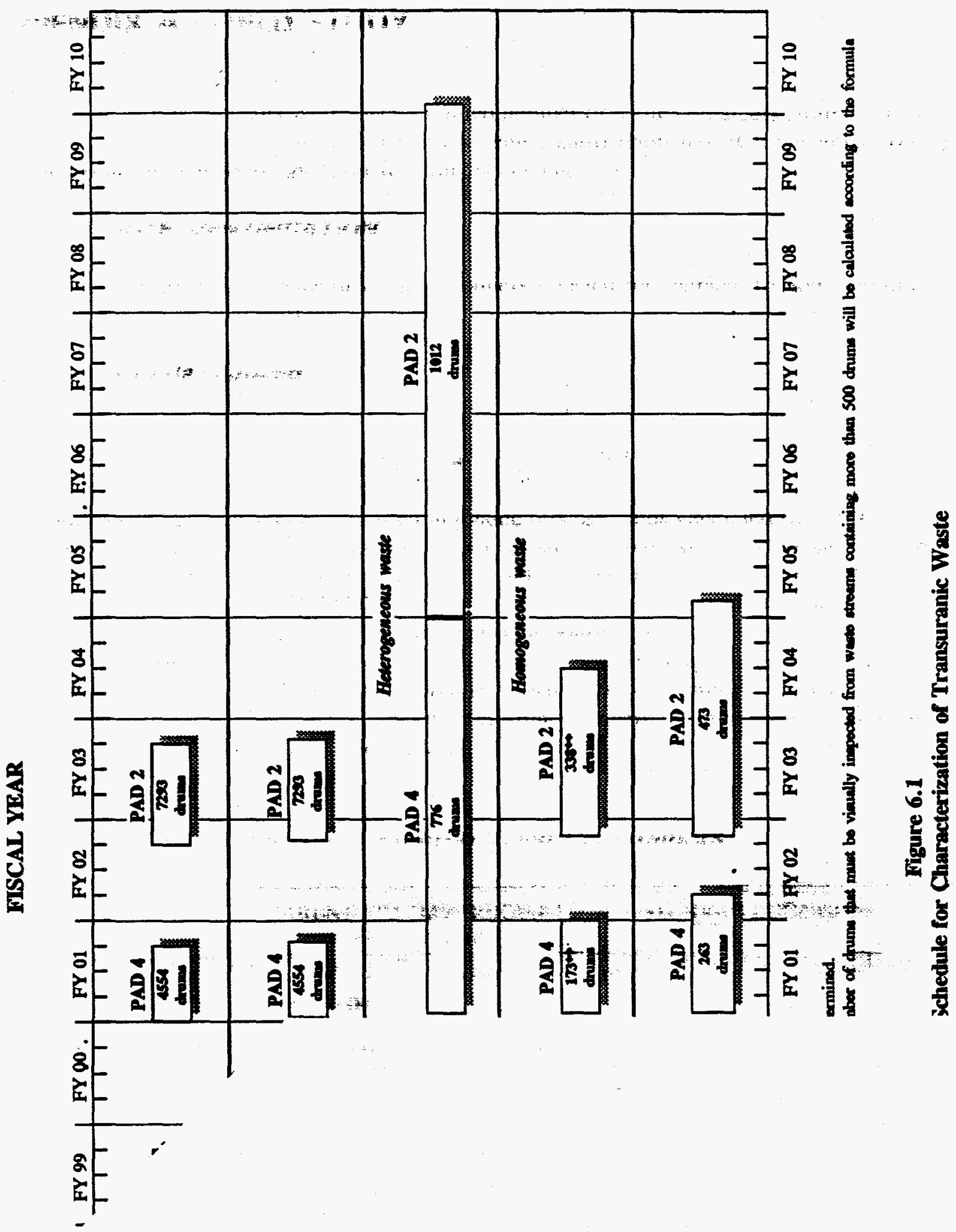


Transuranic Waste Characterization, Sampling, and Analysis Plan Propared for Los Alamos Nationd Laboratory by RAE \& WASTREN, Inc.

- The retrieval Order, retrieval stant dates, and retrieval durafion for each pad wil be:<smiles></smiles>

Pad 1 - April 1, 1998, 15 months

Pad 4 - Octot $+1,2000,9$ months

Pad 2 - July 1, 2002, 12 months

- $\quad$ RTR equipment will be in place and operational by January 1996.

- The RTR rate for each pad will equal the pad's retrieval rate, will commence 15 days after that pad's retrieval starts, and will be completed 15 days after retrieval completion.

- There will be separate gloveboxes and associated equipment for visual inspection of homogeneous and heterogeneous wastes. These will be in place and operational so that visual inspection of:

- Heterogeneous waste can start May 1, 1998, one month after that pads retrieval starts, and proceeds at a rate of one drum per day for 200 days per year.

Homogeneous waste can start May 1, 1998, one month after that pads retrieval starts, and proceeds at a rate of one drum per day for 200 days per year.

- The sampling of homogeneous waste drums will start May 1, 1998, and proceed at a rate of one drum per day for 200 days per year.

- All rates are for one 8-hour shift per day.

- Adequate analytical capabilities will be available, either in-house or through outside contractors, and will not present a time constraint.

- Present budget projections will not change.

- Budget constraints on each activity result in the start dates, rates, and durations shown.

- The categorization of individual drums as either homogeneous waste (WMCs 3000 and 4000) or heterogeneous waste (WMC 5000) was made based on: 
Transuranic Waste Characterization, Sampling, and Anatysis Plan Prepared for Los Alamos National Laboratory by RAE \& WASTREN, Inc.

The Radioactive Solid Waste Dibposal (RSTWi) code stophn for each container in the Laboratory Transuranic Waste Database

- A TRU Waste Database Mahix Code Stummary (utpublishedf provided by the Laboraftit

- A TRU Waste Characterization Reconciliation Table (unpublished) provided by the Laboratory

- An estimate of the homogeneous and heterogeneous waste streams, and the size of each, for individual pads was made as described in Section 6.2.

- An estimate of the number of drums to be visually inspected for each waste stream was made per Section 3.5.2.1. The number of drums subject to visual inspection in waste streams containing over 500 drums is estimated to be 26 for the purpose of completing the schedule.

- An estimate of the number of drums for first round sampling for each homogeneous waste stream was made as outlined in Section 4.2.3. For waste streams containing more than 10 drums, an estimate of 10 percent of the remaining drums was made for second round sampling.

\subsection{ESTMATION OF MDNDUAL WASTE STREAMS AND DRUMS TO BE SAMPLED AND DRUNS TO BE VSUALY WSPECTED .}

Summary sheets provided in the Los Alamos National Laboratory Waste Inventories for Pads 1 , 2 , and 4 were used for waste stream determinations and calculations of visual inspection and sampling requirements (Los Alamos National Laboratory 1994f). Determination of the number of waste streams were made for wastes stored at Pads 1;2, and 4 only. Only drums (including overpacks) were considered in the determinations. The TRU Waste Database Matrix Code Summary was used to differentiate between homogeneous and heterogeneous wastes based on the assigned RSWD code in the waste inventory (Los Alamos National Laboratory 1994f). Only WMCs 3000 (Solid Process Residues), 4000 (Soils), and 5000 (Debris) were considered in the determinations.

An individual waste stream was considered to consist of those drums with the same RSWD code and generated by the same group for a given pad. In some cases, this definition caused individual waste streams to cross between technical areas. Waste streams were assigned on an individual pad basis; that is, if a particular RSWD code and generator combination occurred for two pads, two waste streams were assigned. The number of waste streams for Pads 1, 2, and 4 was independently calculated for homogeneous and heterogeneous wastes. The number of waste streams for Pads 1, 2, and 4 are presented in Table 6.1. 
Transuranic Waste Characterization, Sampling, and Analysis Plan Propered for Los Alamos National Laboratory by RAE \& WASTREN, Inc.

\section{Table 6.1 Number of Waste Streams for Puds 1, 2, and 4}

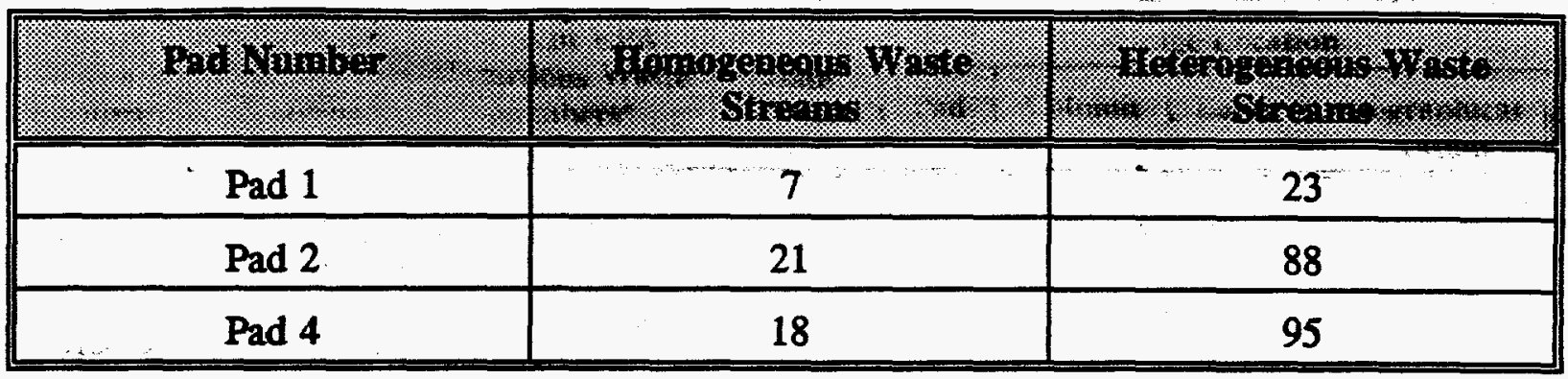

The number of waste drums requiring visual inspection was determined for individual waste streams using the methodology presented in Section 3.5.2.1 of this document. Calculations were made assuming a 2 percent miscertification rate by radiography (see Table 3.1). For waste streams containing less than 22 drums, all drums are to be visually inspected. For waste streams containing 22 to 50 drums, 22 drums are to be inspected. For waste streams containing 50 to 500 drums, Table 3.1 was used to determine the number of drums subject to visual inspection. The numbei of drums subject to visual inspection in waste streams containing over 500 drums is estimated to be 26. As explained in Section 3.5.2.1, a binomial distribution will be used to determine the actual number of drums to be visually examined for waste streams containing over 500 drums, but this will not be done for this preliminary schedule. The number of visual inspections for Pads 1, 2, and 4 was independently calculated for homogeneous and heterogeneous wastes. The number of waste drums requiring visual inspection for Pads 1,2 , and 4 are presented in Table 6.2 below.

\section{Table 6.2 Number of Waste Drums Requining Visual Inspection for Pads 1, 2, and 4}

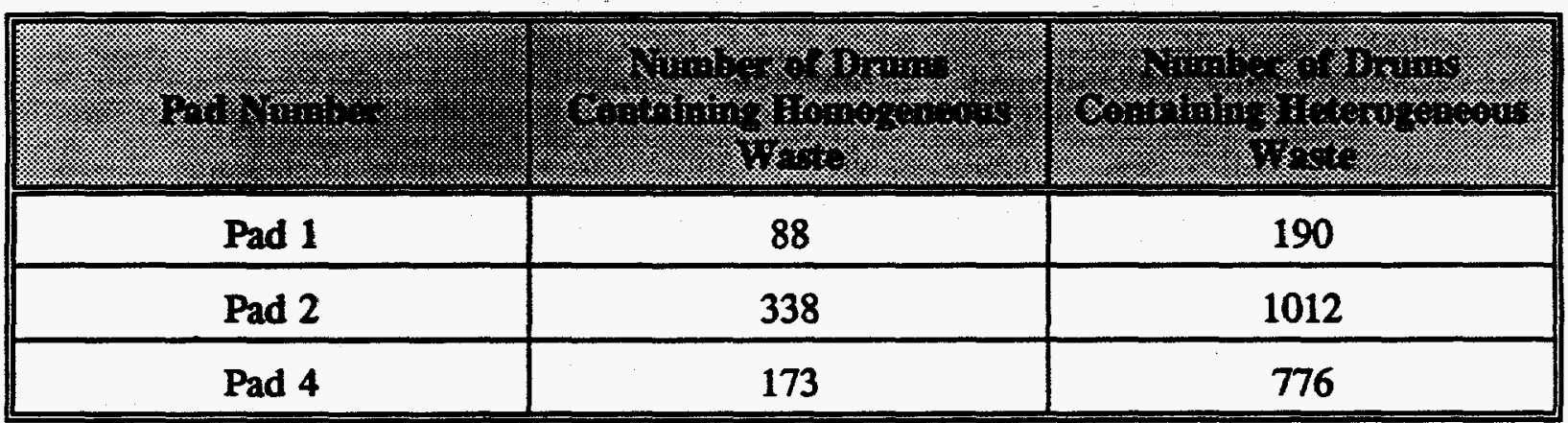

The initial number of waste drums requiring sampling was determined for individual waste streams using the methodology presented in Section 4.2.3 of this document. These calculations were made for homogeneous waste streams only. For waste streams containing less than 10 drums, every drum is sampled. This is true for the initial calculation of sampling events, whereas in actual practice, three total samples will be collected from waste streams containing 
1 and 2 drums. For waste streams containing 10 or more drums, 10 drums are sampled. As described in Section 4.3.1, for waste streams containing more than 10 drums, a second round of sampling may be necessary for complete characterization. For the purpose of compiling a preliminary schedule, an estimate was made on the number of additional drums needed for sampling. This was done by subtracting the number of drums sampled for each waste stream in first round sampling and taking 10 percent of the remaining drums. The number of first and second round sampling events for Pads 1, 2, and 4 are presented in Table 6.3 below.

\section{Table 6.3 Number of Sampling Events for Pads 1, 2, and 4}

\begin{tabular}{|c|c|c|}
\hline 1 & $(290$ \\
\hline Pad 1 & 40 & 290 \\
\hline Pad 2 & 149 & 324 \\
\hline Pad 4 & 85 & 178 \\
\hline
\end{tabular}

\subsection{SCHEDULE AMALYSS}

The Laboratory anticipates that the following activities will not be on the critical path:

$-\quad$ collecting and analyzing the existing waste information

- dividing the containers into broad waste categories (Waste Matrix Codes)

- identifying individual waste streams

- making a preliminary characterization of each waste stream

- sampling analysis

- data validation

Therefore, these activities are not shown on the schedule. 
Transuranic Waste Charactorization; Sampling, and Analysis Plan Prepared for Los Alamos National Laboratory by RAE \& WASTREN, Inc.

\section{APPENDIX A - FIELD STUDY}

The objective of this appendix is to select a limited number of waste containers stored at TA-54, Area G Pads 1, 2, or 4, or Dome 48 for waste stream identification and RCRA characterization to demonstrate the methodology defined in this document.

\section{A. 1 WASTE IDENTIFICATION}

This section identifies two groups of waste containers selected for characterization according to 20 NMAC 4.1, Subpart II, 261.

\section{A.1.1 Waste Background}

\section{A.1.1.1 TRUPACT-// Content Code 114A}

The waste containers selected are solidified inorganic process solids generated by NMT-2 in the Plutonium Facility (PF-4) at TA-55 and are stored at Pad 3 (Dome 48). They consist of twentyseven, 55-gallon drums generated from May 14, 1990, to March 25, 1991, and are all assigned the TRUPACT-II Content (TRUCON) Code 114A (Los Alamos National Laboratory 1992b). This waste consists of process residues from evaporator bottoms and other discardable solutions, process leached solids, ash, filter cakes, salts, metal oxides, and fines which is immobilized in gypsum cement (Los Alamos National Laboratory 1994d, and Los Alamos National Laboratory 1992c). See Table A.1 for a list of the specific drum numbers, closure dates, current EPA hazardous waste numbers, and storage location.

\section{Table A.1 Selected Waste Containers}

\begin{tabular}{|c|c|c|c|c|c|c|c|}
\hline \multirow{2}{*}{ 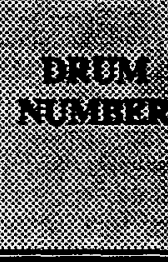 } & \multirow{2}{*}{ 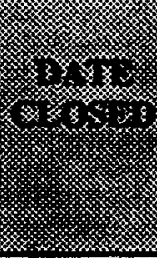 } & \multicolumn{2}{|c|}{ 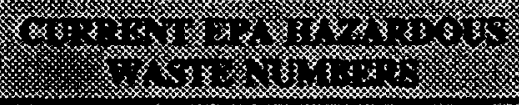 } & \multicolumn{4}{|c|}{ (1) } \\
\hline & & 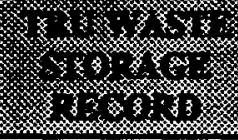 & 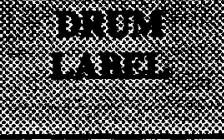 & \% & (3) & (x) & 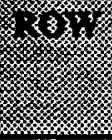 \\
\hline 54021 & $05 / 14 / 90$ & $\begin{array}{c}\text { D006, D007, } \\
\text { D008 }\end{array}$ & D007, D008 & 3 & 105 & 2 & - \\
\hline 54023 & $05 / 16 / 90$ & $\begin{array}{c}\mathrm{D} 006, \mathrm{D} 007, \\
\mathrm{D} 008\end{array}$ & D007 & 3 & 107 & 2 & 2 \\
\hline 54024 & $05 / 18 / 90$ & $\begin{array}{c}\text { D006, D007, } \\
\text { D008 }\end{array}$ & $\begin{array}{c}\text { D006, D007, } \\
\text { D008 }\end{array}$ & 3 & 105 & 1 & 9 \\
\hline 54026 & $05 / 23 / 90$ & $\begin{array}{c}\mathrm{D} 006, \mathrm{D} 007 \\
\mathrm{D} 008\end{array}$ & D007, D008 & 3 & 107 & 2 & 1 \\
\hline
\end{tabular}


Transuranic Waste Characterization, Sampling, and Analysis Plan Prepared for Los Alamos National Leboratory by RAE \& WASTREN, Inc.

\begin{tabular}{|c|c|c|c|c|c|c|c|}
\hline \multirow{2}{*}{ 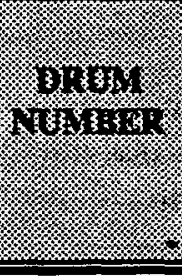 } & \multirow{2}{*}{ 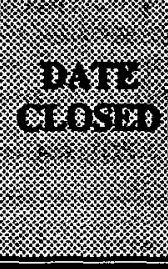 } & \multicolumn{2}{|c|}{ 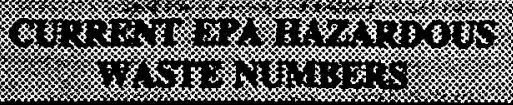 } & \multicolumn{4}{|c|}{ 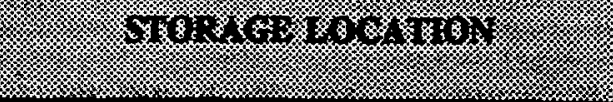 } \\
\hline & & 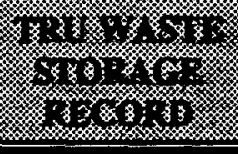 & 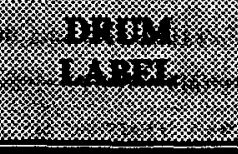 & $\sqrt[8]{3}$ & 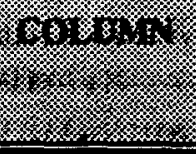 & 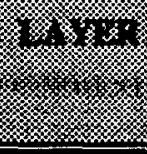 & 燓 \\
\hline 54027 & $05 / 29 / 90$ & $\begin{array}{c}\text { D006, D007; } \\
\text { D008 }\end{array}$ & $\begin{array}{c}\text { D006, D007, } \\
\text { D008 }\end{array}$ & 3 & 105 & 1 & 1 \\
\hline 54033 & $06 / 12 / 90$ & $\begin{array}{l}\text { D006, D007, } \\
\text { D008 }\end{array}$ & D007 & 3 & $\therefore \quad 107$ & 1 & 1 \\
\hline 54034 & $06 / 15 / 90$ & $\begin{array}{c}\text { D006, D007, } \\
\text { D008 }\end{array}$ & D008 & 3 & 105 & 2 & 6 \\
\hline 54035 & $06 / 19 / 90$ & $\begin{array}{c}\text { D006, D007, } \\
\text { D008 }\end{array}$ & $\begin{array}{c}\text { D006, D007, } \\
\text { D008 }\end{array}$ & 3 & $107^{\cdots}$ & 2 & 3 \\
\hline 54038 & $08 / 28 / 90$ & $\begin{array}{c}\text { D006, D007, } \\
\text { DOOB }\end{array}$ & $\begin{array}{c}\text { D006, D007, } \\
\text { D008 }\end{array}$ & 3 & 105 & 2 & 4 \\
\hline 54042 & $07 / 03 / 90$ & $\begin{array}{c}\text { D006, D007, } \\
\text { D008 }\end{array}$ & $\begin{array}{c}\mathrm{D} 006, \mathrm{D} 007 \\
\text { D008 }\end{array}$ & 3 & 105 & 1 & 5 \\
\hline 54043 & $07 / 09 / 90$ & $\begin{array}{c}\text { D006, D007, } \\
\text { D008 }\end{array}$ & $\begin{array}{c}\mathrm{D} 006, \mathrm{D} 007 \\
\text { D008 }\end{array}$ & 3 & 107 & 1 & 3 \\
\hline 54044 & $07 / 09 / 90$ & $\begin{array}{c}\text { D006, D007, } \\
\text { D008 }\end{array}$ & $\begin{array}{c}\text { D006, D007, } \\
\text { D008 }\end{array}$ & 3 & 107 & 2 & 7 \\
\hline 54046 & $07 / 12 / 90$ & $\begin{array}{c}\text { D006, D007, } \\
\text { D008 }\end{array}$ & $\begin{array}{c}\text { D006, D007, } \\
\text { D008 }\end{array}$ & 3 & 105 & 1 & 7 \\
\hline 54047 & $07 / 23 / 90$ & $\begin{array}{c}\text { D006, D007, } \\
\text { D008 }\end{array}$ & $\begin{array}{c}\text { D006, D007, } \\
\text { D008 }\end{array}$ & 3 & 107 & 2 & 8 \\
\hline 54050 & $08 / 17 / 90$ & $\begin{array}{c}\text { D006, D007, } \\
\text { D008 }\end{array}$ & $\begin{array}{c}\text { D006, D007, } \\
\text { D008 }\end{array}$ & 3 & 107 & 1 & 4 \\
\hline 54053 & $09 / 07 / 90$ & $\begin{array}{c}\text { D006, D007, } \\
\text { D008 }\end{array}$ & $\begin{array}{c}\text { D006, D007, } \\
\text { D008 }\end{array}$ & 3 & 107 & 1 & 5 \\
\hline 54055 & $08 / 31 / 90$ & $\begin{array}{c}\text { D006, D007, } \\
\text { D008 }\end{array}$ & $\begin{array}{c}\text { D006, D007, } \\
\text { D008 }\end{array}$ & 3 & 107 & 1 & 7 \\
\hline 54056 & $09 / 07 / 90$ & $\begin{array}{c}\text { D006, D007, } \\
\text { D008 }\end{array}$ & $\begin{array}{c}\text { D006, D007, } \\
\text { D008 }\end{array}$ & 3 & 105 & 1 & 8 \\
\hline 54057 & $09 / 28 / 90$ & $\begin{array}{c}\mathrm{D} 006, \mathrm{D} 007 \\
\mathrm{D} 008\end{array}$ & $\begin{array}{c}\text { D006, D007, } \\
\text { D008 }\end{array}$ & 3 & 105 & 2 & 5 \\
\hline 54058 & $10 / 04 / 90$ & $\begin{array}{c}\mathrm{D} 006, \mathrm{D} 007 \\
\mathrm{D} 008\end{array}$ & $\begin{array}{c}\text { D006, D007, } \\
\text { D008 }\end{array}$ & 3 & 107 & 1 & 6 \\
\hline 54059 . & $10 / 09 / 90$ & $\begin{array}{c}\text { D006, D007, } \\
\text { D008 }\end{array}$ & $\begin{array}{c}\text { D006, D007, } \\
\text { D008 }\end{array}$ & 3 & 107 & 2 & 4 \\
\hline
\end{tabular}


Transuranic Wasto Characterization. Sampling, and Analysis Plan Prepared for Los Alamos National Laboratory by RAE \& WASTREN, Inc.

\begin{tabular}{|c|c|c|c|c|c|c|c|}
\hline \multirow{2}{*}{ 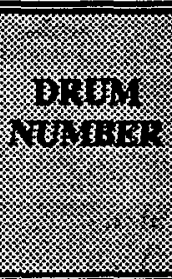 } & \multirow{2}{*}{ 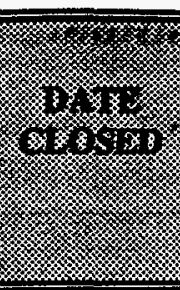 } & \multicolumn{2}{|c|}{ 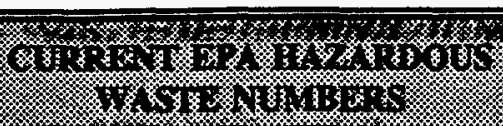 } & \multicolumn{4}{|c|}{ 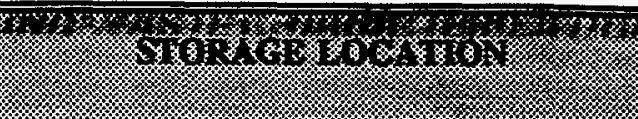 } \\
\hline & & 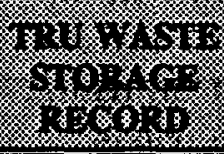 & : & 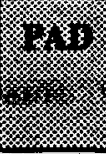 & \% & (3) & 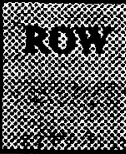 \\
\hline 54061 & $10 / 31 / 90$ & $\begin{array}{l}\text { D006, D007, } \\
\text { D008 }\end{array}$ & $\begin{array}{l}\text { D006, D007, } \\
\text { D008 }\end{array}$ & 3 & 105 & 2 & 7 \\
\hline 54063 & $11 / 09 / 90$ & $\begin{array}{c}\text { D006, D007, } \\
\text { D008 }\end{array}$ & $\begin{array}{l}\text { D006, D007, } \\
\text { D0008 }\end{array}$ & 3 & 107 & 1 & 8 \\
\hline 54064 & $11 / 19 / 90$ & $\begin{array}{c}\mathrm{DOO6}, \mathrm{DO07} \\
\mathrm{DOOS}\end{array}$ & $\begin{array}{l}\text { DOO6, }- \text { DOOA, } \\
\text { DOO8 }\end{array}$ & -3 & +105 & -2 & 3 \\
\hline 54067 & $11 / 27 / 90$ & $\begin{array}{c}\text { D006, DoO7, } \\
\text { D008 }\end{array}$ & $\underset{\text { DoOs }}{\text { DoOs DoO }}$ & 3 & 107 & $+b_{x+4}$ & 10 \\
\hline 54080 & $02 / 27 / 91$ & $\begin{array}{l}\text { D006, D007, } \\
\text { D008 }\end{array}$ & $\begin{array}{l}\text { D006, D007, } \\
\text { DOOB }\end{array}$ & 3 & 107. & 2 & 10 \\
\hline 54091 & $03 / 25 / 91$ & $\begin{array}{c}\text { D006, D007, } \\
\text { D008 }\end{array}$ & $\begin{array}{l}\text { D006, D007, } \\
\text { D008 }\end{array}$ & 3 & 105 & 2 & 10 \\
\hline
\end{tabular}

\section{A.1.1.2 Radioactive Solid Waste Disposal Code A18}

The waste containers selected consist of mixed paper, plastic, rubber, and possibly other debris generated by CMB-11 at TA-55 and are stored at Pad 1. They consist of six, 55-gallon drums generated from December 15, 1981 to December 21, 1981, and are all assigned RSWD Code A18 (Los Alamos National Laboratory 1987, and Los Alamos National Laboratory 1980). See Table A.2 for a list of the specific drum numbers, form numbers, closure dates, current EPA Hazardous Waste Number, and storage location. 
Transuranic Waste Characterization, Sampling, and Analysis Plan Prepared for Los Alamos National Laboratory by RAE \& WASTREN, Inc.

Table A.2 Selected Waste Containers.

\begin{tabular}{|c|c|c|c|c|c|c|c|}
\hline \multirow{2}{*}{ Nomber } & \multirow{2}{*}{ 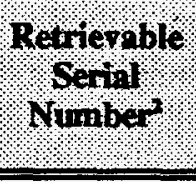 } & \multirow{2}{*}{ 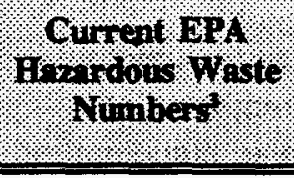 } & \multirow{2}{*}{ Batord? } & \multicolumn{4}{|c|}{ Storage 10001001 } \\
\hline & & & & $180 d$ & Solum, & $41 \%$ & Georivolitionl \\
\hline S818418 & 010335 & None & $12 / 15 / 81$ & 1 & 25 & 3 & West \\
\hline 5818419 & 010321 & None & $12 / 15 / 81$ & 1 & 25 & 3 & West \\
\hline$\$ 818439$ & 010830 & None & $12 / 17 / 81$ & 1 & 28 & 1 & East \\
\hline S818451 & 010194 & None & $12 / 18 / 81$ & 1 & 28 & 2 & West \\
\hline $\mathbf{S 8 1 8 4 5 2}$ & 010199. & None & $12 / 18 / 81$ & 1 & 28: & 2 & West \\
\hline S818729 & 010750 & None & $12 / 21 / 81$ & 1 & 28 & 2 & West \\
\hline
\end{tabular}

Notes: 1. This is the number on the LASL Radiosctive Solid Waste Disposal Record Form.

2. This is the serial number on the drum.

3. EPA Hazandous Waste Numbers were not found for these drums in the TRU Waste Management Database or on the LASL Radioactive Solid Waste Disposal Recond Form.

\section{A.1.2 Waste Description}

\section{A.1.2.1 TRUPACT-// Content-Code 114A}

TRUCON Code 114A applies to solidified inorganic waste. The process residues addressed in this section are solid and liquid transuranic waste left when all economically recoverable quantities of special nuclear materials (SNM) have been removed from scrap nuclear materials. They are received by NMT-7 from many areas throughout the PF-4. No matter, what the source, the residues are usually handled through one of the PF-4 Material Management Rooms or the Cement Fixation Glovebox (CFG) to satisfy existing Nuclear Material Control Accountability requirements (NMC\&A). NMC\&A are guidelines designed to prevent intentional diversion of SNM. The information for TRUCON Cade 114A in this section was obtained from the Los Alamos TRU Waste Certification Plan for Newly Generated TRU Waste, Attachment 6, for the Processing of Certifiable Process Residue Transuranic Waste is NMT Division (Los Alamos National Laboratory 1994d).

Process residues which include evaporator bottoms and other discardable solutions, process leached solids, ash, filter cakes, salts, metal oxides in particulate form, are immobilized in either Portland or Gypsum cement to form a noncorrosive solid matrix in a 55-gallon drum, or 1-gallon cans placed inside 55-gallon drums. The solutions provide the liquid necessary to prepare the cement paste and the solids are incorporated during or immediately following mixing. The stabilized residues may also contain some combustible or noncombustible solid wastes encapsulated by the freshly stirred cement as a matter of convenient disposal. This waste form includes, but may not be limited to, the following. 


\section{Aqueous Solutions}

- Evaporator Bottom Solution

- Uranium/Plutonium Solution.

- Chloride Solution

Residues

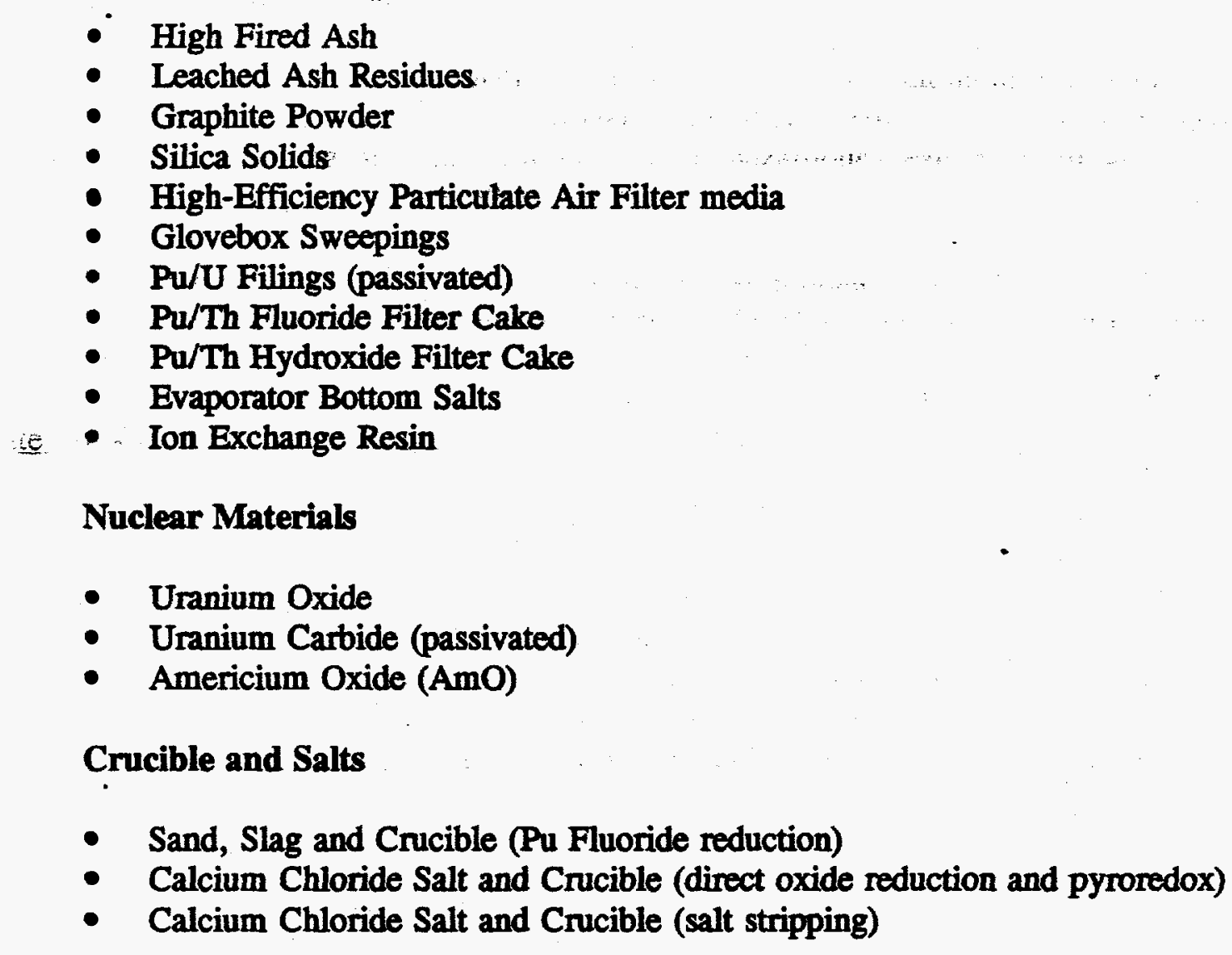

The evaporator bottom liquid and uranium solution are both nitric acid solutions (usually 1 to 7 molar). The chloride solutions are usually 0.5 to 4 molar hydrochloric acid solutions. The solutions often contain large quantities of dissolved nitrate, oxalate, or chloride salts.

The leached ash residues that are cemented at TA-55 are derived from acid leaching of ash from a Thermal Decomposition unit at TA-55.

Graphite powder is the sweepings resulting from the process of striking graphite molds with a hammer until they break into large chunks.

The plutonium-uranium metal filings can be pyrophoric. They are passivated (roasted in air at $600^{\circ} \mathrm{C}$ ) by the generator to form oxides. The latter are particulates and are immobilized in the cement fixation glovebox (CFG). 
Transuranic Waste Charactorization. Sampling, and Analysis Plan Prepared for Los Alamos National Laboratory by RAE \& WASTREN, Inc.

The method of disposal for ion exchange resin is immobilization in cement.

Uranium oxide and uranium carbide are transuranic waste by virtue of being contaminated with plutonium. Because uranium carbide is pyrophoric it is also passivated by heating in air to form the oxide. Both wastes are immobilized in cement.

Up to 122 Curies ( 35 grams) of insoluble americium-241 may be placed in a cement drum without exceeding the surface dose rate limit or the plutonium equivalent Curie limit.

The magnesium oxide sand, magnesium oxide crucible, and calcium fluoride plus calcium iodide slag are residues from the reduction of plutonium fluoride and calcium metal. The slag contains calcium metal with some plutonium. The originator screens the broken mixture using a 16-20 mesh screen $(1,190$ - to 841- micron openings) to separate fines close to the size requiring immobilization. The very hard slag plus other chunks are discarded with noncombustible waste.

The calcium chloride-calcium oxide salt and crucible from the direct oxide reduction and pyroredox process may also contain calcium metal containing some plutonium. A small quantity of pyrophoric crystalline calcium metal is vapor deposited during processing. This material burns when the furnace is opened at $400^{\circ} \mathrm{C}$ at the end of the run producing a particulate oxide. Fines requiring immobilization are separated with a 16-mesh screen. The salt solidified from the molten state is a hard, compact material that can be broken by striking with a hammer. Because of its hardness, it is resistant to abrading into smaller particles during handling and transportation. Thus, once separated from the fines, the chunks can be discarded with noncombustible waste.

The calcium chloride-sodium chloride-potassium chloride salt stripping process may contain metallic sodium. To neutralize its pyrophoricity, the originator remelts this residue and sparges it with air, converting the sodium to the oxide. The remelted mixture is a hard, compact block which can be discarded with the noncombustible waste.

\section{Standard Packaging}

In the one-gallon cement fixation process, the waste is mixed with cement powder in one-gallon cans that serve only as mixing containers for the paste and not as the ultimate packaging containment. The filled cans are then packaged in the 55-gallon DOT 17C or UN $1 \mathrm{~A} 2$ steel drums. The packaging within the drum includes $1 / 16$-inch-thick lead sheet when necessary and one 12-mil PVC bag that contains the cans. The lead serves as a shielding material for gamma radiation. It consists of two circles, placed at the drum top and bottom, and a cylinder fitted inside the drum wall.

In the 55-gallon cement fixation process, the waste will be mixed with cement powder in a 1/8inch-thick polyethylene drum liner that will serve only as a container for the paste, and not as an integral part of the packaging. The waste will be packaged in the same manner as the one-gallon cans. The 12-mil PVC bag will contain the drum liner. 
Transuranic Waste Characterization, Sampling, and Analysis Plan Prepared for Los Alamos National Laboratory by RAE \& WASTREN, Inc.

\section{A.1.2.2 Radioactive Solid Waste Disposal Code A18}

Operations in PF-4 generate numerous wastes that vary considerably in physical, chemical, and radiological properties. The wastes are not necessarily representative of any one operation and may be common to several operations. The information for RSWD A18 was obtained from the Los Alamos TRU Waste Certification Plan for Newly Generated TRU Waste, Attachment 3, for the Processing of Certifiable Combustible and Noncombustible Transuranic Waste in MST Division (Los Alamos National Laboratory 1987).

Most wastes, no matter what the source, are handled through one of the TA-55 Waste Management Rooms to satisfy existing accountability, safeguards, and packaging requirements.

RSWD Code A18 applies to combustible solids consisting of mixed paper, plastic, rubber, and possibly other debris which may include some small fraction of noncombustible solids such as scrap metal. This waste form includes, but is not limited to the following:

\section{Plastics}

- Tape, polyethylene, and vinyl

- Gloves

$-\quad$ Plastic vials

- Polystyrene

- Tygon tubing

- Polyvinyl chloride plastic

- Teflon products -

- Plexiglas

- Drybox gloves (unleaded neoprene base)

\section{Cellulosics}

- Rags

- Wood

- Paper

- Cardboard

- Laboratory coats and coveralls

- Booties and cotton gloves

\section{Miscellaneous}

- Graphite crucibles

- Graphite

Waste is usually packaged in a DOT 17C, steel, 55-gallon drum. The packaging includes either two 5-mil plastic bags or one 90 -mil rigid polyethylene liner with lid. Waste may also be packaged in 30-gallon drums overpacked in 55-gallon drums. 
Transuranic Waste Characterization, Sampling, and Analysis Plan Prepared for Los Alamos National Laboratory by RAE \& WASTREN, Inc.

\section{A.2 HAZARDOUS WASTE DETERMINATION AND WASTE CHARACTERIZATION}

\section{A.2.1 TRUPACT-/l Content Code 1144}

One waste stream was identified for the solidified inorganic process solids which are assigned the TRUCON Code 114A generated by NMT-2 at TA-55. A summary of the characterization reassessment results is presented in Table A.3.

\section{Table A.3 Characterization Reassessment Results Summary}

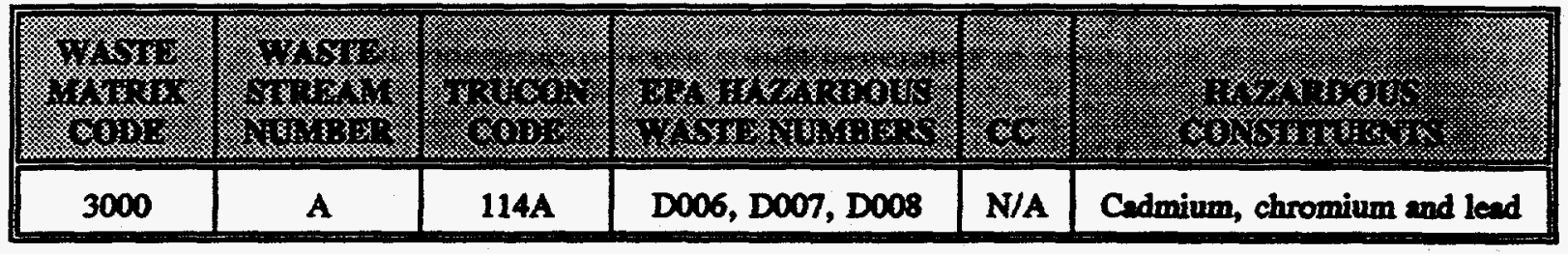

$\begin{array}{lll}\text { Acronyms: } & \text { CC } & \text { Compatibility Code } \\ & \text { EPA } & \text { U.S. Environmental Protection Agency } \\ & \text { N/A } & \text { Not Applicable }\end{array}$

\section{Waste Matrix Code Assignment}

Based on documentation and interview information, all of this waste is solid process residue and therefore meets the definition of WMC 3000 (Los Alamos National Laboratory 1994d, 1992c, and WASTREN 1994a). This will be verified using RTR.

\section{Waste Stream A Identification}

All of this waste was generated from the cementation of evaporator bottoms, hydrochloric acid solutions, resin, ash, and other noncombustible leached solids in Gloveboxes G472 (saltbox) and G465 (cementation) of Building PF-4. These wastes were generated from May 14, 1990, to March 25, 1991, and the process used to cement this waste did not change over this time period (Los Alamos National Laboratory 1992b, 1992c, 1989, and WASTREN 1994a). RTR will be performed on these drums to verify the absence of free liquid or any other anomalies.

\section{Waste Stream A Characterization}

The current characterization of this waste is based on total RCRA-toxic metals analysis from 40 other drums containing similar waste. The highest concentration of each metal found in these analyses was used to define a worst-case metal concentration (Los Alamos.National Laboratory 1992a). 
Transuranic Waste Characterization, Sampling, and Analysis Plan Prepared for Los Alamos National Laboratory by RAE \& WASTREN, Inc.

This waste contains above the regulatory level of lead due to thelled drumliner, which is about 10 percent of the total drum weight (Los Alamer National Laboratory 1992b).

Limited analytical data are available for the waste from samples of evaporator bottoms that went into these drums which consist of total cadmium, chromium, and lead content. Samples were only taken of a portion of the materials prior to solidification (Los Alamos National Laboratory 1989). Because the total metal content cannot be calculated using these data, it is not certain if the waste is above the RTL for cadmium and chromium as well.

TCLP results are available for drums numbers 55307, 55308, 55309, and 55399. These drums contain similar material to the drums in this waste stream but are not actually included in this waste stream. These results show that only chromium leaches above the RTL (Los Alamos National Laboratory 1994c). These results give a good indication that chromium will leach from the material in this waste stream; however, the data do not take the lead drum liner into account. Also, even though these results show cadmium below the RTL, it is uncertain whether these data are representative of this waste stream.

Therefore, this waste exhibits the characteristic of toxicity for cadmium, chromium, and lead (D006, D007, and D008). Drums from this waste stream will be randomly selected for sampling and analysis to confirm this characterization.

\section{A.2.2 Radioactive Solid Waste Disposal Code A18}

Two waste streams were identified for the combustible materials which are assigned RSWD Code A18 generated by CMB-11 at TA-55. A summary of the characterization reassessment results are given in Table A.4.

\section{Table A.4 Charactenization Reassessment Results Summary}

\begin{tabular}{|c|c|c|c|c|c|}
\hline Wy & 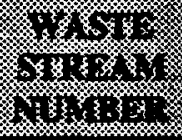 & 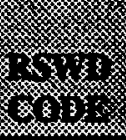 & 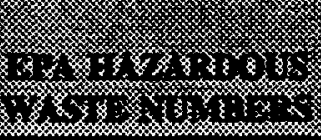 & 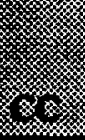 & 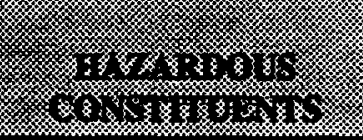 \\
\hline 5000 & $\mathbf{A}$ & A18 & DO08 & N/A & Lead \\
\hline 5000 & B & A18 & $\begin{array}{l}\text { D008, F001, F002, } \\
\text { F003, F004, F005 }\end{array}$ & N/A & Lead and listed solvents \\
\hline
\end{tabular}

Acronyms: $\quad$ CC Compatibility Code

EPA U.S. Environmental Protection Agency

N/A Not Applicable

RSWD Radioactive Solid Waste Disposal 
Waste Matrix Code Assignment

Based on documentation and interview information, all of this waste consists of at least 50 percent by volume, materials that meet the regulatory definition of debris, and therefore, meets the definition of WMC 5000 (Los Alamos National Laboratory 1987, 1980, and WASTREN 1994a). This will be verified by RTR.

Waste Stream A Identification

This waste was generated on December 28 and 29, 1981, from plutonium processing (material types Pu-52 and Pu-53) (Los Alamos National Laboratory 1980). The waste originated from cleaning using Ajax, Fantastic, and possibly other nonhazandous cleaners within gloveboxes for $\mathrm{Pu}-52$ and Pu-53 processing (WASTREN 1994a).

RTR will be performed on the drums to confirm the assignment of RSWD Code A18. If these drums contain wastes other than those described by RSWD Code A18, a reassessment of the characterization will be done.

\section{Waste Stream A Characterization}

Because hazardous solvents were not used in these gloveboxes, this waste is not an F-listed hazardous waste (WASTREN 1994a).

Lead bricks, may have been placed in these drums; therefore, the EPA Hazardous Waste Number D008 (toxic for lead) will be assigned to this waste (Los Alamos National Laboratory 1994b). RTR will be performed on the drums to determine whether lead bricks are actually present. If no lead bricks are found using RTR, the EPA Hazardous Waste Number D008 will no longer be assigned to these drums.

\section{Waste Stream B Identification}

This waste was generated on December 29, 1981, from processing of heat-source plutonium (material type Pu-83) (Los Alamos National Laboratory 1980). The waste originated in the "200-Area" from cleaning using organic solvents within gloveboxes dedicated to Pu-83 processing (WASTREN 1994a).

RTR will be performed on these drums to confirm the assignment of RSWD Code A18. If these drums contain wastes other than those described by RSWD Code A18, a reassessment of the characterization will be done.

\section{Waste Stream B Characterization}

At this time, the specific solvents used are not known. Until additional information is collected on specific solvents used, EPA Hazardous Waste Numbers F001, F002, F003, F004, and F005 will be assigned. 
Transuranic Waste Characterization, Sampling, and Analysis Plan Prepared for Los Alamos National Laboratory by RAE \& WASTREN, Inc.

Because lead bricks may have been placed in these drums, the EPA Hazardous Waste Number D008 (toxic for lead) will be assigned to this waste (Los Alamos National Laboratory 1994b). RTR will be performed on the drums to determine whether lead bricks are actually present. If no lead bricks are found using RTR, the EPA Hazardous Waste Number D008 will no longer be assigned to these drums.

\section{A.3 REGULATORY DISCUSSION}

These wastes were characterized based on 20 NMAC 4.1, Subpart II, 261, The following is a summary of the logic used in reassessing the characterizations for these wastes.

- The material is not excluded from regulation as a solid waste under 20 NMAC 4.1, Subpart II, 261.2(e)(1)(ii), because it is not used or reused as an effective substitute for a commercial product; it is not a source, special nuclear,

- or byproduct material, or certain secondary materials being reclaimed under 20 NMAC 4.1, Subpart II, 261.4(a)(4); and it is being disposed of as provided in 20 NMAC 4.1, Subpart II. Therefore, material is a solid waste.

- The material is not excluded from regulation as a hazardous waste under 20 NMAC 4.1, Subpart II, 261.4(b)(exclusions), 261.4(d)(RCRA sample), or 261.7(empty container). The material is not a recyclable material, as outlined in 20 NMAC 4.1, Subpart II, 261.6. The material exhibits a characteristic of hazandous waste as defined by 20 NMAC 4.1, Subpart II, 261, Subpart C, or is mixed with wastes listed in 20 NMAC 4.1, Subpart II, 261, Subpart D. In addition, the material is derived from the treatment, storage, or disposal of a hazardous waste (20 NMAC 4.1, Subpart II, 261.3(c)(2)(i)).

- A petition for delisting this waste has not been filed and this waste has not been delisted, under 20 NMAC 4.1, Subpart II, 260.20 and 260.22.

\section{A.4 CONCLUSIONS}

The information for this characterization study was collected over a 4-day time period. Considerable information was available for the solidified inorganic process solids, most likely because the waste was generated within the last two years. Details that were not obtained for this waste were what specific solvents were used at the point of generation, and their use. This information, once obtained, will determine if any F-listings apply to the waste. Also, the limited analytical data available for the waste are not conclusive (Los Alamos National Laboratory 1989). Although TCLP analysis has been done on similar wastes, sampling of these containers is necessary (Los Alamos National Laboratory 1994c). 
Transuranic Waste Characterization, Sampling, and Analysis Plan Prepared for Los Alamos National Laboratory by RAE \& WASTREN, Inc.

Little information was obtained on the combustible wastes. The RSWD Form does not contain much characterization information (Los Alamos National Laboratory 1980). The radionuclide material type did help to determine where organic solvents were used, but the specific solvents used were not identified. In the time allotted, key individuals were identified but could not be contacted; they may have additional information, such as logbooks and laboratory notes, to adequately characterize the waste. Also, drum logs and other documentation are available from the generator but are not accessible at this time because they are in a radiation area and must be smeared in order to be released (WASTREN 1994b).

Other sources of information that may be beneficial to further characterize the waste are the database at TA-55, existing files from the generator, additional interviews, inspection of process areas, logbooks, and operating procedures.

\section{A.5 SUMMARY OF CONTACTS}

The following individuals can provide information about the solidified inorganic process solids waste and the mixed paper, plastic, and rubber waste.

Ronald Blankenship, (505) 665-7356. Mr. Blankenship is with FSS-12 and was a generator of the combustible wastes in PF-4.

Kate Camp. Ms. Camp is a retired recordkeeper that may know how historical data were maintained.

I Li Chen, (505) 665-6422. Ms. Chen is familiar with the data packages and the TRU Waste Management Database for the wastes stored at Area G.

Charles L. Foxx (Jim), (505) 667-2328. Mr. Foxx is with NMT-7 and is knowledgeable about much of the operations in PF-4.

Kathleen Greutzmacher, (505) 665-4356. Ms. Greutzmacher is knowledgeable about operations in PF-4.

Darlene Guiterez. (505) 667-2580. Ms. Guiterez may have additional documentation on the combustible waste generated in PF-4.

Virginia Harkleroad, (505) 667-8865. Ms. Harkleroad is familiar with the data packages and the TRU Waste Management Database for the transuranic wastes stored at Area G.

Sạndy Hildner, (505) 667-2580. Ms. Hildner may have additional documentation on the combustible waste generated in PF-4. 
Transuranic Waste Characterization, Sampling, and Analysis Plan Prepared for Los Alamos National Laboratory by RAE \& WASTREN, Inc.

Bace LeBrun, (505) 665.6427. Mr. LeBrun is knowledgeable about waste management at Area $\mathrm{G}$.

Walter Moore. Mr. Moore may have logbooks indicating the specific wastes that were placed in the combustible waste drums in PF-4.

William Schueler, (505) 667-1193. NMT-7, Waste Management.

Mary Seviranhaus. Ms. Seviranhaus may have additional documentation on the combustible waste generated in PF-4.

Chester Smith, (505) 667-2857. Mr. Smith is with NMT-7 and is cognizant of the solidified inorganic process solids generated in PF-4.

Patricia Trupp, (505) 667-3405. Ms. Trupp is with NMT-10 and was a generator of the combustible wastes in PF-4. 


\section{APPENDIX B - APPROACH TO DETERMINING THE NUMBER OF CONTAINERS FOR VISUAL EXAMINATION}

The method for selecting containers to be visually examined is based upon a statistical approach to quantifying the proportion of waste containers miscertified by the radiography process. Because the examination effort will be to estimate a proportion in a finite population, Table 3.1 was developed using the hypergeometric probability distribution as described in the WIPP QAPP (DOE 1994b). This is illustrated in the inequality

$$
\sum_{k=0}^{x} \frac{\left(\begin{array}{c}
M \\
k
\end{array}\right)\left(\begin{array}{c}
N-M \\
n-k
\end{array}\right)}{\left(\begin{array}{l}
N \\
n
\end{array}\right)} \leq \alpha
$$

where

$M=$ the number of miscertified containers in the population

$N=$ the number of containers in the population

$x^{*}=$ the number of miscertified containers in the sample

$n=$ the number of containers in the sample

$\alpha=$ the significance level

To ensure with reasonable certainty that a 90 percent upper confidence limit (UCL miscertification percentage is less than 14 percent, the number of waste containers requiring visual examination was determined by using the inequality with the true population proportion $\mathrm{M} / \mathrm{N} \leq 0.14$, the fraction of miscertified containers $x / n$ that corresponded to the specified miscertified fraction ( 1 to 6 percent, designated $\rho$ ), and $\alpha=0.10$. The value $M / N$ represents a 90-percent upper confidence limit for the proportion that allows a reasonable number of containers to be examined for small proportions (1 to 6 percent).

The hypergeometric probability distribution is a result of sampling to estimate a proportion from a finite population. Because is it easier to use, the normal distribution is sometimes used as an approximation to the hypergeometric probability distribution to estimate confidence limits and sample sizes in applications such as this. However, because the expected proportions are so small, the normal approximation should not be used as it will produce erroneous results. For a large $N$ (say, 500 or more), the binomial distribution may be used with little error added. The binomial distribution is still more difficult to work with than the normal distribution, but may be easier than the hypergeometric probability distribution. 


\section{APPENDIX C - REFERENCES}

ASTM. 1991. Standard Practice for Sampling Waste and Soils for Volatile Organic Compounds. 1983. Standard Practice for Thin-Walled Tube Sampling of Soils.

Atwood, C.L., L.G. Blackwood, G.A. Harris, and C.A. Loehr. 1991. Recommended Methods for Statistical Analysis of Data Containing Less-Than-Detectable Measurements. EGGSARE-9247.

Bowman, V.A. 1992. Professional Environmental Management and Auditing. Des Plaines, IL: Cahners Publishing.

Code of Federal Regulations. Title 40 Parts 260-272. RCRA Subtitle C.

Code of Federal Regulations. Title 40, Part 271-Requirements for Authorization of State Hazardous Waste Programs, and Part 272.1601-New Mexico State-Administered Program:Final Authorization.

Code of Federal Regulations Title 49 Part 173.

DOE. 1994a. TRU Waste Characterization Program Sampling and Analysis Methods Manual. Carlsbad Area Office. U.S. Department of Energy.

- 1994b. TRU Waste Characterization Quality Assurance Program Plan. CAO-941010 Draft.

. 1993a. DOE Waste Treatability Groups Guidance. Final Draft.

1993b. Environmental Restoration and Waste Management Five-Year Plan; Fiscal Years 1994-1998. DOE/S-00097P Vol. 2.

1990. Waste Acceptance Criteria for the Waste Isolation Pilot Plant.

1988. DOE Order 5820.2A. Radioactive Waste Management.

1979. Final Environmental Impact Statement Los Alamos Scientific Laboratory Site. DOE/EIS-0018.

EG\&G Idaho. 1994. Description of the SWEPP Certified Waste Sampling Program for FY-94. Engineering Design File, RWMC-363, Rev. 6. Idaho National Engineering Laboratory. 
Transuranic Waste Characterization, Sampling, and Analysis Plan Prepared for Los Alamos National Laboratory by RAE \& WASTREN, Inc.

Elsevier Science Publishing. 1993. The Hazardous Waste Consultant. Denver, CO: Elsevier Science Publishing.

EPA. Test Methods for Evaluating Solid Waste, Physical/Chemical Methods. 3rd edition, Final Update I.

Gilliom, R.J., and D.R. Helsel. 1986. Estimation of Distributional Parameters for Censored Trace Level Water Quality Data; 1, Estimation Techniques. Water Resources Research. 22:147.

Los Alamos National Laboratory. 1994a. Detailed Operating Procedure TRU Database Validation, CST-7G. Draft 044, Rev. 0.

- 1994b. Draft Transuranic Waste Stream Hazardous Material Characterization Study. Prepared by Benchmark Environmental Corporation. AP.6-CST7G-016, Rev. 0.

. 1994c. Facsimile from B. Schueler to B. Lyon. June 10.

- 1994d. Los Alamos TRU Waste Certification Plan for Newly generated TRU Waste, Attachment 6, for the Processing of Certifiable Process Residue Transuranic Waste in NMT Division. TRUWM-TA55-CPA-06, R00.

. 1994e. RCRA Part B Permit Application.

. 1994f. Transuranic Waste Management Database. Maintained by CST-7.

1992a. Memorandum from B. Reich, EM-7 to P. Shalek, NMT-2. EM-7D-92-649.

. 1992b. TRU Waste Storage Record. Form 1562. Effective October 1992.

. 1992c. Waste Profile Form. Form 1346. Effective June 1992.

1989. Discardable Waste Log Sheet. TRU-NMT7-DR-02, R05. Effective September 13, 1989.

- 1987. Los Alamos TRU Waste Certification Plan for Newly generated TRU Waste, Attachment 3, for the Processing of Certifiable Combustible and Noncombustible Transuranic Waste in MST Division. TRU-MST12-CPA-03, R00.

. 1980. LASL Radioactive Solid Waste Disposal Record Form. Effective April 1980.

Madansky, A. 1988. Prescriptions for Working Statisticians. New York, NY: Springer-Vertiag.

New Mexico Environment Department. 1993. Compliance Orders NMHWA 93-03 and 93-04. 
1993. Notice of Deficiency. NM0890010515-1.

RAE and WASTREN. 1993. Safety Analysis Report for Technical Area 54 Los Alamos National Laboratory. Vol. 1. Draft.

WASTREN, Inc. 1994a. Interview of C. Foxx, C. Smith, R. Blankenship, W. Schueler, and P. Trupp of the Los Alamos National Laboratory by J. Harrison and K. Peters of WASTREN, Inc. October 23.

1994b. Telephone conversation between K. Greutzmacher of the Laboratory and J. Harrison of WASTREN, Inc. November 7. 


\section{APPENDIX D - ACRONYMS}

\begin{tabular}{|c|c|}
\hline ALARA & as-low-as reasonably achievable \\
\hline ASTM & American Standard Testing Methods \\
\hline $\mathrm{CAO}$ & Carlsbad Area Office \\
\hline $\begin{array}{l}\text { CAS no. } \\
\text { CI }\end{array}$ & $\begin{array}{l}\text { Chemical Abstract Service Registry Number } \\
\text { confidence interval }\end{array}$ \\
\hline CFG & cement fixation glovebox \\
\hline CFR & Code of Federal Regulations \\
\hline CSAP & characterization, sampling, and analysis plan \\
\hline CVAA & cold vapor atomic absorption spectroscopy \\
\hline DOE & U.S. Department of Energy \\
\hline DOT & U.S. Department of Transportation \\
\hline DQO & Data Quality Objective \\
\hline EPA & Environmental Protection Agency \\
\hline FFCAct & Federal Facility Compliance Act \\
\hline FLAA & flame atomic absorption spectroscopy \\
\hline FRP & Fiberglass Reinforced Plywood \\
\hline GC/ECD & gas chromatography/electron capture detection \\
\hline GC/FID & gas chromatography/flame ionization detector \\
\hline GCMS & gas chromatography/mass spectrometry \\
\hline GFAA & graphite furnace atomic absorption spectroscopy \\
\hline $\mathbf{H}_{2} \mathbf{S}$ & hydrogen sulfide \\
\hline HAA & hydride generation atomic absorption spectroscopy \\
\hline HCN & hydrogen cyanide \\
\hline HSWA & Hazardous and Solid Waste Act \\
\hline HWA & New Mexico Hazardous Waste Act \\
\hline HWMR & Hazardous Waste Management Regulation \\
\hline ICP-AES & inductively coupled plasma atomic emission spectrometry \\
\hline ICP-MS & inductively coupled plasma mass spectrometry \\
\hline kg & kilogram \\
\hline KOP & Knowledge of Process \\
\hline LAAO & Los Alamos Area Office \\
\hline Laboratory. & Los Alamos National Laboratory \\
\hline $\mathrm{LCL}$ & lower confidence limit \\
\hline LDR & Land Disposal Restrictions \\
\hline LIMW & low-level mixed waste \\
\hline LTD & less than detectable \\
\hline MDL & Method Detection Limit \\
\hline $\mathrm{mg} / \mathrm{kg}$ & milligrams per kilogram \\
\hline $\mathrm{mg} / 1$ & milligrams per liter \\
\hline $\mathrm{mm}$ & millimeter \\
\hline MSDS & Material Safety Data Sheets \\
\hline $\mathrm{nCi} / \mathrm{g}$ & nanocuries per gram \\
\hline
\end{tabular}




$\begin{array}{ll}\text { NMC\&A } & \text { Nuclear Material Control Accountability } \\ \text { NMED } & \text { New Mexico Environment Department } \\ \text { NOD } & \text { Notice of Deficiency } \\ \text { NRC } & \text { Nuclear Regulatory Commission } \\ \text { NS } & \text { not specified } \\ \text { OSHA } & \text { Occupational Safety \& Health Administration } \\ \text { PCB } & \text { polychlorinated biphenyl } \\ \text { PF-4 } & \text { plutonium facility } \\ \text { ppm } & \text { parts per million } \\ \text { PRDL } & \text { program required detection limit } \\ \text { QA } & \text { Quality Assurance } \\ \text { QAPjP } & \text { Quality Assurance Project Plan } \\ \text { QAPP } & \text { Quality Assurance Program Plan } \\ \text { QC } & \text { Quality Control } \\ \text { RCRA } & \text { Resource Conservation and Recovery Act } \\ \text { RTL } & \text { Regulatory Threshold Limit } \\ \text { RTR } & \text { Real-Time Radiography } \\ \text { RPD } & \text { Relative Percent Difference } \\ \text { RSWD } & \text { Radioactive Solid Waste Disposal } \\ \text { SAP } & \text { sampling and analysis plan } \\ \text { SNM } & \text { special nuclear material } \\ \text { SOP } & \text { standard operating procedures } \\ \text { SVOC } & \text { semi-volatile organic compounds } \\ \text { TA } & \text { Technical Area } \\ \text { TCLP } & \text { Toxicity Characteristic Leaching Procedure } \\ \text { UCL } & \text { upper confidence limit } \\ \text { VOC } & \text { volatile organic compounds } \\ \text { WAP } & \text { Waste Analysis Plan } \\ \text { WIPP } & \text { Waste Isolation Pilot Plant } \\ \text { WMC } & \text { Waste Matrix Code } \\ \text { WS } & \text { waste stream } \\ & \end{array}$

\section{DISCLAIMER}

This report was prepared as an account of work sponsored by an agency of the United States Government. Neither the United States Government nor any agency thereof, nor any of their employees, makes any warranty, express or implied, or assumes any legal liability or responsibility for the accuracy, completeness, or usefulness of any information, apparatus, product, or process disclosed, or represents that its use would not infringe privately owned rights. Reference herein to any specific commercial product, process, or service by trade name, trademark, manufacturer, or otherwise does not necessarily constitute or imply its endorsement, recommendation, or favoring by the United States Government or any agency thereof. The views and opinions of authors expressed herein do not necessarily state or refiect those of the United States Government or any agency thereof. 